\title{
I. Einleitung
}

Lage und Kampf der Landarbeiter im ostelbischen Preußen (1919-1945) 



\section{Die Kämpfe der Landarbeiter in der Novemberrevolution und der revolutionären Nachkriegskrise}

Die deutsche Novemberrevolution hatte trotz ihrer Niederlage „Millionenmassen in den politischen Kampf einbezogen, wertvolle Kampferfahrungen vermittelt und viele jahrzehnte-, ja jahrhundertealte Vorurteile und Auffassungen ins Wanken gebracht" ${ }^{1}{ }^{1}$ Das galt auch für das agrarische Ostelbien. Obwohl die Revolution dieses Gebiet anfänglich kaum erfaßte, wurden die Landarbeiter aus ihrer Passivität gerissen, wuchsen ihr revolutionäres Bewußtsein und der Wille zur gewerkschaftlichen Organisation. Es gab Forderungen nach Boden, und es kam zu vereinzelten Landaufteilungen. Mit einiger Verspätung brachen im Frühjahr 1919 in den ländlichen Gebieten Preußens verstärkt Streiks aus. Die Mitgliederzahl des Deutschen Landarbeiter-Verbandes stieg im Laufe des Jahres 1919 auf das 60 fache im Vergleich zum Jahresdurchschnitt $1918 .{ }^{2}$

Die in der Revolution errungenen und gesetzlich verankerten bürgerlichdemokratischen Rechte und Freiheiten hielten Einzug im preußischen Ostelbien. Dazu gehörten das allgemeine und gleiche Wahlrecht, auch für Frauen, die Versammlungs- und Koalitionsfreiheit, der Achtstundentag und das Streikrecht. Den Landarbeitern mußten die Aufhebung der feudalen Gesindeordnung und der Ausnahmegesetze bereits am 12. November 1918, eine „Vorläufige Landarbeitsordnung" und eine Verordnung zur Beschaffung von landwirtschaftlichem Siedlungsland im Januar 1919 zugestanden werden. Auch die Landarbeitergewerkschaften konnten Tarifvereinbarungen abschließen und Betriebsräte wählen.

Diese Entwicklung vollzog sich in harten Klassenauseinandersetzungen zwischen Revolution und Konterrevolution. Dem Kriegsausschuß der deutschen Landwirtschaft und den reaktionären landwirtschaftlichen Organisationen, wie dem Bund der Landwirte, war es seit den ersten Tagen der Revolution gelungen, sich des Rätegedankens unter der Bauern- und Landarbeiterschaft $\mathrm{zu}$ bemächtigen und ihn demagogisch zu mißbrauchen.

1 Illustrierte Geschichte der deutschen Novemberrevolution, hrsg. v. Institut für Marxismus-Leninismus beim ZK der SED, Berlin 1978, S. 425.

2 Vgl. H. Hübner, Lage und Kampf der Landarbeiter im ostelbischen Preußen (Vom Anfang des 19. Jahrhunderts bis zur Novemberrevolution 1918/19), in: Archivalische Forschungen zur Geschichte der deutschen Arbeiterbewegung, hrsg. v. L. Stern, Bd. 8/I, Einleitung, Berlin 1977, S. LXVI. 
Im Gegensatz zu Rußland hatten die revolutionären Linken in Deutschland bis zur Revolution Landarbeiter und Bauern noch ungenügend als Bündnispartner berücksichtigt. Erst im Laufe der Klassenkämpfe kam es zu gemeinsamen Aktionen. Auf dem Höhepunkt der Revolution war ihr Bündnis zu schwach gegenüber den Vereinbarungen, die Vertreter des agrarischen Konservatismus mit rechtsopportunistischen Führern eingingen.

Die konservativen Politiker sahen in der Landbevölkerung die zentralen Adressaten ihrer Politik ${ }^{3}$ und nutzten deren Rückständigkeit und jahrzehntelange Bindung an den deutschen Imperialismus und seine politischen Parteien für die Gegenrevolution aus. Demagogisch versuchten sie für den landwirtschaftlichen Bereich etwas Ähnliches anzuregen wie das Arbeitsgemeinschaftsabkommen in der Industrie und fanden willige Partner in den rechten Gewerkschaftsführern. Solche Versuche der Arbeitsgemeinschaftspolitik gab es vor allem in der Provinz Sachsen, wo der linke Flügel der USPD auch starken Einfluß in den Dörfern hatte und die Großagrarier sich weit konzessionsbereiter zeigen mußten als in anderen Teilen Preußens. Die wendigsten Gutsbesitzer gaben vorübergehend ihren „Herr-im-Hause“-Standpunkt auf.

Als erste landwirtschaftliche Unternehmervertretung in Deutschland vereinbarten die Großagrarier der Provinz Sachsen am 13. Dezember 1918 mit dem sozialdemokratischen Deutschen Landarbeiter-Verband (DLV) und dem Christlich-nationalen Zentralverband der Forst-, Land- und Weinbergsarbeiter Deutschlands (ab 1920 Zentralverband der Landarbeiter, ZdL) die Bildung einer landwirtschaftlichen „Provinzialarbeitsgemeinschaft" und die Schaffung einer, provinziellen Landarbeitsordnung." Diese Vereinbarung, mit der Landarbeiterstreiks abgewürgt. und dem Landproletariat eine „Mitbestimmung“ bei der Regelung seiner Arbeitsund Lebensbedingungen vorgetäuscht werden sollte, bildete die Grundlage für die Ausarbeitung der Vorläufigen Reichs-Landarbeitsordnung 'vom 24. Januar 1919 und diente 1919 und 1920 als Modell für ähnliche Abkommen in anderen preußischen Provinzen und Ländern der Weimarer Republik. ${ }^{5}$ Am Ende des Jahres 1919 gab es neben der Provinz Sachsen in

$3 \mathrm{Vgl}$. Otto Hoetzsch in einer Denkschrift vom 5.11.1918, in: Vierteljahrshefte für Zeitgeschichte (VjZ), 1973/3, S. 346.

4 Vgl. Landarbeitsordnung für die Provinz Sachsen und für Anhalt, Magdeburg 1919 (Dok. Nr. 1, 7); J. Flemming, Landwirtschaftliche Interessen und Demokratie, Bonn 1978, S. 275 ff.

5 Vgl. Dok. Nr. 6; W. Vogler, Die werktätigen Bauern und Landarbeiter in der Novemberrevolution 1918 im Regierungsbezirk Halle-Merseburg und die revolutionäre Agrarpolitik der KPD während der revolutionären Nachkriegskrise, in: Bauern und Landarbeiter im Klassenkampf, hrsg. v. H. Hübner, Halle/S. 1976, S. 82 f. 
Brandenburg eine solche Provinzialarbeitsgemeinschaft. In der Provinz Sachsen vereinbarten seit Dezember 1918 Kreisarbeitsgemeinschaften die Tarife für die Landarbeiter.

Die konterrevolutionäre Verfälschung des Rätegedankens, wie sie seit November 1918 in allen preußischen Provinzen durch junkerlich-konservative Kreise betrieben wurde, trug wesentlich zur reaktionären Lösung der Machtfrage in der Novemberrevolution bei. Der Aufbau der „Räteorganisation" auf dem Lande von oben nach unten (Reichs-, Provinz-, Bezirks-, Kreis- und Orts-Bauern- und Landarbeiterrat) sollte die Rätebewegung „in ruhigen, gesetzlichen Bahnen" halten und einen Keil zwischen die Bauernräte auf der einen und die Arbeiter- und Soldatenräte auf der anderen Seite treiben. ${ }^{6}$

Die rechten Führer der SPD und des DLV, besonders Otto Braun und Georg Schmidt, unterstützten mit Parolen wie "Sicherung der Volksernährung" und „Uberlegenheit des Großbetriebs" die Erhaltung des junkerlichen Eigentums und damit den weiteren politischen Einfluß des Großgrundbesitzes. Otto Braun, Landwirtschaftsminister in der neuen, am 12. November 1918 gebildeten preußischen Regierung, verstand sich später mit der Gloriole eines „Landarbeiterministers" zu umgeben. Diese Geschichtsfälschung hielt sich bis in bürgerliche Untersuchungen der Gegenwart. ${ }^{7}$ Was Braun zwischen 1919 und 1921 an neuen Siedlerstellen durch Gewinnung von Odland und Moorkultivierung schuf, hatte mit einer demokratischen Bodenreform nichts zu tun. Vielmehr stimmte er mit der Reaktion darin überein, die "sehr große Gefahr des Bolschewismus" auf dem Lande zu bekämpfen. ${ }^{8}$

In seinen, 1940 in der Schweizer Emigration geschriebenen Memoiren hat Braun den Verrat zu rechtfertigen gesucht: daß der Ruf nach Enteignung des Großgrundbesitzes zwar „nach großen Kriegen und revolutionären Bewegungen meist akut" werde und "stürmisch nach Befriedigung" dränge, „die Bewegung der Landhungrigen“ aber „ganz unbillige, volkswirtschaftlich nicht zu vertretende Forderungen erhoben“ hätte. „Diesen habe ich widerstrebt", schrieb Braun, „was mir auch aus den Reihen der Linksparteien heftige Angriffe eintrug. Dort wurde oft die restlose Zer-

$6 \mathrm{Vgl}$. Aus revolutionären Tagen... (Erlebnisberichte aus der Zeit der deutschen Novemberrevolution 1918), hrsg. v. d. Bezirkskommission zur Erforschung der Geschichte der Arbeiterbewegung bei der Bezirksleitung der SED, Halle/S., o. O., o. J., S. 75.

7 Vgl. z. B. H. Schulze, Otto Braun oder Preußens demokratische Sendung, Wien-Frankfurt/Main-(West-)Berlin 1977.

8 Zit. nach: H. Muth, Die Entstehung der Bauern- und Landarbeiterräte im November 1918 und die Politik des Bundes der Landwirte, in: VjZ, 1973/1, S. 16. 


\section{XVI}

schlagung des Großgrundbesitzes gefordert, was in jener Zeit der größten Ernährungsschwierigkeiten zu einer Katastrophe geführt hätte. “9

Durch die opportunistische Agrarpolitik unterblieb 1918 die Enteignung des Junkertums. In den ostelbischen Provinzen machte sich weiter die Reaktion breit. In deutschnationalen Kreisen zwar verhaßt, vertrat Braun objektiv die Interessen dieser Konservativen wie sonst kaum ein anderer auf dem rechten Flügel der Sozialdemokratie.

Auch die rechten Gewerkschaftsführer des DLV nahmen für sich in Anspruch, den konterrevolutionären „Bauernräten“ nachträglich durch ihre Verwandlung in „Bauern- und Landarbeiterräte“ die Giftzähne ausgebrochen zu haben. Im Geschäftsbericht des Zentralvorstandes von 1919 hieß es: „Wir haben damals eingegriffen, damit diese Bauern- und Landarbeiterräte nicht zu politischen Organen wurden. Von uns war dieser Treppenwitz der Weltgeschichte, daß die konservativen Vertretungen der Landwirtschaft zum Schutze der revolutionären Errungenschaften beitragen wollten, von vornherein nur als eine vorübergehende Erscheinung gewürdigt worden. Jedenfalls haben wir damit erreicht, daß der Schachzug der Agrarier, sich das Rätesystem für ihre reaktionären Zwecke nutzbar zu machen, nicht gelungen ist." ${ }^{10}$ In Wirklichkeit wurden die Bauern- und Landarbeiterräte von den DLV-Führern bewußt als Vorstufe für die integrative Arbeitsgemeinschaftspolitik mit den Unternehmerverbänden genutzt, um die keimende revolutionäre Bewegung und die Entwicklung des Klassenbewußtseins im Landproletariat abzuwürgen. ${ }^{11}$ Sie mißbrauchten das Vertrauen, das Hunderttausende von elementar zuströmenden Landarbeitern in die "freie" Gewerkschaft setzten, und handelten gemeinsam mit dem ZdL und den konservativen Vertretern des Reichs-Bauern- und Landarbeiterrats kompromißlerisch die „Vorläufige Landarbeitsordnung“ aus.

Diese Landarbeitsordnung ${ }^{12}$ brachte weder den Gewerkschaften die volle Anerkennung noch den Landarbeitern die Bestätigung der Koalitionsfreiheit. Sie bezog nur die Lösung der dringendsten Fragen der Arbeitsvertragsverhältnisse, wie die Lohnfrage über Tarife, ein. Eine Zusatzvereinbarung enthielt den Kern einer Schlichtungsordnung. Betrogen wurden die Landarbeiter um den Achtstundentag ${ }^{13}$, den die Industriearbeiter in der Novemberrevolution erkämpft hatten. Die Landarbeitsordnung regelte für je ein Jahresdrittel eine durchschnittliche tägliche Höchstarbeitszeit von

9 O. Braun, Von Weimar zu Hitler, Hamburg 1949, S. 23.

10 Geschäftsbericht des Deutschen Landarbeiter-Verbandes für die Jahre 1914 bis 1919, Berlin 1920, S. 61.

$11 \mathrm{Vgl}$. E. Hoernle, Die Große Sozialistische Oktoberrevolution und das deutsche Dorf, in: Unser stärkstes Argument, Berlin 1977, S. 233.

12 Abgedruckt in: Archivalische Forschungen, Bd. 8/II, S. 558-562.

13 Vgl. Der kommunistische Landarbeiter, Nr. 18 (September 1921). 
acht, zehn und elf Stunden und die Vergütung der Uberstunden. Die tägliche Normalarbeitszeit festzusetzen überließ sie dem Tarifvertrag, der auf kollektiver Grundlage zwischen den Arbeitgeberorganisationen und der Gewerkschaft für ein bestimmtes Gebiet und einen bestimmten Zeitraum ausgehandelt wurde. Das war im Vergleich zur rechtlichen Lage der Arbeiter vor 1918 ein gewaltiger Fortschritt, blieb aber hinter den realen Möglichkeiten zurück, die durch die Novemberrevolution für die Einschränkung der Ausbeutung auf dem Lande bestanden hätten. Die Landarbeiter wurden in ihrer rechtlichen und sozialen Lage nicht den Industriearbeitern gleichgestellt. Vieles trug sozialreformerischen Charakter und ging nicht über das hinaus, was einzelne sozialkonservative Großgrundbesitzer, Agrarwissenschaftler und -publizisten schon in den letzten Jahrzehnten des 19. Jahrhunderts gefordert hatten. ${ }^{14}$

Trotzdem widersetzten sich die Großgrundbesitzer und ihre Interessenvertreter Verhandlungen mit den Gewerkschaften und Zugeständnissen an die Landarbeiter. Bis 1923/24 wurde um die Durchsetzung der neu geregelten arbeitsrechtlichen- und Tarifbestimmungen erbittert gerungen, wofür die Landarbeiter gegen den Willen der gewerkschaftlichen Verbandsführung wiederholt streikten. Die erneute Festigung ihrer ökonomischen und politischen Position erlaubte es den Junkern, ab Mitte der 20er Jahre offen zur Beseitigung dieser wenigen sozialen Errungenschaften überzugehen.

Angesichts der anhaltenden Revolutionierung der Landarbeiterschaft hielten es Teile der Agrarier nach der Niederlage der Novemberrevolution für angebracht, den Arbeitsgemeinschaftsgedanken fortzusetzen. Der Betriebsrätegesetzentwurf, der seit Juni 1919 vorlag und auch die Landwirtschaft einbeziehen sollte, ließ den Führern der landwirtschaftlichen Arbeitgeberorganisation erneute Ubereinkünfte mit den Gewerkschaften geraten erscheinen. Offene Proteste des Reichsausschusses der deutschen Landwirtschaft und der Provinziallandbünde gegen die Einführung von Betriebsräten beim Reichsarbeitsminister waren zunächst unwirksame Varianten agrarkapitalistischer Politik. ${ }^{15}$

Die Initiative für das Fortbestehen des Reichs-Bauern- und Landarbeiterrats als Reichsarbeitsgemeinschaft land- und forstwirtschaftlicher Arbeitgeber- und Arbeitnehmervereinigungen ging im Herbst 1919 ebenfalls von der Provinz Sachsen aus. ${ }^{16}$ Der Vorsitzende der provinzialsächsischen

14 Vgl. H. Schumacher, Land und Politik, Düsseldorf 1978, S. 113.

$15 \mathrm{Vgl}$. Landwirtschaftliche Wochenschrift für die Provinz Sachsen, Jg. 21, Nr. 31/32 (2. und 9. 8. 1919), S. 295, 304; ZStA Merseburg, Rep. 87 B, Nr. 320, Bl. $88 \mathrm{ff}$.

16 Vgl. C. v. Dietze, Die ostdeutschen Landarbeiterverhältnisse seit der Revolution, Berlin 1922, S. $47 \mathrm{ff}$. 


\section{XVIII}

Arbeitgeberorganisation, Rittergutsbesitzer Alwin Schurig, wurde zusammen mit Georg Schmidt zu Vorsitzenden, der schlesische Graf von Keyserlingk und Franz Behrens (ZdL) zu stellvertretenden Vorsitzenden gewählt. Um dieses Prinzip der Parität zwischen Arbeitgeberorganisation und Gewerkschaften hatte es im Reichs-Bauern- und Landarbeiterrat monatelange Auseinandersetzungen gegeben ${ }^{17}$, so daß das Abkommen erst am 20. Februar 1920 unterzeichnet wurde.

„Vornehmstes Ziel“ der Vertragspartner sollte die Förderung gemeinsamer Berufs- und Wirtschaftsinteressen und der Abbau von Gegensätzen sein, um „insbesondere durch Vorbereitung, Beschluß und Durchführung von Tarifverträgen“ den „Wirtschaftsfrieden“ zu erreichen. ${ }^{18}$ Diese Grundsätze wurden nach dem Kapp-Putsch bestätigt.

In einem Aufruf vom 5. Mai 1920 verlangten Schurig und Schmidt im Namen der Landwirtschaft wirksamen Schutz für „die Sicherheit der Person und des Eigentums gegen Ausschreitungen und Ubergriffe". ${ }^{19}$ Damit verteidigten die rechten Gewerkschaftsführer weiterhin die Interessen des Großgrundbesitzes und hofften auf den „Ausgleich der Interessengegensätze“. Wie in der Zentralarbeitsgemeinschaft (ZAG) der Industrie bestimmten aber auch hier die Unternehmer Richtung und Ziel.

Große Teile der Großgrundbesitzer erkannten zunächst die Vorteile der Arbeitsgemeinschaftspolitik an. Das bezog sich nicht nur auf die Tarife, mit denen die Landarbeiter materiell und politisch zu ködern waren ${ }^{20}$, sondern auch auf die Sicherung des "sozialen Friedens" in der Landwirtschaft. Angesichts der zahlreichen Landarbeiterstreiks, die seit Frühjahr/ Sommer 1919 bis in die nachfolgenden Jahre der revolutionären Nachkriegskrise hinein die preußischen Provinzen erschütterten, reichten terroristische Mittel zur Abwehr allein nicht aus. So fielen Versuche, eine einheitliche „Landvolkideologie“ zu entwickeln, bereits in der Frühphase der Weimarer Republik günstig aus. Besonders in Pommern entstand jenes „Prinzip“ der „wahren Arbeitsgemeinschaft auf dem Lande“, das von seinen Ideologen als „vorbildlich“ im Kampf um die „Seele des Arbeiters“ bezeichnet wurde. Von der „natürlichen Lebensgemeinschaft“ auf den Gütern ausgehend, sollte an Stelle des Klassenkampfgedankens ein patriarchalischer Gemeinschaftsgedanke treten. ${ }^{21}$ Für die Existenz und Unterstützung

17 Vgl. ZStA Merseburg, Rep. 87 B, Nr. 345, Bl. 200 ff.

$18 \mathrm{Vgl}$. Reichsarbeitsgemeinschaft land- und forstwirtschaftlicher Arbeitgeberund Arbeitnehmervereinigungen, (Berlin 1920).

$19 \mathrm{Vgl}$. Deutsche Landwirtschaftliche Presse, 1920, Nr. 36, S. 263.

$20 \mathrm{Vgl}$. Vortrag des Grafen Keyserlingk über das Arbeits- und Lohnverhältnis in der Landwirtschaft auf der 8. Vorstandssitzung der deutschen land- und forstwirtschaftlichen Arbeitgebervereinigungen am 14. Dezember 1920 (Dok. Nr. 21), in: WAPw Opolŭ, Schloßarchiv Praschma, Nr. 1105, Bl. 101 ff.

21 Vgl. C. v. Eickstedt, Wiederaufbau und wirtschaftsfriedliches Prinzip, Ber- 
wirtschaftsfriedlicher Verbände in Pommern wurde die Arbeitnehmergruppe des pommerschen Landbundes typisch.

Die Streiks der Landarbeiter zwischen 1919 und 1923/24 hatten vorrangig wirtschaftliche und soziale Ursachen und Ziele. An der Abwehr des Kapp-Putsches 1920, der mitteldeutschen Märzaktion 1921 und dem Generalstreik gegen Cuno im August 1923 beteiligten sich auch Landarbeiter. Charakteristisch für alle politischen Streiks waren ihre örtliche und regionale Begrenztheit, die teilweise kurze Dauer und geringe zahlenmäßige Beteiligung.

$\mathrm{Zu}$ den wirtschaftlichen und sozialen Forderungen der Streikenden gehörten Lohn- und Deputaterhöhungen, Arbeitszeitverkürzung und Verbesserung der Wohnraumsituation; alles Fragen, die mit der „Vorläufigkeit“ der Landarbeitsordnung zusammenhingen. Weigerungen der Großgrundbesitzer, Tarifverträge abzuschließen, Betriebsräte auf den Gütern anzuerkennen, gewerkschaftlich organisierte entlassene Arbeiter wieder einzustellen, lösten ebenfalls Streiks aus, die von ihrem Charakter her bereits politische Streiks waren. In einigen Fällen beteiligten sich die Landarbeiter an Massenstreiks im regionalen ${ }^{22}$ oder Generalstreiks im überregionalen Rahmen ${ }^{23}$ und führten Sympathiestreiks mit der Industriearbeiterschaft.

Zahl der Landarbeiterstreiks $1919-1924^{24}$

\begin{tabular}{lrrrrrr}
\hline Preußische Provinzen & 1919 & 1920 & 1921 & 1922 & 1923 & 1924 \\
\hline Ostpreußen & 2 & 34 & 41 & 23 & 4 & 2 \\
Grenzmark & & & & & & \\
Posen-Westpreußen & 5 & 4 & 33 & 2 & 1 & - \\
Pommern & 39 & 41 & 46 & 10 & - & 1 \\
Brandenburg & 3 & 15 & 27 & 9 & 17 & 1 \\
Schlesien & 4 & 27 & 64 & 41 & 4 & - \\
Sachsen & 57 & 64 & 27 & 17 & 5 & 1 \\
Preußen & 127 & 249 & 254 & 244 & 42 & 8 \\
Deutsches Reich & 163 & 366 & 302 & 331 & 70 & 17 \\
\end{tabular}

lin 1923, S. 45, 88; ders., Wahre Arbeitsgemeinschaft auf dem Lande, Langensalza 1925, S. 30 ff.; ders., Die berufsständische Lösung der Landarbeiterfrage in Pommern, Berlin o. J., S. 8 ff.

22 Vgl. W. Wilhelmus, Der Kampf der Werktätigen in Vorpommern im Juli 1919, in: ZfG, 1958, Sh., S. 222 ff.

23 Vgl. M. Polzin, Kapp-Putsch in Mecklenburg, Rostock 1966, S. $112 \mathrm{ff}$;; E. Könnemann, H.-J. Krusch, März 1920, Berlin 1981, S. 63 ff.

24 Statistik des Deutschen Reiches von 1920/21. Reichsarbeitsblatt 1923-1926. Zit. nach: C. v. Schwerin, Die Landarbeiterorganisationen Ostdeutschlands und ihre klassenmäßige und ständische Struktur, Langensalza 1928, S. 44. 
Aus der Streikstatistik lassen sich die Höhepunkte der Streikbewegung erkennen, die die ostelbischen Provinzen Preußens unterschiedlich erfaßten.

Für die Jahre 1919/1920 fällt die große Zahl von Landarbeiterstreiks in der Provinz Sachsen auf. Das resultierte vor allem aus der hohen Konzentration der Industriearbeiterschaft in diesem Gebiet ${ }^{24 a}$ und der unmittelbaren Ausstrahlungskraft der revolutionären Arbeiterbewegung, vor allem der linken USPD, auf die Landarbeiter. Schon im Zusammenhang mit dem mitteldeutschen Generalstreik im Februar/März 1919 beteiligten sich erstmals seit Ausbruch der Novemberrevolution Landarbeiter an diesen Kämpfen. ${ }^{25}$

Im Sommer und Herbst 1919 waren Forderungen nach Arbeitszeitverkürzung und Verbesserung der Wohnverhältnisse Hauptursache von Streiks $;{ }^{26}$ alle waren lokal und zeitlich begrenzt. Sie erfaßten meistens nur einzelne oder einige benachbarte Güter und dauerten ein bis zwei Tage. Ursache dafür war vor allem das Verhalten der DLV-Funktionäre, die sich möglichst schnell in die ökonomischen Kämpfe einschalteten, sie für „wilde Streiks" erklärten und für ihre rasche Beendigung sorgten. Die Landwirtschaftliche Wochenschrift der Provinz Sachsen schätzte im November 1919 ein: „Dem tatkräftigen Eingreifen der Gewerkschaftsbeamten ist es zu danken, daß die bisherigen Landarbeiterstreiks in unserer Provinz keine gröBere Ausdehnung genommen haben und nach verhältnismäßig kurzer Zeit wieder beigelegt werden konnten. Wo es not tat, sind sie den Arbeitern gegenüber sehr energisch aufgetreten, sie haben sie immer auf die Notwendigkeit der Tariftreue und auf die Verwerflichkeit der wilden Streiks hingewiesen". ${ }^{27}$

Eine eindeutig politische Stoßrichtung hatte die Beteiligung mitteldeutscher Landarbeiter am Generalstreik gegen den Kapp-Putsch. Bewußt setzten diese sich für die Erhaltung der Republik und der Errungenschaften der Novemberrevolution ein. So ruhte am 15. März 1920 auf vielen Gütern die Arbeit. Es entstanden revolutionäre Gutsräte. Gemeinsam mit Indu-

Vgl. auch J. B. Beßler, Die Streikbewegung in der Landwirtschaft, Diss. Bamberg 1927, S. 34, 59, 61 ff., 85 ff.; Streik. Zur Geschichte des Arbeitskampfes in Deutschland während der Industrialisierung, hrsg. v. Tenfelde/ Volkmann, München 1981, S. $304 \mathrm{ff}$.

24a Vgl. allg. K. H. Leidigkeit/I. Herrmann, Auf leninistischem Kurs. Geschichte der KPD-Bezirksorganisation Halle-Menseburg bis 1933. Halle/S. 1979.

$25 \mathrm{Vgl}$. W. Vogler, Probleme des Klassenkampfes zwischen den Landarbeitern und Gutsbesitzern im Regierungsbezirk Merseburg (1918-1923), phil. Diss., Halle/S. 1974, S. $172 \mathrm{ff}$.

26 Vgl. ZStA Merseburg, Rep. 87 B, Nr. 276, B1. 206 ff.

27 Landwirtschaftliche Wochenschrift für die Provinz Sachsen, Jg. 21, Nr. 46 (15. 11. 1919), S. 451. 
striearbeitern entwaffneten Landarbeiter die Einwohnerwehren, spürten Waffenverstecke auf und beteiligten sich an bewaffneten Auseinandersetzungen. ${ }^{23}$

Schon ab Herbst 1920 überwogen in der Provinz Sachsen wiederum Streiks zur Verbesserung der Arbeits- und Lebensbedingungen, die die Großgrundbesitzer der Provinz geschickt unterwanderten. So erklärten sie sich zu gewissen Zugeständnissen, wie Erhöhung der Barlöhne, bereit. Das Landes-Arbeitsamt warnte auch eindringlich vor einer Kürzung der Deputate.

Etwa ein Jahr später als in der mitteldeutschen Provinz Sachsen kam es in den ostelbischen Provinzen Brandenburg, Ostpreußen, Posen-Westpreußen und Schlesien zur Streikbewegung für wirtschaftliche und soziale Forderungen. Einen Höhepunkt erreichte sie 1921, als sich die Angriffe der herrschenden Klasse auf die elementaren Lebensrechte der Werktätigen auch unmittelbar auf die Landarbeiter auswirkten. Die KPD orientierte in ihrem "Offenen Brief" vom Januar 1921 auf gemeinsames Handeln der Arbeiterparteien und Gewerkschaften. Im Gegensatz dazu arbeiteten landwirtschaftliche Arbeitgeberorganisationen und rechte Gewerkschaftsführung auf antikommunistischer Basis zusammen und praktizierten immer besser die Methode der Beilegung von Streiks unter „Vermittlung von Berufsvereinigungen oder dritten Personen" (Schlichter).

Nach der Statistik beantragten in überwiegender Zahl die Großgrundbesitzer die Verhandlungen und erreichten, daß die meisten Streiks in diesen preußischen Provinzen zwischen 1919 und 1923 ohne Erfolg endeten. ${ }^{29}$ Das von großen Teilen der Junker widerwillig anerkannte, wenn nicht abgelehnte Tarifsystem und die Institution des Schlichtungswesens funktionierten auch in der Landwirtschaft zur Dämpfung des Klassenkampfes. „Die zahlreichen Streiks nach der Revolution hatten die Frage nach einem Aushilfsmittel aufwerfen lassen, mit dem der Arbeitsfrieden aufrecht erhalten werden könnte, ohne daß den Forderungen der Werktätigen völlig Rechnung getragen werden müsse, aber auch ohne daß die staatlichen Machtmittel dauernd brutal und offen eingesetzt werden müßten, um den Standpunkt der Unternehmer durchzusetzen, was unter den gegebenen Umständen auch kaum ratsam gewesen wäre. “30

Demgegenüber suchte in Pommern der Landbund die offene Konfrontation zu den Landarbeitern. Er bezog auch den preußischen Landwirtschaftsminister Braun in diese Auseinandersetzung ein. Die Großagrarier stellten die Koalitionsfreiheit, das Recht auf eigene gewerkschaftliche Ver-

28 Vgl. W. Vogler, Probleme, S. $223 \mathrm{ff}$.

$29 \mathrm{Vgl}$. J. B. Beßler, a. a. O., S. 86 ff.

30 M. Nussbaum, Wirtschaft und Staat in Deutschland während der Weimarer Republik, Berlin 1978, S. 244. 


\section{XXII}

tretung, die Tariffähigkeit des DLV und vor allem das Streikrecht der Landarbeiter in Frage. ${ }^{31}$ Außerdem wurden im Sommer 1919 Versuche des Landbundes bekannt, das platte Land zu bewaffnen, sich mit den militärischen Kommandostellen, den Staatsorganen und der Pommerschen Landwirtschaftskammer gegen die Landarbeitergewerkschaft zu verbünden. Die preußische Regierung ordnete zwar Haussuchungen in der Landwirtschaftskammer Stettin an, und Braun sprach in seinen Memoiren von „erfolgreicher Haussuchung“ bei Dewitz, dem Vorsitzenden des Pommerschen Landbundes, die er unter Überschreitung seiner Ressortzuständigkeit vorgenommen habe ${ }^{32}$, doch die Hand an die Wurzel des Ubels legte die Regierung nicht. Selbst Georg Schmidt stellte im Dezember 1919 auf der „Pommern-Konferenz" des DLV kritisch fest, „daß damals nicht von der Regierung mit Entschiedenheit zugegriffen wurde, wie das notwendig gewesen wäre".33

Im Juli 1919 brachen gleichzeitig auf verschiedenen Gütern des Kreises Franzburg im Regierungsbezirk Stralsund Streiks aus. Der Landrat und das Generalkommando des II. Armeekorps hielten am 12. Juli die Verhängung des Belagerungszustandes für den Kreis Franzburg, später auch für den gesamten Regierungbezirk Stettin für dringend geboten. Damit war endlich ein Grund gefunden, mit militärischen Mitteln gegen die demokratischen Rechte und Freiheiten vorzugehen. Fortschrittliche Zeitungen, vor allem Blätter der KPD, wurden verboten, etwa 50 Landarbeiter verhaftet. ${ }^{34}$ Industriearbeiter und Landarbeiter Vorpommerns antworteten auf diese Provokationen und halbherzigen Maßnahmen der sozialdemokratisch geführten preußischen Koalitionsregierung mit dem Generalstreik, der einzigen Möglichkeit, die „Junkerrevolte“ in die Schranken zu weisen. Die Landarbeiter erkämpften sich die zehnstündige Arbeitszeit, festgeschrieben in neuen Tarifverträgen, die die Landbundvertreter zusammen mit der Einführung des Schlichtungswesens zusichern mußten.

Trotzdem gingen die Auseinandersetzungen weiter, so daß sich Braun am 2. September 1919 zum Erlaß einer Verordnung zum Abschluß von Zwangsarbeitsverträgen genötigt sah. Um diese Verordnung, die rechtlich dem preußischen Demobilmachungskommissar die Befugnis zusprach, über Zwangstarifverträge zur "Sicherstellung landwirtschaftlicher Arbeiten“ beizutragen, entbrannte in der Folgezeit ein heftiger Streit. Braun war

31 Vgl. Brief des Vorsitzenden des pommerschen Landbundes, v. Dewitz, an den Reichskanzler Scheidemann vom 21. 5. 1919, ZStA Merseburg, Rep. 87 B, Nr. 329, B1. 162; Der Pommersche Landbund, eine Gefahr für die deutsche Volksernährung, Berlin 1920, S. $77 \mathrm{ff}$.

32 Vgl. O. Braun, a. a. O., S. 53.

33 Vgl. Der Pommersche Landbund, S. 9.

$34 \mathrm{Vgl}$. W. Wilhelmus, a. a. O., S. $228 \mathrm{ff}$. 
Hetzkampagnen des Pommerschen Landbundes ausgesetzt ${ }^{35}$, der damit die Konfrontation des Agrarkonservatismus gegen die liberal-reformistische Variante bourgeoiser Herrschaft demonstrierte. Der Schutzverband des Deutschen Grundbesitzes sprach für 2,5 Millionen landwirtschaftliche Arbeitgeber, als er Braun vorwarf, an Stelle friedlicher Verständigung auf wirtschaftlichem Gebiet den Klassengedanken und den Klassengegensatz zu vertreten und damit Zwiespalt in die Landbevölkerung zu tragen. ${ }^{36}$ Eingriffe in das privat-kapitalistische Eigentum waren mit dieser Verordnung nicht verbunden.

In Pommern wandten die Junker auch in der Folgezeit verstärkt terroristische Mittel wie Massenkündigungen organisierter Landarbeiter an und maßregelten sie durch Aussperrung oder Räumungsklagen. Sofort nach Aufhebung der Zwangstarife flammten im Mai 1920 in Pommern wieder Streiks auf, die brutal durch die Polizei, teilweise durch das Militär und die Technische Nothilfe bekämpft wurden. Wie Übersichten ergaben, wurde die Technische Nothilfe (Teno) am häufigsten in der Landwirtschaft und hier besonders in Schleswig-Holstein, Magdeburg-Anhalt ${ }^{37}$, Brandenburg und Pommern eingesetzt.

Kamen im Durchschnitt 1919/20 auf 1 landwirtschaftlichen Betrieb 10 Nothelfer und 640 Arbeitsstunden, 1920/21 auf 1 landwirtschaftlichen Betrieb 10 Nothelfer und 603 Arbeitsstunden, 1921/22 auf 1 landwirtschaftlichen Betrieb 9 Nothelfer und 580 Arbeitsstunden $^{38}$, so waren es in Vorpommern im Oktober 1920416 Nothelfer, im Juli 1921208 Nothelfer. $^{30}$

Sie brachen als Erntesicherungskommandos den Landarbeiterstreiks die Spitze ab und wurden als vorgeblich klassenneutrale Organisation auch nach $1924 \mathrm{im}$ „Interesse der Sicherung des Lebens" zum Schutz des großgrundbesitzerlichen Eigentums eingesetzt. Hinzu kamen die gut organisierten preußischen Landjägereinheiten, die, teilweise beritten, den Landräten als Vollzugsorgane zur Verfügung standen. ${ }^{40}$

Die Streikbewegung der revolutionären Nachkriegskrise erreichte ihren Höhepunkt mit dem schlesischen Landarbeiterstreik im Juni $1923 .{ }^{41}$ Dieser bekam einmal durch seinen Umfang besonderes Gewicht. Zum anderen

35 Vgl. ZStA Merseburg, Rep. 87 B, Nr. 197, Bl. 181 ff., 187 ff.; ebenda, Nr. 199, Bl. $164 \mathrm{f}$.

36 Vgl. Brief vom 19. 9. 1919, ebenda, Nr. 197, Bl. $32 \mathrm{ff}$.

37 Vgl. W. Vogler, Probleme, S. 405 ff.

38 Vgl. ZStA Potsdam, Deutscher Landwirtschaftsrat, Nr. 73, Bl. 47.

39 Vgl. ebenda, Bl. 107 ff.; Die Räder, 1925, S. 144; M. H. Kater, Die „Technische Nothilfe" im Spannungsfeld von Arbeiterunruhen, Unternehmerinteressen und Parteipolitik, in: VjZ, 1/1979, S. 33 f., 46, 71.

40 Vgl. P. Riege, Die preußische Polizei, Berlin 1929, S. 36 ff.; S. Zaika, Polizeigeschichte, Lübeck 1979, S. 165.

41 Vgl. Dok.Nr. 28-30; M. I. Orlova, Stačka silezskich batrakov v ijune 1923 g., 


\section{XXIV}

trug er als Bestandteil einer breiten Streikbewegung der Industriearbeiter und des nationalen Befreiungskampfes der deutschen Werktätigen gegen die Ruhrbesetzung zur Herausbildung einer revolutionären Situation im Sommer/Herbst 1923 bei. Gemeinsam mit anderen Aktionen bereitete er den Generalstreik gegen Cuno vor.

Der Streik, der nach erfolglosen Tarifverhandlungen am 27. Mai im Kreis Striegau elementar ausbrach, dauerte einen Monat und erfaßte in dieser Zeit fast 120000 Landarbeiter Mittel- und Niederschlesiens. ${ }^{42}$ Die Forderungen der Streikenden waren nicht nur rein wirtschaftlich und bezogen sich nicht nur auf Lohn- und Deputaterhöhung. Die Landarbeiter verlangten die Auflösung der paramilitärischen Organisation „Jungdeutscher Orden", strenge Aufsicht über die Verteilung von Lebensmitteln sowie die Erhöhung der Besitzsteuern, vor allem der Steuern für Luxuswaren.

Die rechten DLV-Führer, sowohl der Zentrale als auch der Gauleitung in Breslau, versuchten, die Führung des Streiks an sich zu reißen. Sie konnten es sich nicht leisten, bei schwindender Mitgliederzahl des Verbandes abseits zu stehen. Außerdem erwarteten die Mitglieder, „daß die Verbandsführung hinter ihnen steht und dies ist auch der Fall“, resümierte G. Schmidt Mitte Juni in einem Streikbericht. ${ }^{43}$ Zum gleichen Zeitpunkt erklärte er die jederzeitige Bereitschaft zu Verhandlungen, die sich aber infolge unnachgiebigen Verhaltens der Provinzial-Arbeitgeberorganisation unter Leitung des Grafen Keyserlingk (Cammerau) lange hinzogen.

Die schlesischen Junker setzten gegen die Streikenden bewaffnete Banden und Selbstschutzorganisationen wie die "Orgesch" ein und riefen zum Teil die Reichswehr zu Hilfe. Die rechten Sozialdemokraten in der preußischen Regierung billigten dieses Vorgehen. Carl Severing erklärte als Innenminister und Polizeipräsident am 19. Juni im preußischen Landtag, er handle nicht als irgendein Sozialist, sondern als ältester preußischer Beamter. ${ }^{4}$

Zum anderen konnte die herrschende Schicht mit dem christlich-nationalen Zentralverband der Landarbeiter die Streikfront spalten. Die Leitung des relativ starken Bezirksverbandes Breslau hielt ihre Mitglieder vom Streik ab und verhinderte so einen Generalstreik. Dem ZdL gegenüber erklärte sich der Arbeitgeberverband in Verhandlungen eher zu Zugeständnissen bereit.

Mit Beginn der Ernte forderten die schlesischen Junker von den preußi-

in: Novaja i novejšaja istorija, 1961/4, S. 78 ff.; dies., Revolucionnyj krizis

1923 g. v Germanii i politika Kommunističeskoj partii, Moskva 1973, S. $273 \mathrm{ff}$.

42 Vgl. Geschichte der deutschen Arbeiterbewegung, Bd. 3, Berlin 1966, S. 398.

43 Vgl. ZStA Merseburg, Rep. 87 B, Nr. 290, Bl. 162.

44 Vgl. M. I. Orlova, Stačka, a. a. O., S. 86. 
schen Behörden die Beendigung des Streiks. Technische Nothelfer, die als Streikbrecher fungierten, beschleunigten den Abbruch über Verhandlungen. Der Schiedsspruch des Reichsarbeitsministers vom 27. Juni 1923 brachte nur geringe Ergebnisse im Hinblick auf die Sicherung des Barund Deputatlohnes. Streiks in anderen preußischen Provinzen wie Brandenburg, Pommern, Ost- und Westpreußen, Sachsen und Hannover wurden im Keim erstickt. Obwohl die KPD ihren Einfluß unter den Landarbeitern und Kleinbauern seit ihrer Gründung verstärkt hatte, war ihre Massen- und Bündnispolitik noch indifferent und fehlerhaft. So gelang es ihr nicht, die Vorherrschaft der reformistischen Führer im DLV zurückzudrängen. Trotz seiner Niederlage war der Streik der schlesischen Landarbeiter die größte und bedeutendste Aktion landwirtschaftlicher Arbeiter Deutschlands in der revolutionären Nachkriegskrise. Er fand im Moment schärfster Zuspitzung der wirtschaftlichen und politischen Situation statt und kündete vom Entstehen einer revolutionären Krise, die im Herbst 1923 voll zum Ausbruch kam.

Wie in der Industrie klang die Streikbewegung auch in der Landwirtschaft erst im ersten Halbjahr 1924 ab. Zwischen April und Mai 1924 erfaßte ein Landarbeiterstreik 18 Kreise Ostpreußens und dauerte etwa vier Wochen. ${ }^{45}$ Der ostpreußische Landwirtschaftsverband hatte am 15. März 1924 die Arbeitsgemeinschaft mit dem DLV gelöst, um am 16. April einseitig mit dem ZdL einen Tarifvertrag auszuhandeln. Aùch hier führte der frühzeitige Einsatz der Technischen Nothilfe und das „tariftreue Verhalten der Mitglieder des ZdL während der ganzen Bewegung “46 zur Isolierung der streikenden Arbeiter des DLV.

Die revolutionäre Bewegung der Landarbeiter war in den Jahren zwischen 1919 und 1923 untrennbar mit dem Kampf der Arbeiterklasse und der demokratisch gesinnten Kräfte verbunden. In entscheidenden Situationen kam es zu gemeinsamen und einheitlichen Aktionen mit dem Industrieproletariat gegen den Ansturm der Konterrevolution, die die Errungenschaften der Novemberrevolution zu beseitigen und vor allem die Dörfer zu konterrevolutionären Zentren auszubauen versuchte. Die Rechte und Freiheiten, die die Landarbeiter der herrschenden Klasse abgerungen hatten, mußten immer wieder neu erkämpft werden. Dabei spielten die gewerkschaftlichen Organisationen des Landproletariats eine große Rolle. Trotzdem zeigte sich, daß weder die kleinbürgerlich-reformistische Agrarkonzeption der rechten SPD- und Gewerkschaftsführer noch christlichnationale oder werksgemeinschaftliche Eliminierung des Klassenkampfes den wirklichen Interessen der Landarbeiterschaft entsprachen. Die junge

45 Vgl. Dok. Nr. $33 ;$ J. B. Beßler, a. a. O., S. 50 ff.

$46 \mathrm{Vgl}$. ebenda, S. 54. 
XXVI

Kommunistische Partei Deutschlands war erst dabei, opportunistische und sektiererische Auffassungen in der Agrarfrage zu überwinden. Dem Klassengegner gelang es durch große Variabilität seiner Taktik, Streiks der Landarbeiter niederzuschlagen oder im Keim zu ersticken. Erfolgreich nutzte er die Spaltung der Landarbeiterschaft in verschiedene Organisationen aus. 


\section{Zur rechtlichen Stellung und sozialen Lage der Landarbeiter in der Weimarer Republik}

Deutschland war in den 20er Jahren von seiner Struktur her ein entwickeltes Industrieland. Auch in Preußen, das weite agrarische Gebiete hatte, überwog der Anteil der in der Industrie Beschäftigten. Eine Gegenüberstellung zeigt die annähernde Gleichheit der Werte für Preußen und das Reich. ${ }^{1}$

Prozentuale Verteilung der Erwerbstätigen auf Industrie und Landwirtschaft im Reich und in Preußen 1925

\begin{tabular}{lll}
\hline & $\begin{array}{l}\text { Industrie und } \\
\text { Handwerk }\end{array}$ & $\begin{array}{l}\text { Land- und } \\
\text { Forstwirtschaft }\end{array}$ \\
\hline Reich & 41,4 & 30,5 \\
Preußen & 41,0 & 29,5
\end{tabular}

Für den agrarischen Bereich verbargen sich hinter diesen Prozentzahlen für ganz Deutschland - nach der amtlichen Statistik - etwa 14,3 Millionen Arbeitskräfte, von denen 3,3 Millionen in einem Lohn- oder Gehaltsverhältnis standen. ${ }^{2}$ Diese Landarbeiter, die auf den großen Gütern Ostelbiens fast 90 Prozent und in den großbäuerlichen Wirtschaften 60 Prozent der Arbeitskräfte ausmachten, lebten und arbeiteten auch in der Weimarer Republik nicht viel anders als im Kaiserreich, denn das Produktionsniveau der Landwirtschaft blieb hinter dem der Industrie zurück. Ein gewisser Aufschwung der Produktivkräfte wurde in der Periode der relativen Stabilisierung des Kapitalismus durch die Motorisierung und Mechanisierung der Landwirtschaft erreicht. Die Subventionen, die die Monopole nach heftigen Auseinandersetzungen als „Osthilfe“ ab 1929/30 zugestanden, dienten jenem Zweck, womit diese Kreise aber den agrarischen Besitzstand des Großgrundbesitzes konservierten, ohne daß die Industrie allerdings das Interesse an einer weiteren Modernisierung der Landwirtschaft aus dem Auge verlor. ${ }^{3}$

1 Vgl. W. Woytinsky, Zehn Jahre Neues Deutschland, Berlin 1929, S. 21.

2 Vgl. R. Berthold, Zur sozialökonomischen Struktur des kapitalistischen Systems der deutschen Landwirtschaft zwischen 1907 und 1925, in: Jahrbuch für Wirtschaftsgeschichte, T. III, Berlin 1974, S. 122.

3 Vgl. M. Nussbaum, a. a. O., S. 346. 


\section{XXVIII}

In der Novemberrevolution hatte es zunächst so ausgesehen, als ob auch für die Landarbeiter die neuen arbeits- und sozialrechtlichen Gesetze und Bestimmungen gelten sollten. Bald zeigte sich aber, daß die Landarbeiter gegenüber den Industriearbeitern teilweise erheblich benachteiligt waren. Alles lief auf eine Sondergesetzgebung oder - wie es die KPD nannte Ausnahmegesetzgebung" gegenüber den Landarbeitern hinaus. Das begann bereits bei der Vorläufigen Landarbeitsordnung, die nicht öffentlich-rechtlichen, d. h. mit Strafandrohungen versehenen Charakter hatte, sondern lediglich ein privates Arbeitsvertragsrecht war. ${ }^{5}$ Sie regelte zwar den landwirtschaftlichen Arbeitsvertrag mit Arbeitszeit, Arbeitslohn, Kündigungsfristen und Arbeitsordnung, enthielt aber nicht jene Schutzbestimmungen in bezug auf Sonn- und Feiertagsarbeit, Ruhepausen, Kündigungsrecht, Lohnzahlungen, Lehrlingswesen, Kinderschutz, Beschäftigung Jugendlicher, Wöchnerinnenschutz u. ä., wie sie die Gewerbeordnung wenigstens auf dem Papier vorsah. ${ }^{6}$ Deshalb galt in der Weimarer Republik der Landarbeiter als der am meisten ausgebeutete Proletarier, der am schlechtesten entlohnt wurde und die längste Arbeitszeit hatte.

Auch das Betriebsrätegesetz vom 4. Februar 1920 schränkte in $\S 4$ die Anwendung dieses Gesetzes auf die Landwirtschaftsbetriebe beträchtlich ein. Die Wahl eines Betriebsobmannes war erst dann zulässig, wenn das Gut mindestens zehn ständige Arbeitskräfte hatte ${ }^{7}$, während für einen Industriebetrieb schon fünf Arbeiter genügten. Von vornherein war die Wahl eines Betriebsobmannes in kleineren und solchen Landwirtschaftsbetrieben ausgeschlossen, die vorwiegend Saisonarbeiter beschäftigten.

Nach den Erhebungen des preußischen Landwirtschaftsministeriums hatten in den östlichen Regierungsbezirken erst Betriebe von 200 bis 500 Hektar einen solchen Arbeitskräftebesatz, daß die Wahl eines Betriebsobmannes erfolgen konnte; nur auf Gütern über 500 Hektar konnte ein Betriebsrat aus mehreren Mitgliedern gewählt werden. ${ }^{8}$ Aber auch dieses Recht mußte erkämpft werden. Die Betriebsratsmitglieder hatten Drohungen und Maßregelungen der Gutsbesitzer in Kauf zu nehmen, mit Entlassung und Wohnungsausweisung zu rechnen.

Die Kommunistische Partei setzte sich im Preußischen Landtag und im Reichstag wiederholt für den Ausbau der Rechte der Betriebsräte ein. ${ }^{9}$

$4 \mathrm{Vgl}$. Landarbeiter, heraus aus Eurem Elend! Hrsg. v. ZK der KPD, Berlin 1928 , S. 22.

5 Vgl. L. Preller, Sozialpolitik in der Weimarer Republik, Stuttgart 1949, S. 233.

6 Vgl. Gesetzgebung und Landarbeiterschaft, in: Landarbeiter-Archiv, 1928, Nr. 4, S. 180.

7 Vgl. Reichs-Gesetzblatt, 1920, Nr. 26, S. 148.

8 Vgl. ZStA Merseburg, Rep. 87 B, Nr. 322, B1. 158.

9 Vgl. Preußischer Landtag, 1. Wahlperiode, 1. Tagung 1921, Große Anfrage 
In Preußen zeigte sich nicht nur $1923 / 24^{10}$, sondern noch $1929 / 30^{11}$, daß in den Betrieben, wo es keine Betriebsräte gab, die Großagrarier entsprechenden Druck ausgeübt hatten. Vielfach wirkten Werksgemeinschafts- und Landvolkideologie so, daß die Arbeiter selbst angesichts des "guten Einvernehmens" mit dem Gutsbesitzer den Betriebsrat für überflüssig hielten. Die organisatorische Zersplitterung der Landarbeiter und ihr mangelndes politisches und fachliches Wissen hemmten die volle Wahrnehmung ihrer Rechte. Bewußt verlangte die KPD ab Mitte der 20er Jahre die gewerkschaftliche Sammlung und verstärkte Schulung des Landproletariats.

Nicht nur um die in der Revolution erkämpften sozialen Rechte der Landarbeiter mußte immer wieder mit parlamentarischen und außerparlamentarischen Mitteln gerungen werden. Auch die 1927 angenommenen Gesetze zur Arbeitszeit, Schwangerenfürsorge, Arbeitsvermittlung und Arbeitslosenversicherung fanden ebenso wie die Reichsversicherungsordnung in bezug auf Unfall- und Krankenversicherung für den landwirtschaftlichen Bereich überhaupt keine oder nur eine einengende Anwendung.

Die Junker im RLB, in der DNVP und den Landwirtschaftskammern bereiteten zusammen mit schwerindustriellen Kreisen in der Mitte der 20er Jahre einen erneuten Generalangriff auf die Errungenschaften der Novemberrevolution vor. Ihre übereinstimmende Zielstellung hieß Kampf gegen die Sozialdemokratie und die gewerkschaftlichen Forderungen und Abwehr von sozialen Fortschritten. ${ }^{12}$ An die Stelle einer Erneuerung der Zentralarbeitsgemeinschaft trat die Werksgemeinschaft und die von A. Vögler (Vereinigte Stahlwerke) seit 1925 propagierte DINTA-Ideologie ${ }^{13}$, die über Ausbildung und Wohlfahrtseinrichtungen für Arbeiter verbreitet wurde.

Ständisch-nationalistische Organisationen der Ruhrindustrie und der pommerschen Junker und ein Heer von Ständeideologen führten den "Kampf um die Seele des Arbeiters", die „weder eine sozialistische noch eine klerikale, sondern eine deutsche Seele" sein sollte. „Alle Arbeiter, die so eingestellt sind", führte Thyssen auf der Mitgliederversammlung

Nr. 11 der Abgeordneten Schulz (Neukölln) und Genossen vom 14. April 1921, in: Ebenda, Nr. 312, Bl. 201; Reichstag, III. Wahlperiode 1924/27, Interpellation der Fraktion der KPD vom 3. Oktober 1927, in: Ebenda, Nr. 322, Bl. 261.

$10 \mathrm{Vgl}$. ebenda, $\mathrm{Bl} .158 \mathrm{f}$.

$11 \mathrm{Vgl}$. ebenda, Nr. 323, Bl. 199, 199 a.

12 Vgl. Jahrbuch des ADGB 1926, Berlin 1927, S. 60 f.; K. H. Pohl, Weimars Wirtschaft und die Außenpolitik der Republik 1924-1926, Düsseldorf 1979, S. 115; Feldman/Steinisch, Die Weimarer Republik zwischen Sozial- und Wirtschaftsstaat, in: Archiv für Sozialgeschichte, Bd. 18, Bonn 1978, S. 354, 435.

$13 \mathrm{Vgl}$. L. Preller, a. a. O., S. $131 \mathrm{f}$. 


\section{$\mathrm{XXX}$}

des Langnamvereins am 1. Oktober 1926 aus, „stehen uns gleich nahe.“14 Damit brachte er auch die Ziele ostelbischer Junker zum Ausdruck, die erneut zur vollen Durchsetzung ihres Herr-im-Hause-Standpunkts antraten. So forderten bereits im Sommer 1925 schlesische Landbünde die Einführung eines Entlassungsscheins für landwirtschaftliche Arbeiter, um der verstärkten Landflucht zu begegnen und Einstellungen von Landarbeitern in der Industrie zu verhindern. ${ }^{15}$

Dieses Ansinnen, das die Arbeiterorganisationen und die demokratische Offentlichkeit immer wieder herausforderte ${ }^{16}$, bedeutete nichts anderes, als schwarze Listen anzulegen, die Arbeiter - wenn nötig - mit Polizeigewalt an das Gut zu fesseln und ihre verfassungsrechtlich garantierte Freizügigkeit einzuschränken. Es stand im schroffen Gegensatz zur Sozialgesetzgebung vom Sommer 1927, die nach jahrelangen, wenn nicht jahrzehntelangen Kämpfen angenommen werden mußte.

Die Ansätze, die es für arbeitsrechtliche Regelungen in der Novemberrevolution und in den Beschlüssen der Washingtoner Konferenz der Internationalen Arbeiterorganisation des Völkerbundes (ILO) vom Herbst 1919 gegeben hatte, waren von der herrschenden Klasse Deutschlands verschleppt, verwässert und schon 1922/23 hart angegriffen worden. Erst die massiven parlamentarischen und außerparlamentarischen Vorstöße der Arbeiterparteien und Gewerkschaften, die günstige konjunkturelle Lage und die zeitweilige Zurückdrängung der Führungsposition der Schwerindustrie durch die Silverberg-Gruppe im Herbst $1926^{17}$ erbrachten sozialpolitische Zugeständnisse, die von den reaktionären Kreisen aber sofort wieder in Frage gestellt wurden.

Der Reichsverband der land- und forstwirtschaftlichen Arbeitgebervereinigungen griff seit Herbst 1927 das Tarifsystem, das Schlichtungswesen und die Arbeitslosenversicherung scharf an. ${ }^{18}$ Das Reichsarbeitsministerium - eine Schöpfung der Revolutionstage und bis zum Amtsantritt Papens ständig von reformistischen oder christlichen Gewerkschaftsführern in systemstabilisierender Weise geleitet ${ }^{19}$ - gab zunehmend den Forderun-

14 Zit. nach: K. H. Pohl, a. a. O., S. 263; auch F. Fricke, Sie suchen die Seele!, Berlin 1927, S. 3 f., $40 \mathrm{ff}$.

15 Vgl. ZStA Merseburg, Rep. 87 B, Nr. 268, B1. 292 ff.; auch Dok. Nr. 40.

16 Vgl. ebenda, Bl. 311 ff., 387; ebenda, Nr. 269, Bl. 11 f.; auch Dok. Nr. 41, 43, 49,50 .

$17 \mathrm{Vgl}$. D. Stegmann, Die Silverberg-Kontroverse 1926, in: Sozialgeschichte heute, Festschrift für H. Rosenberg, Göttingen 1974, S. 606 ff.; K. H. Pohl, a. a. O., S. 259 ff.

18 Vgl. ZStA Potsdam, RAM, Bd. 6511, Bl. 76, 82; Die wirtschaftliche Lage der Landarbeiter und Landarbeiterinnen Deutschlands, Berlin 1928, S. 3; auch Dok. Nr. 48.

19 Vgl. M. Nussbaum, a. a. O., S. 242 f. 
gen der herrschenden Klasse nach und konstatierte spätestens 1930 einen Stillstand in der Sozialpolitik bzw. „ein fast von den gesamten bürgerlichen Parteien getragenes Rückwärtsstreben" auf diesem Gebiet. ${ }^{20}$ Der ADGB, der jahrelang die Illusion genährt hatte, daß diese Zugeständnisse durch sein vorbehaltloses Bekenntnis zum bürgerlichen Staat entstanden waren, mußte in seinem Jahrbuch für 1931 eingestehen: „Die Mauern des stolzen Gebäudes, das sich die Arbeiterschaft in dem kollektivistischen System moderner Sozialpolitik geschaffen hatte, stehen noch. Aber im Innern ist dieses Gebäude bereits heute zerbröckelt und teilweise zerstört." 21

Im Zusammenhang mit dem Arbeitsrecht wurde für Preußen ab 1927 auch die Frage der Einbeziehung der Landarbeiter in die Berufsorganisation, die Landwirtschaftskammern, erneut diskutiert. Dazu waren bereits im Sommer 1918 Reformvorstellungen der kaiserlichen Regierung entwickelt worden. Sie wollte von vornherein der Meinung der aus dem Krieg heimkehrenden Landarbeiter entgegentreten, daß ihnen die Gleichberechtigung mit den Industriearbeitern versagt bliebe. ${ }^{22}$ Aber trotz der Revolution hatte sich in Preußen - zum Unterschied von anderen deutschen Ländern - bis 1927 nichts an der Zusammensetzung der Landwirtschaftskammern geändert. Sie waren Sammelpunkte der Reaktion, in denen der Großgrundbesitz und seine Verbände den Ton angaben. 1920/21 hatten sie alle Hebel in Bewegung gesetzt, um eine grundlegende Veränderung der Zusammensetzung der Kammern zu verhindern. ${ }^{23}$

Seit 1928 durchlief der neue Gesetzentwurf die Parlamentsmühlen des preußischen Landtags. Die Vertreter der reformistischen und christlichen Gewerkschaften ${ }^{2 / 4}$ wandten sich gegen die provinziellen Landbünde, die den Kampf gegen die „Politisierung“ der Kammern führten und jegliche gewerkschaftliche Mitbestimmung ablehnten. ${ }^{25}$ Das neue Gesetz fiel schließlich dem Abbau des Parlamentarismus zum Opfer.

Zeigte sich die Benachteiligung der Landarbeiter bereits in bezug auf die Gesetzestexte, um wie viel schlimmer mußte es da in der praktischen Verwirklichung von Arbeitsrecht und Sozialpolitik in der Landwirtschaft aussehen! Die Junker nutzten ihre ökonomische Macht, vor allem aber ihren politischen Einfluß zur Unterdrückung und Ausbeutung, zur ideologischen Bevormundung, Manipulierung und Korrumpierung des Landproletariats aus. Bis Anfang 1928 hatten sie als Vorsteher der 12000 in Ost-

20 Vgl. R. Wissell, 21 Monate RAM, in: Die Arbeit, 4/1930, S. $217 \mathrm{ff}$.

21 Jahrbuch 1931 des ADGB, Berlin 1932, S. 85.

22 Vgl. ZStA Merseburg, Rep. 87 B, Nr. 55, Bl. 1 ff.

23 Vgl. ebenda, Nr. 13282, Bl. 37, 209 f.; ZStA Potsdam, Film-Nr. 8596, Bl. 42 ff.

24 Vgl. ZStA Merseburg, a. a. O., Nr. 13 314, Bl. $166 \mathrm{ff}$.

$25 \mathrm{Vgl}$. ebenda, Nr. 13320 , Bl. 72 ff., 148; ZStA Potsdam, Film-Nr. 8596, Bl. $223 \mathrm{ff}$. 


\section{XXXII}

elbien bestehenden Gutsbezirke zugleich die polizeiliche Gewalt. Erst Ende 1927 war die sozialdemokratische Fraktion darangegangen, eine „nach neuzeitlichen Gesichtspunkten gestaltete Landgemeindeordnung “ im preuBischen Landtag durchzubringen. ${ }^{26}$ Unter den $1 \frac{1}{2}$ Millionen Einwohnern Ostelbiens, die bis zu diesem Zeitpunkt kein kommunales Wahlrecht hatten, waren auch Zehntausende von Landarbeitern.

Die Großgrundbesitzer erreichten über ökonomische Machtmittel eine enge Bindung der Landarbeiter an den junkerlichen Betrieb. Sie nutzten die unterschiedlichen Lohnsysteme zur sozialen Differenzierung aus. Im ostelbischen Preußen gab es folgende soziale Kategorien von Landarbeitern $^{27}$, die sich nach ihrer ökonomischen und rechtlichen Stellung voneinander unterschieden:

Da waren zunächst die Deputanten (männliche Deputatempfänger oder Tagelöhner), die meistens über einen Jahresarbeitsvertrag gebunden waren, in Werkwohnungen (mit Stall und Garten) wohnten und den größten Teil ihres Lohnes in Naturalien (Getreide, Brennholz und Viehfutter) erhielten. Der Barlohn war äußerst niedrig. Diese Landarbeiter waren vertraglich gezwungen, zu bestimmten Arbeitsspitzen Familienangehörige, mit denen kein Arbeitsvertrag bestand, zur Arbeit auf die Güter mitzubringen (Hofgänger). Das waren meistens die Deputantenfrauen, deren Lohn weit unter dem der Männer lag oder deren Lohnanteil im Lohn der Männer enthalten war (Familienlohn).

Eine rechtlich und sozial andere Kategorie waren die männlichen und weiblichen Freiarbeiter. Sie wurden mit oder ohne Arbeitsvertrag zu Spitzenarbeitszeiten eingestellt. Sie wohnten selten in Werkwohnungen, und ihr Barlohn lag höher. Freiarbeiter wurden vorrangig in den Hackfruchtgebieten der Provinzen Sachsen und Schlesien beschäftigt und waren auch in der Weimarer Republik häufig polnische Wanderarbeiter.

Die männlichen und weiblichen jugendlichen Arbeitskräfte, die es auf den Gütern gab, waren die Kinder der Deputanten und rechtlich im Status eines Hofgängers. Sie waren sozial besonders benachteiligt. Beim Fehlen eigener Kinder war der Deputant verpflichtet, fremde gleichwertige Arbeitskräfte zu stellen. Sie erhielten Kost und Unterkunft in den Familien der Deputanten.

Das Gesinde (Knechte und Mägde) bekam Kost und Wohnung auf den Gütern. Es wurde durch schwere körperliche Arbeit, ungeregelte Arbeitszeit, Sonn- und Feiertagsarbeit besonders ausgebeutet. Das Gesinde lebte unter ständiger Kontrolle und Aufsicht des Gutsbesitzers.

26 Vgl. Preußentag der SPD, o. O. o. J. (1928), S. 5.

$27 \mathrm{Vgl}$. W. Hucho, Die Naturalentlohnung in der deutschen Landwirtschaft, Berlin 1925, S. $5 \mathrm{f}$; f für das 19. Jh. vgl. H. Plaul, Landarbeiterleben im 19. Jahrhundert, Berlin 1979, S. $90 \mathrm{ff}$. 
Die Naturalentlohnung war die Hauptform des Lohnes ostelbischer Landarbeiter in der Zeit der Weimarer Republik. Sie herrschte in den Getreideanbaugebieten Ostpreußens, Brandenburgs, Schlesiens, Pommerns und Schleswig-Holsteins vor, während in der Provinz Sachsen der GeldIohn überwog. ${ }^{28}$ Zunächst bedingt durch Krieg und Inflation, hielten die ostelbischen Grundbesitzer auch in den 20er Jahren an dieser Lohnform fest. Das war Ausdruck der geringen Intensität ihrer Betriebe, wurde aber ebenso bewußt zur Förderung der „Interessengemeinschaft“ von Junkern und Landarbeitern und der Vertiefung der sozialen Unterschiede zwischen Industrie- und Landproletariat ausgenutzt. So hatte der schlesische Graf von Keyserlingk Ende 1920 auf der Vorstandssitzung des Reichsverbandes der land- und forstwirtschaftlichen Arbeitgebervereinigungen betont: „Jeder Arbeitgeber, der das natürliche Band, das ihn mit seinem Arbeitnehmer verbindet, festigen will, muß die Naturalentlohnung fördern, die den Landarbeiter über den Industriearbeiter stellt, wie es recht und billig ist. “ 29

Partei für die Junker in der Frage der Naturalentlohnung ergriffen die christlichen und „gelben" Gewerkschaften, die über das Deputat das Interesse des Landarbeiters an einer kleinen Eigenwirtschaft wecken und damit seine Bindung an den Boden festigen wollten. Der DLV, der vor dem 1. Weltkrieg das Deputat als Fessel für den Landarbeiter betrachtet hatte ${ }^{30}$, trat in der Mitte der 20er Jahre für die Annäherung der Landarbeiterlöhne an die Industriearbeiterlöhne ein $^{31}$ und verstand darunter sowohl Geld- wie Deputatlohn. Die KPD forderte Erhöhung der Barlöhne und ausreichende Deputate und band die Lohnfrage in ein ganzes Bündel zu lösender sozialer Probleme ein.

Die Landarbeiterlöhne waren in der Regel Tariflöhne. Durch die Trennung in Bar- und Deputatlohn erfolgte ihre Berechnung nach einem komplizierten System und war für den Naturallohnanteil von den Preisen für landwirtschaftliche Produkte (Berliner Börsenpreis) abhängig. Dadurch differierten die Bewertungsmaßstäbe für die Werkwohnungen, das Lohnland und die Naturalien in den einzelnen Jahren stark und wurden von den Unternehmerorganisationen anders als von den offiziellen staatlichen Stellen und den Gewerkschaften berechnet. ${ }^{32}$ Einen vermittelnden Stand-

28 Vgl. W. Hucho, a. a. O., S. 6.

29 Vortrag des Grafen Keyserlingk vom 14. Dezember 1920, a. a. O., Bl. 101 f.

$30 \mathrm{Vgl}$. G. Schmidt, Lohnfragen und Arbeitsverhältnisse in der Landwirtschaft, Berlin 1913, S. 15.

$31 \mathrm{Vgl}$. Industriearbeiterlöhne für Landarbeiter! Berlin 1929.

32 Vgl. W. Hucho, a. a. O., S. 19, 25; Deputatbewertungsschlüssel vom Juli 1926, in: Baade, Bernier, Kwasnik, Die wirtschaftliche Lage der Landwirtschaft. Die Lohnfrage in der Landwirtschaft. Sozialpolitik in der Landwirtschaft. 


\section{XXXIV}

punkt erreichte in den Anfangsjahren der Weimarer Republik das Tarifamt Halle, das aus der „Arbeitsgemeinschaft" hervorgegangen war. Aber auch hier gaben die landwirtschaftlichen Unternehmer den Ton an.

In der Mitte der 20er Jahre wurden die Führungsgremien des DLV und ZdL infolge der Landflucht von Tausenden von Landarbeitern und des Drucks der Mitgliedermassen gezwungen, sich mehr mit den Arbeits- und Lebensverhältnissen der Landarbeiter zu beschäftigen. Die Regierung setzte einen Enqueteausschuß ein, der aber vorrangig die Erzeugnis- und Absatzbedingungen der deutschen Landwirtschaft untersuchte. Ergebnis der gewerkschaftlichen Analyse waren zahlreiche Untersuchungen zur Arbeitszeit, Lohn- und Sozialfrage in der Landwirtschaft.

Dabei fiel als erstes ins Auge, daß in keinem junkerlichen Betrieb der Achtstundentag garantiert war. Statt $2400 \mathrm{Jahresarbeitsstunden} \mathrm{betrug} \mathrm{für}$ die Landarbeiter Ostelbiens die tarifmäßige Arbeitszeit von 1923 bis $1928^{33}$

Tarifliche Arbeitsstunden

\begin{tabular}{llllllll}
\hline Provinz & Tarifbezirk & 1923 & 1924 & 1925 & 1926 & 1927 & 1928 \\
\hline Ostpreußen & Königsberg & 2788 & 2895 & 2895 & 2903 & 2903 & 2903 \\
Pommern & Randow & 2900 & 2900 & 2900 & 2963 & 2963 & 2964 \\
Brandenburg & Teltow und & & & & & & \\
& Niederbarnim & 2700 & 2850 & 2850 & 2850 & 2850 & 2850 \\
Schlesien & Schlesien & 2840 & 2857 & 2856 & 2856 & 2856 & 2856 \\
Sachsen & Börde & 2675 & 2750 & 2750 & 2750 & 2750 & 2750
\end{tabular}

Diese Ubersicht verdeutlicht, daß die Arbeitszeit in den rückständigen Gebieten des Ostens höher war als in Mitteldeutschland. Ähnlich gelagert waren auch die Einkommensunterschiede. Der Naturallohnanteil betrug in den östlichen Provinzen zwischen 60 und 80 Prozent, während er in der Provinz Sachsen 30 Prozent ausmachte. Eine Analyse, die 1929/30 über Lebenshaltung, Lohn- und Arbeitsverhältnisse von 145 Landarbeiterfamilien angefertigt wurde, wies folgende prozentuale Verteilung von Naturalund Barlohn aus ${ }^{3 / 4}$ :

Drei Vorträge, Berlin 1927, S. 27; Deputatbewertungsschlüssel vom Oktober 1927, in: Die wirtschaftliche Lage, S. 6.

33 Bericht des Verbandsvorstandes über die Verbandsarbeit in den Jahren 1926 bis 1928, Berlin 1929, S. 35.

34 Vgl. W. Bernier, Die Lebenshaltung, Lohn- und Arbeitsverhältnisse von 145 deutschen Landarbeiterfamilien, Berlin 1931, S. 57. 


\begin{tabular}{lll}
\hline Provinz & Naturallohn in \% & Barlohn in \% \\
\hline Pommern & 83,7 & 16,3 \\
Ostpreußen & 77,3 & 22,7 \\
Brandenburg einschl. Grenzmark & 64,4 & 35,6 \\
Schlesien & 56,0 & 44,0 \\
Sachsen-Anhalt einschl. Braunschweig & 30,9 & 69,1
\end{tabular}

Für alle Gebiete Preußens gleichermaßen ungünstig fiel ein Vergleich der Landarbeiterlöhne mit denen der Industriearbeiter aus. Eine Gegenüberstellung ergab für Oktober 1927, daß nur bei Mitarbeit der Frau des Deputanten und eines 18jährigen Hofgängers annähernd der Lohn eines Bauhilfsarbeiters als des schlechtbezahltesten Industriearbeiters erreicht wur$\mathrm{de}^{35}$ :

\begin{tabular}{|c|c|c|c|}
\hline Provinz & Landkreis & $\begin{array}{l}\text { Gesamt- } \\
\text { stundenverdienst } \\
\text { aller drei Land- } \\
\text { arbeiter (Pf.) }\end{array}$ & $\begin{array}{l}\text { Stundenlohn } \\
\text { eines Bau- } \\
\text { hilfsarbeiters } \\
\text { (Pf.) }\end{array}$ \\
\hline
\end{tabular}

$\begin{array}{llll}\text { Ostpreußen } & \text { Königsberg } & 64,97 & 63 \\ \text { Schleswig- } & \text { alle Landkreise } & 87 & 88 \\ \text { Holstein } & & & \\ \text { Schlesien } & \text { Ohlau } & 77,32 & 71 \\ \begin{array}{l}\text { Mitteldeutsch- } \\ \text { land (Börde) }\end{array} & \text { Wolmirstedt } & 92,68 & 80\end{array}$

In diesem Zusammenhang ist es wichtig, einen Blick auf die Löhne der etwa $1 \frac{1}{2}$ Millionen Landarbeiterinnen sowie der Jugendlichen zu werfen. War die Frau im imperialistischen Deutschland schon allgemein diskriminiert, so die Landarbeiterin im besonderen. Das bezog sich vor allem auf ihren Lohn. In der Inflationszeit betrugen die Frauenlöhne zwei Fünftel der Löhne der männlichen Landarbeiter. „Das ist unter allen Erwerbszweigen bei weitem das ungünstigste Verhältnis “36, hieß es in einer Untersuchung aus dem Jahre 1924. Stieg dieser Anteil in den Jahren nach 1924 auch etwa auf drei Fünftel $\mathrm{an}^{3 \bar{z}}$, so war in der Weltwirtschaftskrise ein Lohnabbau von 30 Prozent keine Seltenheit.

$35 \mathrm{Vgl}$. Die wirtschaftliche Lage, S. 7.

36 Vgl. Dok. Nr. 57; A. Geyer, Die Frauenerwerbsarbeit in Deutschland, Jena 1924 , S. 61 f., zit. nach: J. Kuczynski, Geschichte des Alltags des deutschen Volkes, Bd. 5, Berlin 1982, S. 311.

37 Vgl. ebenda, S. 313; Die wirtschaftliche Lage, S. 8. 
XXXVI

Die KPD ermittelte 1931 folgenden Stundenlöhne in Pf. ${ }^{38}$ :

\begin{tabular}{lllll}
\hline Provinz & $\begin{array}{l}\text { männliche } \\
\text { Freiarbeiter }\end{array}$ & $\begin{array}{l}\text { weibliche } \\
\text { Freiarbeiter }\end{array}$ & Deputanten & $\begin{array}{l}\text { Deputanten- } \\
\text { frauen }\end{array}$ \\
\hline Ostpreußen & 36,38 & 15,35 & 34,82 & 18,33 \\
Pommern & 30,32 & 25,00 & 41,54 & 26,00 \\
Schlesien & 40,68 & 17,00 & - & -
\end{tabular}

Zu dieser Lohndiskriminierung kam der Zwang für die Frauen der Deputanten, auf dem Gutshof zu arbeiten, auch wenn sie eine Eigenwirtschaft und kleine Kinder zu versorgen hatten. Die KPD prangerte diese Mißstände ebenso an wie den fehlenden Wöchnerinnenschutz. Darstellungen über Mißhandlungen, Beleidigungen und Vergehen gegen schwangere Frauen häuften sich in der Presse. ${ }^{39}$

Neben den Frauen wurden jugendliche Arbeiter und auch Kinder in das Zwangssystem des Hofgängerwesens einbezogen. Während in der Industrie jugendliche Arbeiter vom 18. Lebensjahr ab den vollen Lohn erhielten, erreichten in der ostelbischen Landwirtschaft 14- bis 20 jährige 1927 nur folgenden prozentualen Anteil am Spitzenlohn eines vollwertigen Arbeiters ${ }^{40}$ :

$\begin{array}{ll}\text { in Ostpreußen } & 25-40 \%, \\ \text { in Pommern } & 30-50 \%, \\ \text { in Brandenburg } & 29-45 \%, \\ \text { in Schlesien } & 36-45 \%, \\ \text { in der Provinz Sachsen } & 37-51 \%\end{array}$

Dieser geringe Verdienst erlaubte es den jungen Landarbeitern nicht, sich selbständig zu machen. Die Landarbeiterfamilie konnte nur durch den Verkauf eines Teils des Deputats und der Produkte der Eigenwirtschaft, vor allem aber durch eine übermäßig lange Arbeitszeit aller Familienangehörigen existieren.

Auch Kinderarbeit gab es im hochindustrialisierten Deutschland. Die gesetzlichen Schutzbestimmungen bezogen sich nicht auf die Landwirtschaft, so daß nur einige landwirtschaftliche Berufsgenossenschaften in ihren Unfallverhütungsvorschriften das Mindestalter von 12 Jahren für die Beschäftigung von Kindern an Maschinen festsetzten. Die Unfallziffern nahmen bei 12 - bis 16 jährigen - wie die Unfälle generell - in den 20er Jahren erschreckend zu. Nach einer amtlichen Zählung waren 1925 in der deut-

38 Vgl. Not und Kampf der Landarbeiterinnen, o. O. o. J.' (1931), S. 3.

39 Vgl. Baade, Bernier, Kwasnik, a. a. O., S. 25.

$40 \mathrm{Vgl}$. Die wirtschaftliche Lage, a. a. O., S. 7 f. 
schen Landwirtschaft 400000 Kinder unter 14 Jahren tätig. Die KPD veranschlagte diese Zahl für die Zeit der Weltwirtschaftskrise bedeutend höher. ${ }^{41}$ Selbst die Einzeluntersuchung in 145 Landarbeiterfamilien ergab zusammen die Mitarbeit von 29 Kindern unter 14 Jahren. ${ }^{42}$

Die KPD verlangte immer wieder, die Kinderarbeit $\mathrm{zu}$ verbieten und jugendlichen Landarbeitern bis 18 Jahren einen Lohnanteil von 60 bis 85 Prozent der Vollarbeiter zu gewähren. ${ }^{3}$ Sie beschrieb darüber hinaus anklagend das Milieu, in dem das proletarische Kind aufwachsen mußte: „Umgeben von Schmutz, Feuchtigkeit, Gestank, Elend, frühzeitig zu schwerer körperlicher Arbeit mißbraucht, unterernährt und dauernder Gesundheitsschädigung durch unhygienische Wohnräume ausgesetzt. Unausgeschlafen und körperlich ermüdet, bleich und scheu kommt es zur Schule, meist uninteressiert und unfähig zu geistiger Mitarbeit $(20 \%$ der proletarischen Landkinder sind deshalb nur aufnahmefähig). “44

Das Wohnungselend der Landarbeiter hatte verheerende gesundheitsschädigende Folgen nicht nur für die Kinder, sondern auch für die Erwachsenen. Die menschenunwürdigen Wohnungen waren mit Ursache für eine hohe Säuglingssterblichkeit und einen dreimal so hohen Tuberkulosekrankenstand wie in den Städten. Die ungesunden Lehmkaten, ohne Licht und Sonne, meistens zu klein für die vielköpfigen Landarbeiterfamilien, führten neben der niedrigen Entlohnung verstärkt zur Landflucht. Hinzu kam, daß das Werkwohnungswesen den Landarbeiter an das Arbeitsverhältnis band und ihn zusätzlich der Willkür des Gutsbesitzers auslieferte. Dieser konnte mit dem Arbeitsvertrag auch die Wohnung kündigen, weil er entschied, wer sich darin aufhalten durfte.

Wohnungsklagen waren nach Lohn- und Deputatklagen, Kündigungsund Entlassungsklagen die häufigsten Rechtsfälle, die der DLV für seine Mitglieder auszufechten hatte. Aber sowohl er als auch die SPD, die im preußischen Landtag wiederholt den Bau von gemeindeeigenen Mietwohnungen für Landarbeiter, die Errichtung von Eigenheimen mit Hilfe der wertschaffenden Arbeitslosenfürsorge und die Verwendung günstiger Siedlungskredite auch für die Landarbeitersiedlung forderte ${ }^{45}$, unterbreiteten nur Reformvorschläge zur Beseitigung der schlimmsten Auswüchse des

$41 \mathrm{Vgl}$. Not und Kampf der Landarbeiterinnen, S. 12.

42 Vgl. W. Bernier, Die Lebenshaltung, a. a. O., S. 68.

43 Vgl. Landarbeiter, heraus aus Eurem Elend! S. 22; Preußischer Landtag, 3. Wahlperiode, 1. Tagung 1928/30, Urantrag Nr. 5553 vom 13 . November 1930, in: ZStA Merseburg, Rep. 169 D, XIe, F 4, Bd. 2, Bl. 227.

44 Not und Kampf der Landarbeiterinnen, a. a. O., S. 13.

45 Vgl. z. B. Preußischer Landtag, 2. Wahlperiode, 1. Tagung, 1925/26, Entschließungsantrag Nr. 2962 der SPD-Fraktion vom 24. März 1926, in: ZStA Merseburg, Rep. 87 B, Nr. 172, Bl. 161; Preußischer Landtag, 3. Wahlperiode, 1. Tagung 1928, Urantrag Nr. 80 der SPD-Fraktion vom 22. Juni 


\section{XXXVIII}

gutsbesitzerlichen Regimes. Sie mobilisierten die demokratische Offentlichkeit und appellierten an das Gewissen der Gutsbesitzer, ohne daß sich an den Verhältnissen grundlegend etwas änderte.

Erschreckend niedrig war auch das Bildungsniveau ostelbischer Landarbeiter. Das begann beim unzureichenden Volksschulwesen in Preußen. Nur in den Städten gab es halbwegs ausgebaute achtklassige Schulen. Auf dem Lande bestand das wenig gegliederte System fort. Von den Schülern preußischer Landgemeinden besuchten in der Mitte der 20er Jahre über 50 Prozent ein- bzw. zweiklassige Dorfschulen. ${ }^{46}$ Sie erhielten dort nur eine kurze und kümmerliche Ausbildung. Das preußische Berufsschul- und Fortbildungswesen und die Volkshochschulen berücksichtigten noch am Ende der 20er Jahre die Landarbeiter kaum. ${ }^{47}$ Als stark hemmende Faktoren standen dem Bildungsdrang der Landarbeiter lange Arbeitszeit, weite Entfernungen, geringe geldliche Mittel und die Einbindung in das Hofgängerwesen entgegen.

Der DLV-Funktionär Bernier mußte nach seiner Untersuchung in 145 Landarbeiterhaushalten feststellen, daß die Ausgaben für Bildung, Schulgeld und Zeitungen äußerst niedrig waren. Die Recherchen bei den Familien Ostpreußens wiesen den geringsten Pro-Kopf-Anteil von 2,72 M auf, während der höchste Satz von 12,93 M im Freistaat Thüringen einschließlich Regierungsbezirk Erfurt erreicht wurde. In den vier Ostprovinzen gaben die Landarbeiterfamilien im Untersuchungszeitraum von Mitte 1929 bis Mitte 1930 im Durchschnitt pro Person 4,62 M aus. ${ }^{18}$

In den 20er Jahren intensivierten DLV und ZdL ihre Schulungstätigkeit unter den Landarbeitern mit der Absicht, reformistisches und ständischnationalistisches Gedankengut als Gegengewicht gegen revolutionäre Ideen zu verbreiten. ${ }^{9}$ Sie versuchten, in ihren Lehrgängen vor allem die "gehobenen" Landarbeiter politisch und fachlich zu schulen. ${ }^{50}$

Mit der voranschreitenden Technisierung der Landwirtschaft forderten neben dem $\mathrm{DLV}^{51}$ auch Agrarwissenschaftler und Betriebswirtschaftler

1928, Urantrag Nr. 80 der SPD-Fraktion vom 22. Juni 1928, in: Ebenda, Nr. 174, B1. 82.

46 Vgl. Geschichte der Erziehung (11. Auflage), Berlin 1973, S. 588 ff.; A. Leschinsky, Volksschule zwischen Ausbau und Auszehrung, in: VjZ, 1/1982, S. 42; W. W. Wittwer, Die sozialdemokratische Schulpolitik in der Weimarer Republik, (West-)Berlin 1980, S. $240 \mathrm{f}$.

47 Vgl. C. Lomberg, Landarbeiter und Agrarpolitik, Berlin 1929, S. 74; ZStA Merseburg, a. a. O., Nr. 20 528, Bl. 151 ff.; W. W. Wittwer, a. a. O., S. 256 f.

$48 \mathrm{Vgl}$. W. Bernier, Die Lebenshaltung, S. $90 \mathrm{f}$.

49 Vgl. C. Lomberg, a. a. O., S. 76.

$50 \mathrm{Vgl}$. ZStA Merseburg, a. a. O., Nr. 379, Bl. $38 \mathrm{ff}$.

51 Vgl. Baade, Bernier, Kwasnik, a. a. O., S. 20. 
immer häufiger eine bessere Berufsausbildung für Landarbeiter ${ }^{52}$ Sie stellten sich in den Dienst des Deutschen Instituts für Technische Arbeitsschulung (DINTA), das in der zweiten Hälfte der 20er Jahre in solchen preußischen Provinzen wie Schlesien an Einfluß gewann ${ }^{53}$, und strebten an, über eine verbesserte Landarbeitslehre zur "Lösung der Landarbeiterfrage“ beizutragen. ${ }^{54}$ Besonders in den technisch gut ausgestatteten Betrieben der Provinz Sachsen, wo außerdem ständig die Gefahr des Abwanderns in die Industrie bestand, sollten Arbeitswille und Arbeitsfreude der Landarbeiter durch qualifizierten Einsatz und solche Lohnformen erreicht werden, die die Leistung über Akkord-, Prämien-, Prämienstaffel- oder Prämienpensumlohn berücksichtigten..$^{5}$

Auch andere Veränderungen, die sich aus dem Prozeß der Mechanisierung und Rationalisierung für die Arbeits- und Lebensbedingungen der Landarbeiter ergaben, machten sich zunächst in solchen Provinzen wie Sachsen und Schlesien bemerkbar. So traten in Mitteldeutschland an die Stelle der ständigen Arbeitskräfte zunehmend Freiarbeiter, die meistens polnische Saisonarbeiter waren.

Um die Frage der polnischen Wanderarbeiter gab es seit Mitte der 20er Jahre Auseinandersetzungen zwischen den großagrarischen Kreisen auf der einen und den preußischen Regierungsstellen und den Gewerkschaften auf der anderen Seite. Die Großgrundbesitzer widersetzten sich einem weiteren Rückgang der Zulassungszahlen, wie ihn die gewerkschaftliche Seite im Zusammenhang mit dem Ansteigen der Arbeitslosigkeit forderte. ${ }^{56}$ Für die Unternehmer verband sich mit der polnischen Saisonarbeit Billigkeit und Leistungsfähigkeit.

Polnische Wanderarbeiter hatten weder das Streikrecht noch das Recht

52 Vgl. J. W. Seedorf, Die Vervollkommnung der Landarbeit und die bessere Ausbildung der Landarbeiter unter besonderer Berücksichtigung des TaylorSystems, in: Archiv der Landarbeiterfrage, H. 2, 1919, S. 71 ff.; Die Landarbeiterfrage. Vorträge auf der Arbeitsnachweistagung in Magdeburg am 8.10.1926 (= Schriftenreihe des Landesarbeitsamtes Sachsen-Anhalt, H. 6), Leipzig 1927, S. 17 f.; E. Hoernle, Die Industrialisierung der Landwirtschaft - eine neue Phase kapitalistischer Monopolherrschaft, in: Ders., Zum Bündnis zwischen Arbeitern und Bauern, Berlin 1972, S. 149 ff.

$53 \mathrm{Vgl}$. Drei Jahre berufsständische Arbeit in der praktischen Landwirtschaft Ober- und Niederschlesiens, Breslau 1930 (Dok. Nr. 60).

$54 \mathrm{Vgl}$. W. Lüders, Landarbeitslehre und Landarbeiterfrage, in: Die Landarbeiterfrage, a. a. O., S. 23.

$55 \mathrm{Vgl}$. ebenda, S. $17 \mathrm{ff}$.

56 Vgl. K. Dohse, Ausländische Arbeiter und bürgerlicher Staat, Königstein/ Ts. 1981, S. 112 ff., allg. J. Sobczak, Die polnischen Landarbeiter in Deutschland in den Jahren 1919-1939 und ihre Behandlung, in: Deutscher Imperialismus und polnische Arbeiter in Deutschland 1900-1945 (= Fremdarbeiterpolitik des Imperialismus, H. 2), Rostock 1977, S. 48 ff. 
der Freizügigkeit und waren in billigen Schnitterkasernen untergebracht. Besonders beliebt waren polnische Saisonarbeiterinnen wegen ihres niedrigen Lohnes. Außerdem durften sie keinerlei soziale Forderungen stellen. Selbst nationalistische Großagrarier zogen polnische Arbeiter den sogenannten Artamanen vor, die sich seit Mitte der 20er Jahre als eine Art freiwilliger Arbeitsdienst anboten und gleichzeitig unter arbeitslosen Jugendlichen völkisches und faschistisches Ideengut propagierten. ${ }^{57}$

Die arbeitsrechtliche und sozialpolitische Benachteiligung der Landarbeiter zeigte sich in der Weltwirtschaftskrise besonders kraß. Im Frühjahr 1932 betrug die amtliche Arbeitslosenquote in der Land- und Forstwirtschaft 12 Prozent $^{58}$, wobei anzunehmen ist, daß diese Zahl wesentlich höher war, da sich nicht alle Arbeitslosen beim Arbeitsamt meldeten.

Diese Arbeitslosen bekamen nur dann eine Unterstützung, wenn sie ihren Lebensunterhalt ausschließlich durch Lohnarbeit bestritten. Bewirtschafter von Kleinstparzellen waren ebenso wie das Gesinde von Zahlungen ausgeschlossen. Für die Landarbeiter, die eine versicherungspflichtige Tätigkeit von 26 Wochen nachweisen konnten, wurde eine Erwerbslosenunterstützung nach dem Verdienst der letzten 13 Wochen berechnet, die bei dem niedrigen Lohn unter dem Existenzminimum lag.

Für die noch im Arbeitsverhältnis Stehenden erfolgte eine erhebliche Lohnreduzierung, die auf Grund der Brüningschen Notverordnungen sowohl den Barlohn als durch das Sinken der Preise für landwirtschaftliche Produkte auch den Deputatlohn betraf. In den preußischen Provinzen lag die Lohnkürzung zwischen 25 und $30 \%{ }^{59}$ Zur Unterbezahlung kamen verlängerte Arbeitszeit und gesteigerte Arbeitsintensität, was besonders für einheimische und ausländische Saisonarbeiterinnen auf den Gütern der mitteldeutschen Agrarkapitalisten galt.

Landarbeiter und Kleinbauern reagierten zunehmend mit Streiks und Protestaktionen auf die sich verschärfenden Auswirkungen der Krise. Die Landarbeitergewerkschaften DLV und ZdL hielten am Prinzip der Tarifverhandlungen fest; Streiks lehnten sie ab. ${ }^{60}$ Die Mitglieder antworteten mit Austritten und wandten sich dem Einheitsverband der Land- und Forstarbeiter (EVLF) zu.

57 Vgl. ZStA Merseburg, Rep. 87 B, Nr. 346, Bl. 211, 262 a; ebenda, Nr. 380, Bl. 291; allg. W. Schlicker, Die Artamanenbewegung - eine Frühform des Arbeitsdienstes und Kaderzelle des Faschismus auf dem Land, in: ZfG, $1 / 1970$, S. $66 \mathrm{ff}$.

58 Vgl. V. Klemm, Agrargeschichte. Von den bürgerlichen Agrarreformen zur sozialistischen Landwirtschaft in der DDR, Berlin 1978, S. 102.

$59 \mathrm{Vgl}$. ebenda: Jahrbuch der Christlichen Gewerkschaften 1931, Berlin 1931, S. 129.

60 Vgl. Jahrbuch 1931 des ADGB, S. 262 f.; Jahrbuch der Christlichen Gewerkschaften 1931, S. $58 \mathrm{f}$. 


\section{Die gewerkschaftlichen Organisationen der Landarbeiter}

Die bedeutendste und mitgliederstärkste gewerkschaftliche Organisation der Landarbeiter war der 1909 gegründete Deutsche LandarbeiterVerband (DLV), der zwischen 1919 und 1933 dem Allgemeinen Deutschen Gewerkschaftsbund (ADGB) als Berufsverband und damit den Freien Gewerkschaften angehörte. Er profitierte aus der Revolutionierung der Landarbeiterschaft nach 1919, so daß sich die Mitgliederbewegung wie folgt entwickelte:

\begin{tabular}{clcc} 
Jahresdurchschnitt & $1918^{1}$ & \multicolumn{2}{c}{9923 Mitglieder } \\
Jahresende & 1918 & 16349 & $"$ \\
$\#$ & 1919 & 624935 & $"$ \\
$\#$ & $1920^{2}$ & 680174 &
\end{tabular}

Bereits 1921 setzte eine rückläufige Bewegung ein, die rasch zunahm, so daß sich für die nächsten Jahre folgende Zahlen nachweisen lassen:

\begin{tabular}{|c|c|c|c|}
\hline Jahresende & 1921 & \multicolumn{2}{|c|}{626160 Mitglieder } \\
\hline ” & $1922^{3}$ & 499107 & $\eta$ \\
\hline " & $1923^{4}$ & 101503 & ” \\
\hline ” & 1924 & 180000 & ” \\
\hline ” & 1925 & 185000 & ” \\
\hline ” & 1926 & 142000 & ” \\
\hline ” & 1927 & 153000 & 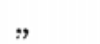 \\
\hline ” & 1928 & 178000 & $"$ \\
\hline ” & 1929 & 180000 & ” \\
\hline ” & $1930^{5}$ & 166000 & ” \\
\hline ", & $1931^{6}$ & 131000 & ” \\
\hline
\end{tabular}

1 Vgl. Geschäftsbericht des DLV für die Jahre 1914-1919, Berlin 1920, S. 65 ff.

$2 \mathrm{Vgl}$. Bericht des Verbandsvorstandes über die Verbandsarbeit in den Jahren 1920-1922, Berlin 1926, S. 5.

3 Vgl. ebenda.

$4 \mathrm{Vgl}$. Bericht des Verbandsvorstandes über die Verbandsarbeit in den Jahren 1923-1925, Berlin 1926, S. 13.

$5 \mathrm{Vgl}$. Internationales Handwörterbuch des Gewerkschaftswesens, Bd. 2, Berlin 1932, S. 1733.

6 Vgl. Jahrbuch 1931 des ADGB, S. 300. 


\section{XLII}

Aus den Zahlen geht hervor, daß sich bereits während der revolutionären Nachkriegskrise eine innere Auseinandersetzung vollzog, die auf das Aufeinanderprallen der zwei Klassenlinien im Verband zurückzuführen war. Der opportunistische Verbandsvorstand löste diese Widersprüche mit Brachialgewalt. So kam es im Zusammenhang mit der Linksentwicklung der Arbeiterbewegung besonders im mitteldeutschen Raum seit 1921/22 zu Ausschlüssen bzw. Massenaustritten oppositioneller USPD-Mitglieder. Der Mitgliederschwund, der im ADGB erst an der Jahreswende 1923/24 zu Buche schlug, vollzog sich im DLV bereits ein bis zwei Jahre früher. Kein anderer Berufsverband des ADGB war so stark opportunistisch beherrscht wie der DLV. Das hing auch damit zusammen, daß es vielen Landarbeitern, die erst kurz zuvor zum Verband gestoßen waren, an Klassenbewußtheit, Organisationserfahrung und Ausdauer fehlte. Sie brachten den rechten Führern großes Vertrauen entgegen.

Der DLV galt schon von seiner Organisationsstruktur her als undemo$\mathrm{kratisch}^{7}$, da er nur alle drei Jahre einen Verbandstag einberief und die Funktionäre (Gauleiter) durch den Vorstand ernannte und entließ, anstatt sie zu wählen. Für alle Streiks war eine Zentralvorstandsgenehmigung notwendig, ebenfalls dann, wenn ein Zwei-Drittel-Mehrheitsbeschluß vorlag. So kam es wiederholt zu diktatorischem Verhalten des Vorstandes bei Streikkämpfen, die entweder verhindert, abgewürgt, zu „wilden Streiks“ erklärt oder wo Unterstützungsgelder verweigert wurden.

Den Vorsitz des DLV hatte der rechte Sozialdemokrat Georg Schmidt von 1909 bis 1933 inne. Seit 1919 gehörten dem Vorstand weiter Wilhelm Bernier, Fritz Faaß, Walter Kwasnik, Emil Hartung, Paul Löhrke und Emil Woldt an. ${ }^{8}$ Von den 33 Gauen des DLV in der Anfangsphase der Weimarer Republik (1928 bestanden 14 Gaue, 147 Kreisgruppen und 6071 Zahlstellen) waren im Gau 16 mit Sitz in Köthen, später in Halle und im Gau 3 (Magdeburg) sowohl die Gauleiter (W. Theuerjahr bzw. W. Berkling) als auch viele Kreisleiter Mitglieder des linken Flügels der USPD. Das führte zu scharfer Konfrontation zwischen dem Berliner Vorstand und der Organisation in Mitteldeutschland. Die Unzufriedenheit und der Druck der Mitglieder waren so stark, daß es zur Spaltung der Landarbeitergewerkschaft kam. Die Abteilung Land der Zentrale der KPD stellte hierzu fest: „.. doch ist es unmöglich, die Landarbeiter noch länger im DLV zu halten. Nicht allein die verratenen Streiks, sondern vor allen Dingen auch die schandmäßigen Tarife, die die DLV-Bürokratie mit den Junkern abge-

7 Vgl. Beiträge zur Agrarfrage, hrsg. unter der Redaktion von E. Varga, Hamburg 1924, S. 162; allg. G. Laubscher, Die Opposition im Allgemeinen Deutschen Gewerkschaftsbund (ADGB) 1918-1923, Frankfurt a. M. 1979, S. 168, 231.

8 Vgl.Niederschrift über die Konferenz der Gauleiter des DLV, Dezember 1919, Berlin 1920, S. 3. 
schlossen hat, ... haben eine so tiefe Kluft zwischen den Landarbeitern und der Gewerkschaftsbürokratie geschaffen, daß selbst unsere intensive Aufklärungsarbeit und all unsere Mahnungen, im DLV zu verbleiben, um die Bürokratie desselben zu überwinden, ohne Erfolg geblieben" sind. ${ }^{9}$

Die opportunistische Politik der Klassenversöhnung und der Arbeitsgemeinschaft erwies sich mit wachsender Revolutionierung der Massen in den Jahren 1922/23 als immer ungeeigneter, die Interessen der Landarbeiter zu vertreten. Nur auf ein gewerkschaftliches Minimalprogramm wie wirtschaftliche und soziale Verbesserung der Lage der Landarbeiter und ihren Rechtsschutz ausgerichtet, blieben die Ergebnisse dieses Kampfes durch die selbstgewählte Beschränkung der Mittel gering. Die Tarife, die die Führung mit den Arbeitgeberorganisationen aushandelte, entsprachen mehr den Forderungen der Großagrarier als denen der Landarbeiter. Anträge der Mitglieder aus dem Jahr 1923, die Austritt aus der Arbeitsgemeinschaft, Wiederaufnahme der ausgeschlossenen oppositionellen Mitglieder, Propagierung der Arbeiter- und Bauern-Regierung und Proklamierung des Generalstreiks verlangten ${ }^{10}$, deuteten auf die tiefen Gegensätze zwischen Führung und Mitgliederschaft hin. Ende 1923 betrug die Stärke des DLV nur noch ein Sechstel gegenüber 1920. Erst im Laufe der nächsten Jahre stieg die Zahl wieder an, erreichte aber nicht das Doppelte von 1923. In den ostelbischen Provinzen profitierten die „nationalen“ Organisationen vom Schwund des DLV.

Nach 1924 hielt die DLV-Führung an ihrer opportunistischen Gewerkschaftspolitik fest. Die objektiv günstigen Bedingungen der Konjunktur, die aber in der Landwirtschaft schon 1927/28 - eher als in der Industrie zu Ende ging, förderten Illusionen über eine "Wirtschaftsdemokratie" und eine rasche und durchgreifende Verbesserung der Arbeits- und Lebensbedingungen der Landarbeiter. Da die Verbandsführung nie eine Agrarrevolution und die Zerschlagung des Großgrundbesitzes plante, beschränkte sich ihre Einflußnahme auf reformistische Tagesforderungen. Es standen nicht politische oder bündnispolitische, sondern ausschließlich Konsuminteressen im Vordergrund. Im Verhältnis zu den Junkern schien alles über Tarifverträge regelbar, von denen es $1928 \mathrm{im}$ landwirtschaftlichen Bereich 200 gab, davon zwei Rahmen-, 24 Landes-, 12 Provinzial-, 41 Bezirks-, 66 Kreis- und 10 Kommunaltarife und 45 Werktarife und sonstige Abkommen. ${ }^{11}$ Die DLV-Presse wie "Der Landarbeiter" und das "LandarbeiterArchiv" unterstützte die Mlusionen über den Staat von Weimar.

9 Jahresbericht der Abteilung Land der Zentrale der KPD (1. 10. 1921-30. 9. 1922), in: IML/ZPA, 3/10/94, Bl. 8; Dok. Nr. 23.

$10 \mathrm{Vgl}$. Bericht des Verbandsvorstandes über die Verbandsarbeit in den Jahren 1923-1925, S. 13.

11 Vgl. Internationales Handwörterbuch, Bd. 1, Berlin 1931, S. 373. 


\section{XLIV}

Die Ablehnung außerparlamentarischer Kampfmethoden auch unter den verschärften Bedingungen der Weltwirtschaftskrise und des Faschisierungsprozesses ab 1929 führte zur Polarisierung der Klassenkräfte und zur Spaltung der Gewerkschaft ähnlich der Anfangsphase der Weimarer Republik. Der DLV hatte von 1930 zu 1931 einen Mitgliederschwund von 20 Prozent. $^{12}$ Mit der SPD- und ADGB-Führung versagte auch die DLVBürokratie am 30. Januar 1933 und bezahlte ihren legalistischen Kurs des Abwartens und Stillhaltens gegenüber der faschistischen Diktatur mit der Auflösung der Gewerkschaft am 2. Mai 1933.

Die zahlenmäßig zweitstärkste Landarbeiterorganisation war der als christlich-nationale Arbeitnehmergewerkschaft 1912 gegründete „Zentralverband der Forst-, Land- und Weinbergsarbeiter Deutschlands" (ab 1920 „Zentralverband der Landarbeiter"). Er stellte die größte bürgerliche Landarbeitergewerkschaft dar, nicht nur christlich-sozial, sondern auch stark nationalistisch ausgerichtet. Franz Behrens, der langjährige evangelische erste Vorsitzende, war zunächst als Mitglied der DNVP und ab 1929 als Mitglied des Christlich-sozialen Volksdienstes Reichstagsabgeordneter.

Auch der ZdL profitierte aus der Novemberrevolution. So wuchsen die Mitgliederzahlen ${ }^{13}$ in den ersten Jahren der Weimarer Republik von

$\begin{array}{lr}1918 & 6972 \text { (im Jahresdurchschnitt) auf } \\ 1919 & 55753 \\ 1920 & 89108 \\ 1921 & 103722 \\ 1922 & 103321 \\ 1923^{14} & 87786 .\end{array}$

Ab Mitte der 20er Jahre entwickelte sich der Mitgliederstand (am Jahresende) wie folgt:

$\begin{array}{ll}1926 & 80000 \\ 1927 & 80000 \\ 1928 & 81000 \\ 1929 & 81000 \\ 1930^{15} & 73000 \\ 1931^{16} & 62000 .\end{array}$

12 Vgl. Jahrbuch 1931, S. 184.

13 Vgl. Zehn Jahre christlich-nationale Landarbeiterbewegung 1913-1923, Berlin 1923 , S. 46.

$14 \mathrm{Vgl}$. Verhandlungsbericht über den 3. Verbandstag des Zentralvorstandes der Landarbeiter vom 18.-20. Juli 1926 in Berlin, Berlin 1926, S. 32.

15 Vgl. Internationales Handwörterbuch, Bd. 2, S. 1736.

16 Vgl. Jahrbuch der Christlichen Gewerkschaften 1932, Berlin 1932, S. 50. 
Die Mitglieder kamen nicht nur aus der katholischen Landarbeiterschaft Schlesiens, sondern auch aus der protestantischen der Provinzen OstpreuBen und Sachsen. Für die relative Stetigkeit der Mitgliederstärke war ähnlich wie bei der Zentrumspartei die konfessionelle Bindung ausschlaggebend.

Der ZdL, der sich im Laufe der 20er Jahre immer mehr zu einer "gelben“ Gewerkschaft mauserte ${ }^{17}$, war 1918/19 unter dem Druck der Klassenauseinandersetzungen auf dem Lande gezwungen, „die Landarbeiterfrage als eine soziale Frage" in den Vordergrund zu rücken. ${ }^{18}$ Bewußt erkannte er den Streik als Kampfmittel an, verlangte aber Tariftreue und stellte die gewerkschaftlichen Rechte seiner Mitglieder wie Arbeitsvermittlung, kostenlose Rechtsberatung, Unterstützung bei Krankheit und Sterbefällen, ländliche Wohlfahrt und Verbesserung von Wohnungs- und Gesundheitswesen in den Mittelpunkt seiner Tätigkeit. Sein Programm, ein Konglomerat von christlich-sozialen und bürgerlich-nationalistischen Elementen, lief darauf hinaus, ein ideologisches und organisationspolitisches Gegengewicht gegen den sozialdemokratisch ausgerichteten Deutschen Landarbeiterverband zu schaffen, die Landarbeiter vom Klassenkampf und von revolutionären Forderungen nach Enteignung des Großgrundbesitzes abzuhalten und eine Politik des "sozialen“ und „Wirtschaftsfriedens“, der Klassenharmonie und der „Dorfgemeinschaft" ${ }^{19}$ zu propagieren.

In diesen Auffassungen traf sich die Bielefelder Zentrale des ZdL mit Ansichten von Agrarkapitalisten, die die Notwendigkeit einer starken, äußerlich von den Einflüssen der Unternehmer freien Organisation der Landarbeiter erkannten. Zu den Förderern des ZdL gehörte der oberschlesische Graf Hans von Praschma, der als einflußreicher Vertreter des adligen Flügels der Zentrumspartei im Frühjahr 1919 im Briefwechsel mit dem deutsch-nationalen Vorsitzenden des ZdL, F. Behrens, die Formierung einer starken Provinzialorganisation Schlesien anregte. ${ }^{20}$

Im Laufe der Zeit trat auch die Ubereinstimmung mit den Zielen des Reichslandbundes (RLB) immer deutlicher zutage, der durch seine nationalistische Landvolkideologie die Fiktion einer "Schicksalsgemeinschaft" zwischen Großgrundbesitzern und werktätiger Landbevölkerung zu schaffen suchte. Nachdem der Hauptvorstand des ZdL beschlossen hatte, sich nicht am Generalstreik gegen den Kapp-Putsch zu beteiligen, war die

17 Vgl. Beiträge zur Agrarfrage, S. 163.

$18 \mathrm{Vgl}$. F. Behrens, Gewerkschaftliche Selbsthilfe der Landarbeiter, Bielefeld 1919, S. 5; Dok. Nr. 3.

19 Vgl. P. Zanona, Dorfgemeinschaft (= Schriftenreihe des Schlesischen Landbundes, H. 8), Schweidnitz 1922; allg. M. Schneider, Die christlichen Gewerkschaften 1894-1933, Bonn 1982, S. 530 ff., $578 \mathrm{ff}$.

20 Vgl. WAPw Opolŭ, Schloßarchiv Praschma, Nr. 1140, Bl. 147 ff. (Dok. Nr. 4, 5). 
Bahn frei für eine Rechtsentwicklung, die im Herbst 1921 zu einem Abkommen des ZdL mit dem RLB führte. ${ }^{21}$

In den Provinzen Schlesien ${ }^{22}$ und Sachsen ${ }^{23}$ trat der ZdL den Landbünden korporativ bei und vereinbarte mit ihnen die „Förderung des Landarbeiterstandes“. Gemeinsames Ziel war die Ablehnung der „staats- und gesellschaftsfeindlichen Auffassung von Klasseninteressen und Klassenkampf“ und die Erziehung der Landarbeiter zu antiproletarischem Bewußtsein. Die Großagrarier münzten es in ihrem Interesse in antikapitalistische, ständische Vorstellungen um. Insofern waren die Unterschiede zwischen diesem, in Schlesien und der Provinz Sachsen praktizierten christlich-nationalen Modell und dem pommerschen Prinzip des organisatorischen Anschlusses der Landarbeiterorganisation an den Landbund in Gestalt des Reichslandarbeiterbundes gar nicht so groß. Trotz einer in vieler Hinsicht ähnlichen Programmatik gab es Gegensätze zwischen der christlich-nationalen und der wirtschaftsfriedlichen Landarbeiterorganisation. ${ }^{24}$

Der ZdL, bewußt auf Massengewinnung in solchen preußischen Provinzen ausgerichtet, wo die Landwirtschaft innigere Fühlungnahme mit der Industrie hatte und der Einfluß von KPD, USPD und SPD entsprechend groß war, hielt auch in den Jahren der relativen Stabilisierung des Kapitalismus an seinem gewerkschaftlichen Charakter fest. Die verstärkten Angriffe der Großgrundbesitzer auf die wenigen sozialen Rechte der Landarbeiter ab Mitte der 20er Jahre forderten ihn immer wieder zu Vorschlägen sozialer Versöhnung heraus. ${ }^{25}$ Dabei ließ er den ostelbischen Junkern so Gerechtigkeit widerfahren: „Der unsoziale Arbeitgeber ist keine typisch ,ostelbische' Erscheinung. Der ,Herr-im-Hause-Standpunkt' ist auch ,westelbich' sehr stark vertreten. Es ist für uns ein Gebot der Gerechtigkeit, ausdrücklich zu betonen, daß in dem so viel und abfällig genannten und doch recht wenig bekannten ,Ostelbien“ weit mehr soziales Verantwortungsbewußtsein anzutreffen ist als anderwärts. “26

Der ZdL, immer wieder zur Neubelebung der gescheiterten Arbeitsgemeinschaftspolitik bereit ${ }^{27}$, ordnete sich parteipolitisch und ideologisch den beiden großbürgerlichen Parteien, Zentrum und DNVP, unter, auch wenn

21 Vgl. P. Zanona, a. a. O., S. 15 ff.; Zehn Jahre, S. 31.

22 Vgl. P. Zanona, a. a. O., S. $18 \mathrm{f}$.

23 Vgl. W. Vogler, Probleme, a. a. O., S. 371; J. Flemming, Großagrarische Interessen und Landarbeiterbewegung, in: Industrielles System und politische Entwicklung in der Weimarer Republik, Düsseldorf 1974, S. $759 \mathrm{f}$.

24 Vgl. J. Flemming, a. a. O., S. 760.

$25 \mathrm{Vgl}$. z. B. H. Böhm, Vorschläge zur Lösung der Landarbeiterfrage. Vortrag, gehalten auf dem 3. Verbandstag des ZdL (18.-20. Juli 1926 in Berlin), Berlin 1926.

26 Ebenda, S. 46.

27 Vgl. ebenda, S. 48. 
es dabei zu Kontroversen kam. ${ }^{28}$ Seine nationalistische, an der katholischen Soziallehre orientierte „antimodernistische“ Ständevorstellung knüpfte an die Rückständigkeit Tausender Landarbeiter an und schuf schließlich einen günstigen Nährboden für die faschistische Agrarideologie.

Eine von den Großgrundbesitzern ausgehaltene und in ihrem Sinn agierende Landarbeiterorganisation war der Reichslandarbeiterbund (RLAB), der am 20. Mai 1920 unter Vorsitz des deutschnationalen Reichstagsabgeordneten und ehemaligen Landarbeiters Johannes Wolf gegründet wurde. Ausgangspunkt war Pommern, wo die Junker schon 1919 an berufsständische Gedanken anknüpften, um die Landarbeiter von einer Organisierung in Gewerkschaften abzuhalten. Was in der Industrie nach der Novemberrevolution nur schwer durchzusetzen war, auf den ostelbischen Gütern schienen die Voraussetzungen gegeben, um an die Stelle des Klassenkampfes den "friedlichen“ Ausgleich der Interessengegensätze zwischen Großagrariern und Landarbeitern treten zu lassen. ${ }^{29}$ Grundanliegen war die Verhinderung von Streiks. Darüber hinaus waren Antikommunismus, Gewerkschaftsfeindlichkeit, Nationalismus und Protestantismus als gemeinsame Klammer gedacht.

Die pommerschen Junker korrumpierten ihren Landarbeiterbund offen durch materielle Besserstellung wie höhere Deputate und finanzielle Propagandazuschüsse und bevormundeten ihn organisatorisch. Der Bund wuchs in Pommern von 54841 Mitgliedern (1921) auf 72061 (Ende 1922) und hatte 1927 eine Stärke von $435833^{30}$ In den Jahren der revolutionären Nachkriegskrise erreichte er die gleiche Mitgliederzahl wie die Provinzialorganisation des DLV.

In den anderen Provinzen Preußens war diese "wirtschaftsfriedliche“ Bewegung weit schwächer ausgeprägt. ${ }^{31}$ Das hing hauptsächlich mit der ablehnenden Haltung der Agrarkapitalisten zusammen; das Prinzip der Arbeitsgemeinschaft brachte bessere Möglichkeiten zur Anpassung an die Anforderungen der neuen Epoche des Ubergangs vom Kapitalismus zum Sozialismus als das Festhalten an vorrevolutionären Leitbildern. Nur im Brandenburgischen Landbund gab es eine starke, "wirtschaftsfriedlich" ausgerichtete Landarbeitergruppierung (Ende 1922: 19 887, 1927: 16154 Mitglieder ${ }^{32}$ ), während es in Schlesien, Ostpreußen und der Provinz Sachsen

$28 \mathrm{Vgl}$. M. Schneider, a. a. O., S. $526 \mathrm{ff}$., $563 \mathrm{ff}$.

29 Vgl. C. $v$. Eickstedt, Wiederaufbau, a. a. O.; H. Brauweiler, Die ständische Bewegung und die Landwirtschaft, Berlin 1922.

$30 \mathrm{Vgl}$. H. Hildebrandt, Die Rolle der sog. "wirtschaftsfriedlichen " Landarbeiterbewegung in Ostelbien während der Weimarer Republik, phil. Diss. A, Rostock 1969, S. 67.

31 Vgl. K. Vorwerck, Die wirtschaftsfriedliche Arbeitnehmerbewegung, Jena 1926, S. $128 \mathrm{f}$.

$32 \mathrm{Vgl}$. H. Hildebrandt, a. a. O. 


\section{XLVIII}

zur Vereinigung der zahlenmäßig kleinen Gruppen des Landarbeiterbundes mit dem ZdL kam. Der Mitgliederschwund nach 1924 hing mit den veränderten konjunkturellen Bedingungen zusammen, wodurch die Streikbewegung abflaute und sich die gewerkschaftliche Stellung konsolidierte. Der pommersche Landbundführer Hans-Joachim von Rohr (Demmin) versuchte 1926 mit der Gründung der „Berufsständischen Arbeitsgemeinschaft auf dem Lande" dem zu begegnen. Sie fiel in dasselbe Jahr wie die Installierung des „Bundes für Nationalwirtschaft und Werksgemeinschaft" in der Ruhrindustrie. $\mathrm{Zu}$ diesem Zeitpunkt trat der in der DNVP parteimäßig gebundene, stark am Junkertum orientierte Konservatismus auch politisch in den Vordergrund.

Trotzdem erfolgte die Zuerkennung des RLAB auf gesetzliche Gleichberechtigung mit den Gewerkschaften erst durch den Reichsarbeitsminister Schäffer im Oktober 1932. Die Papen-Regierung rechnete dem Bund an, daß er jahrelang für den „Frieden“ zwischen den antagonistischen Klassen gekämpft und freiwillig auf den Streik verzichtet hatte. Seldte bestätigte das als Arbeitsminister am 6. April $1933 .{ }^{33}$ Damit war das „Monopol der Gewerkschaften" endgültig gebrochen.

So ergab sich die widersprüchliche Tatsache, daß einerseits die konservativ-ständische Lösung der „Arbeiterfrage“, wie sie der Pommersche Landbund ideologisch und praktisch-politisch vertrat, dem seit Beginn der 30er Jahre wachsenden Masseneinfluß der Nazis auf dem Land unmittelbar Vorschub leistete. Andererseits konnten die Faschisten diese Erfolge nur deshalb erringen, weil sie sich von den anachronistischen Vorstellungen des Pommerschen Landbundes lösten und mit scheinradikalen Phrasen und sozialdemagogischen Mitteln und Methoden operierten. Letztendlich entsprach die faschistische „Lösung“ der Landarbeiterfrage den Gesamtinteressen von Monopolkapital und Großgrundbesitz.

Neben diesen opportunistisch, christlich-national und „gelb“ ausgerichteten Landarbeiterorganisationen gab es in der Weimarer Republik zeitlich begrenzt oppositionelle Landarbeiterverbände, die kommunistisch beeinflußt waren. Dazu gehörte der „Freie Landarbeiterverband“, der in die „Union der Hand- und Kopfarbeiter Deutschlands (Räteorganisation)“ aufging. Er wurde im November 1920 aus den durch die Spaltung der mitteldeutschen Organisationen des DLV entstandenen Verbänden und einer erheblichen Anzahl von ausgetretenen DLV-Mitgliedern im Freistaat Braunschweig als „Freier Verband der Landarbeiter und verwandter Berufe Deutschlands, Sitz Braunschweig“, in Magdeburg gegründet. ${ }^{3 / 4}$

$33 \mathrm{Vgl}$. ebenda, S. 124.

$34 \mathrm{Vgl}$. Seid einig! - Ein Mahnwort an alle Mitglieder des Deutschen Landarbeiterverbandes, hrsg. v. Vorstand des DLV, Berlin 1921, S. 31, in: ZStA Merseburg, Rep. 87 B, Nr. 348, Bl. 100; G. Laubscher, a. a. O., S. $207 \mathrm{f}$. 
Dem DLV waren nach eigenen Angaben 374 Ortsgruppen mit 30411 Mitgliedern verlorengegangen. ${ }^{35}$ Trotzdem läßt sich die Mitgliederzahl des „Freien Landarbeiterverbandes“, wie er später kürzer genannt wurde, nicht exakt nachweisen. Die Angaben schwanken zwischen 1000 und $100000 .^{36}$ Sie dürften aber zwischen $20000^{37}$ und 30000 gelegen haben.

Der Verband setzte sich die Sozialisierung der Landwirtschaft und die Besserung der wirtschaftlichen und sozialen Lage der Landarbeiter zum Ziel. Folgende Forderungen wurden gestellt: „a) Ausbau des Rätesystems, b) Einführung von Landarbeitergerichten, c) Abschaffung aller Ausnahmebestimmungen gegen die Landarbeiterschaft, d) Gewährung von freiem Rechtsschutz bei Streitigkeiten mit den Arbeitgebern und der Sozialgesetzgebung, e) Gewährung von Streiks- und Maßregelungsunterstützung, f) Gewährung von Krankenunterstützung, g) Wochenhilfe, h) Begräbnishilfe, i) Einführung einer Wohnungskontrolle, j) Pflege der geistigen Ausbildung durch Abhaltung von Versammlungen, Kursen, Schaffung von Bibliotheken und Zeitungen. “38

Die Zielstellung des Verbandes, sein Eintritt in die Rote GewerkschaftsInternationale (RGI), die im Juli 1921 in Moskau gegründet wurde, und der Vertrieb der von der KPD herausgegebenen Zeitung „Der Kommunistische Landarbeiter" in den Ortsgruppen ${ }^{39}$ verdeutlichen den vorherrschenden kommunistischen Einfluß. Die Zentrale der KPD, die auf dem Vereinigungsparteitag mit dem linken Flügel der USPD solche Spaltungen als sektiererisch und deshalb als falsch und schädlich einschätzte ${ }^{40}$, war zu diesem Zeitpunkt noch nicht in der Lage, durch langwierige und geduldige Ubberzeugungsarbeit die oppositionellen Mitglieder im DLV zu stärken, die opportunistische Verbandsführung $\mathrm{zu}$ isolieren und den DLV insgesamt in eine revolutionäre Klassenorganisation umzuwandeln. Bald schon zeigte sich, daß die Abspaltung vom DLV ein schwerwiegender Fehler war.

Im Jahre 1921 wies die KPD nach, daß sich der Freie Landarbeiterverband und die anderen kleineren Verbände, die sich vom DLV getrennt hatten, wegen ihrer schmalen organisatorischen Basis und der damit verbundenen relativ geringen finanziellen Kraft für Streikkämpfe, aber auch auf Grund der zum Teil abenteuerlichen Politik ihrer Führer und starker organisatorischer Mängel, die Streikniederlagen zur Folge hatten, nirgends

$35 \mathrm{Vgl}$. Bericht des Verbandsvorstandes über die Verbandsarbeit in den Jahren 1920 bis 1922, a. a. O., S. $5 \mathrm{f}$.

$36 \mathrm{Vgl}$. W. Vogler, Probleme, a. a. O., S. $374 \mathrm{f}$.

37 Vgl. Beiträge zur Agrarfrage, S. 163.

38 Seid einig!, S. $30 \mathrm{f}$.

39 Vgl. ZStA Merseburg, Rep. 87 B, Nr. 348, Bl. 95.

$40 \mathrm{Vgl}$. Bericht über die Verhandlungen des Vereinigungsparteitages der USPD (Linke) und der KPD (Spartakusbund), abgehalten in Berlin vom 4.12. bis 7. 12. 1920, Berlin 1921, S. 188. 
durchsetzen oder halten konnten. Die Konsequenz war die Isolierung revolutionärer Kräfte von der Masse der Gewerkschafter. „Die ehrlich gesonnenen Landarbeiter sind auch hier enttäuscht worden und zum Teil ,Führern' in die Hände gefallen, die wohl radikaler als die DLV-Bürokraten, aber auch stark von persönlichen Motiven, Ehrgeiz oder Abenteuerlust geleitet wurden. Immer jedenfalls sind sie getrennt von der Masse der Landarbeiter, ohne deren Zusammenfassung und Schulung die Revolution nun einmal nicht durchzuführen ist. “41

Von Anfang an versuchte die KPD, die abgespaltenen Splittergruppen in die sich entwickelnde Einheitsfront einzubeziehen. Ihr "Offener Brief“ vom Januar 1921 bot dazu einen guten Ansatz. Die fehlerhafte Haltung verschiedener Führer der KPD zur Märzprovokation in Mitteldeutschland und das brutale Vorgehen der Reaktion gegen die des Freien Landarbeiterverbandes nach Niederschlagung der Aktion schwächten den Verband weiter. Hinzu kam, daß die im Mitteldeutschen Tarifamt vereinigten „Arbeitgeber" und „Arbeitnehmer" (DLV, ZdL, Allgemeiner Schweizerbund) ihm unter antikommunistischen Verleumdungen die Tariffähigkeit absprachen. Viele enttäuschte Landarbeiter verließen im Laufe des Jahres 1921 den Verband wieder, suchten erneut Anschluß an den DLV, traten dem ZdL bei oder blieben unorganisiert. ${ }^{2}$

Der Rest des Freien Landarbeiterverbandes vereinigte sich am 6. September 1921 in Halle mit der Freien Arbeiter-Union (Gelsenkirchen) und dem Verband der Hand- und Kopfarbeiter zur „Union der Hand- und Kopfarbeiter Deutschlands (Räteorganisation)".43 15 Delegierte des Freien Landarbeiterverbandes vertraten auf dem Vereinigungskongreß 25000 Mitglieder. Unter dem Einfluß der KPD beschloß der Kongreß, die bisherige sektiererische Losung der drei vereinigten Verbände „Heraus aus den Gewerkschaften" aufzugeben und sich zum Ziel der RGI zu bekennen, den Kampf für die Eroberung und nicht für die Zerstörung der Gewerkschaften zu betreiben. Die praktische Politik der Führer der „Union“ aber blieb weiter auf die Spaltung der Gewerkschaft gerichtet. Unter den Landarbeitern Mitteldeutschlands lösten sie im April 1922 einen Streik aus, der, politischideologisch völlig unvorbereitet, als Niederlage mit ernsten negativen Folgen endete. ${ }^{44}$ Die Mitglieder verließen scharenweise den Verband, so daß er völlig bedeutungslos wurde.

Die KPD orientierte in den Jahren 1922/23 immer wieder darauf, den

41 Die Rote Fahne, Nr. 322, v. 16. 7. 1921, zitiert nach: W. Vogler, a. a. O., S. 348.

42 Vgl. ebenda, S. 379.

$43 \mathrm{Vgl}$. Geschichte der Deutschen Arbeiterbewegung, Chronik, Teil II, Berlin 1966, S. 117.

44 Vgl. W. Vogler, a. a. O., S. $383 \mathrm{ff}$. 
DLV von innen her zu erobern. Es war die arbeiterfeindliche und antikommunistische Haltung des DLV, die viele Mitglieder, verbittert und enttäuscht, zum Verlassen des Verbandes zwang oder die oppositionellen Mitglieder ausschloß. Forderungen nach Neubildung eines kommunistisch beeinflußten Landarbeiterverbandes wurden laut.

Im November 1923 vereinigten sich in Berlin oppositionelle DLV-Mitglieder mit den Resten der Industriegruppe Landwirtschaft der „Union der Hand- und Kopfarbeiter". Der neue Verband erhielt den Namen „Verband der Wald- und Landarbeiter Deutschlands" und schloß sich der RGI an. Seine wichtigsten Einflußgebiete waren Ostpreußen, Brandenburg und die Regierungsbezirke Merseburg und Magdeburg der Provinz Sachsen. ${ }^{45}$ Aber auch dieser Verband konnte keine Massenbasis gewinnen. Ende 1924 löste er sich selbst auf, da sich der DLV bereit erklärt hatte, die ehemaligen Mitglieder wieder aufzunehmen. Die KPD orientierte auf die Einheit der gewerkschaftlichen Organisation und die Bildung kommunistischer Zellen innerhalb des DLV. ${ }^{46}$

Nach der Bildung des Thälmannschen ZK 1925 setzte die KPD immer konsequenter auch in der Gewerkschaftspolitik marxistisch-leninistische Positionen durch und verstärkte ihre Arbeit auf dem Lande. Wegen des scharfen antikommunistischen Kurses und der Spaltungsmaßnahmen der reformistischen Gewerkschaftsinstanzen war es außerordentlich schwierig, den Kurs der Partei auf „Formierung der revolutionären Front in den Gewerkschaften" durchzuhalten. ${ }^{47}$ Es gelang nicht, die ausgetretenen Landarbeiter für den DLV zurückzugewinnen.

Im Zusammenhang mit der Weltwirtschaftskrise, dem verschärften imperialistischen Kurs auf Abbau der sozialen Errungenschaften der Arbeiterklasse und ihrer Revolutionierung kam es erneut zu Ausschlüssen von Kommunisten, ganzen Branchengruppen und Ortsorganisationen aus dem ADGB. Die KPD suchte nach Wegen, die kampfbereiten Arbeiter zu mobilisieren. „Auf der Suche nach entsprechenden Organisationsformen entwickelte sich die in den Gewerkschaften bestehende revolutionäre Opposition jedoch zunehmend zu einer selbständigen Organisation. Sie bildete Ende 1929/Anfang 1930 eine zentrale Reichsleitung der revolutionären Gewerkschaftsopposition, die sich auch bezirkliche Leitungen schuf. Die revolutionären Gewerkschafter und die KPD waren der Meinung, daß sie die Massen auf diese Weise besser und umfassender für den einheitlichen Kampf gewinnen und organisieren können. Solche Utberlegungen waren die Antwort auf die Stillhalte- und Streikbruchpolitik der rechten Gewerk-

45 Vgl. F. Hering, Die Landarbeiter und ihre Gewerkschaften, Berlin 1929, S. $34 \mathrm{f}$.

$46 \mathrm{Vgl}$. IML/ZPA, St. 12/47, Bd. 1, Bl. $166 \mathrm{f}$.

47 Vgl. Ernst Thälmann. Eine Biographie, Berlin 1979, S. 407. 


\section{LII}

schaftsführer. Sie drückten aber auch eine Uberschätzung des Bewußtseinsstandes der Massen der Arbeiter sowie Stimmungen revolutionärer Ungeduld aus. “48

1930/31 entstanden nach dem Streikbruch rechter Führer in verschiedenen Branchengewerkschaften Rote Einheitsverbände. Es wurde auch eine revolutionäre Landarbeitergewerkschaft gefordert. Im März 1931 kam es in fast allen preußischen Provinzen zur Gründung des „Einheitsverbandes der Land- und Forstarbeiter" (EVLF), der Mitglied der Revolutionären Gewerkschaftsopposition (RGO) und der RGI war. Entsprechend den Satzungen hatte der EVLF die Aufgabe, die Landarbeiter in einem revolutionären Klassenverband zusammenzufassen. Zur Durchsetzung der Kampfforderungen sollten ständige Einheitsfrontorgane wie rote Gutsräte und RGOBetriebsvertrauensleute gebildet werden, zeitweilig unterstützt durch Kampfausschüsse, Delegiertenkonferenzen, Streikleitungen und Wahlausschüsse. ${ }^{49}$ In der Provinz Brandenburg ${ }^{50}$, in Ostpreußen ${ }^{51}$ und in der Provinz Sachsen ${ }^{52}$ wuchs die Mitgliederzahl rasch an. Sie rekrutierte sich aus oppositionellen Mitgliedern von DLV und ZdL und unorganisierten Landarbeitern.

Die KPD intensivierte seit 1930 und besonders seit Verkündung des Bauernhilfsprogramms im Mai 1931 ihre Arbeit auf dem Lande. Zahlreiche Frühjahrs- und Erntestreiks der Landarbeiter in den Jahren 1931 und 1932 fanden unter ihrer Leitung statt. Es gelang den KPD-Abteilungen Land durch bezirkliche Kampfkongresse der Landarbeiter und EVLFFunktionäre, durch Dorfzeitungen und Flugblätter den Streikforderungen eine einheitliche Stoßrichtung zu geben. Verlangt wurde die unmittelbare Verbesserung der Lebenslage der Landarbeiter wie Lohnerhöhung, Gewährung von Erntezulagen, gleiche Entlohnung für Männer und Frauen, Wiederaufnahme der Arbeitslosenversicherung u. ä. Darüber hinaus gehörte es zur Strategie und Taktik der Partei im Kampf gegen den aufkommenden Faschismus, den "roten“ Einheitsverband für die Einheitsfront der Arbeiterklasse und die sich entwickelnde Antifaschistische Aktion zu gewinnen.

Die organisatorische Selbständigkeit der oppositionellen Landarbeitergewerkschaft erwies sich auch in dieser Situation als Fehler. Der EVLF blieb eine kleine Splittergruppe mit einigen zehntausend Mitgliedern. Es dominierten die traditionelle Bindung an die alten Gewerkschaften und

48 Geschichte des FDGB, Berlin 1982, S. 131.

$49 \mathrm{Vgl}$. Dok. Nr. 64; IML/ZPA, St. 10/105, Bd. 5, Bl. 486 f.

$50 \mathrm{Vgl}$. ebenda, Bd. 6a, Bl. $143 \mathrm{f}$.

$51 \mathrm{Vgl}$. $R$. Neddermeyer, Es begann in Hamburg ..., Berlin 1980, S. $160 \mathrm{ff}$.

$52 \mathrm{Vgl}$. H. Zeise, Der Kampf der KPD-Bezirksorganisation Halle-Merseburg um die Verwirklichung des Bauernhilfsprogramms der KPD, phil. Diss. A, Halle 1981, S. $142 \mathrm{f}$. 
der damit verbundene Einfluß der reformistischen Führer. ${ }^{53}$ Hinzu kam, daß unter den Landarbeitern weiterhin reaktionäre Parteien und Organisationen wie der RLB und der Stahlhelm starken Einfluß ausübten. Ab 1931/32 war es die Nazipartei, die durch die Bildung nationalsozialistischer Betriebszellen auf den Gütern die zunehmende Unzufriedenheit der Landarbeiter in eine scheinradikale Richtung zu lenken versuchte.

53 Vgl. Geschichte des FDGB, a. a. O. 


\section{Der Kampf der KPD um die Gewinnung der Landarbeiter}

Teil der Gesamtpolitik der KPD war die Gewinnung der Landarbeiter. Um das Landproletariat von kapitalistischer Ausbeutung und Unterdrükkung zu befreien, mußte dessen Klassenbewußtsein entwickelt und es organisatorisch in Gewerkschaften als Schulen des proletarischen Klassenkampfes zusammengefaßt werden. Fast ein Drittel in Gewerkschaften organisierte Landarbeiter waren unmittelbar nach der Novemberrevolution ein gewaltiges Potential.

Die im Vergleich zu den Industriearbeitern unterschiedliche Arbeits- und Lebensweise des Landproletariats erforderte nicht nur modifizierte Formen und Methoden der politischen Beeinflussung, sondern auch eine klare marxistisch-leninistische Agrarkonzeption der KPD. Deren Ausarbeitung vollzog sich über einen längeren Zeitraum und stand in engem Zusammenhang mit der schöpferischen Anwendung der Leninschen Revolutionstheorie auf Deutschland. Die Befreiung der Landarbeiter war Teil der Bauernbefreiung, die über eine antiimperialistische Agrarrevolution führte und in der sozialistischen Umgestaltung der Landwirtschaft ihre Vollendung fand.

Bereits auf ihrem Gründungsparteitag betrachtete die KPD das Einbe.ziehen der werktätigen „Landbevölkerung in den Kampf gegen Großbourgeoisie und Großgrundbesitz" als Voraussetzung für den Sieg der Revolution. ${ }^{1}$ Rosa Luxemburg rief die Delegierten auf, im Interesse der revolutionären Umgestaltung ihr Augenmerk auf das flache Land und die Industriezentren gleichermaßen zu richten. Sie forderte, besonders „das landlose Proletariat und das Kleinbauerntum mobil zu machen" und dazu die Landarbeiter und die Kleinbauern in das Rätesystem einzubeziehen. ${ }^{2}$

Das Gründungsprogramm der KPD enthielt als grundlegendes Ziel die entschädigungslose Enteignung des Großgrundbesitzes, setzte sich aber nicht für die Aufteilung dieser Ländereien ein. Die KPD forderte „Bildung sozialistischer landwirtschaftlicher Genossenschaften im ganzen Reiche". ${ }^{3}$ Auch die ungenügende Differenzierung der Bauernschaft ${ }^{4}$, die sich in

1 Vgl. Protokoll des Gründungsparteitages der KPD, Berlin 1972, S. 59.

2 Vgl. ebenda, S. 219.

3 Ebenda, S. 321.

4 Vgl. H. Schäwel, Die Bedeutung des II. Weltkongresses der Kommunistischen Internationale für die weitere Ausarbeitung der Bündnispolitik der 
den Gründungsdokumenten und der praktischen Bündnispolitik ausdrückte, bewies, daß die umfassenden Erfahrungen der Bolschewiki noch unberücksichtigt geblieben waren.

Einen großen Schritt voran machte die KPD mit ihrem Agrarprogramm vom Sommer 1919, das mit einigen Veränderungen auf dem Vereinigungsparteitag im Dezember 1920 beschlossen wurde. ${ }^{5}$ Um die Wirksamkeit der Agitation unter den Landarbeitern und Bauern zu erhöhen, wurde im Juli 1919 eine Abteilung Land bei der Zentrale der KPD gebildet und die Zeitung „Der Pflug“ herausgegeben.

Der Leitgedanke des Agrarprogramms war die Revolutionierung der Landarbeiter und das enge Zusammenwirken von Arbeiterklasse und Bauernschaft. Die Forderung nach einer Bodenreform wurde aber noch nicht erhoben. ${ }^{6}$

Ein wichtiger Meilenstein bei der Uberwindung sektiererischer Auffassungen in der Agrarfrage war der 4. Parteitag der KPD vom April 1920. Er würdigte das Verhalten der Landarbeiter während des Kapp-Putsches und schlußfolgerte, daß die „Landarbeiterschaft in ihrer Masse ... in den aktiven revolutionären Kampf bereits eingetreten" ist. Edwin Hoernle und andere Redner betonten die „Empfänglichkeit“ der Landarbeiter für die „kommunistischen Grundsätze und Parolen“.?

Der Einfluß der Partei auf dem Land war im Frühjahr 1920 erheblich gewachsen. Die Reaktion des Klassengegners bestätigte das. Der Staatskommissar für die Uberwachung der öffentlichen Ordnung gab zu, daß er „bezüglich der Bekämpfung der kommunistischen Agitation unter den Landarbeitern ... mit dem Vorsitzenden des Landarbeiterverbandes, Herrn Abgeordneten Schmidt", in Verbindung stehe. ${ }^{8}$ Auch das Preußische Landwirtschaftsministerium tauschte mit dem DLV-Vorstand vertraulich Materialien über die kommunistische Landagitation aus. Dabei wurde der DLVFührung empfohlen, die Taktik der KPD mit „schärfster Aufmerksamkeit“ $\mathrm{zu}$ verfolgen und eine wirkungsvolle Gegenpropaganda zu entfalten. ${ }^{9}$

KPD mit den werktätigen Bauern, in: Studien zur ideologischen Entwicklung der KPD 1919-1923, hrsg. v. W. Imig und W. Kisljakow, Berlin 1981, S. $124 \mathrm{f}$.

5 Vgl. Dokumente und Materialien zur Geschichte der deutschen Arbeiterbewegung, Bd. VII/1, Berlin 1966, S. 373 ff. (Dok. Nr. 20).

6 Vgl. Edwin Hoernle, Ein Leben für die Bauernbefreiung, Berlin 1965, S. 37.

7 Vgl. Dok. Nr. 13; Bericht über den 4. Parteitag der KPD am 14. und 15. April 1920, o. O. o. J., S. 81.

8 Vgl. ZStA Merseburg, Rep. 87 B, Nr. 348, Bl. 2 (Schreiben des Staatskommissars für die Uberwachung der öffentlichen Ordnung an das Preußische Landwirtschaftsministerium vom 12.2.1920).

9 Vgl. ebenda, B1. 3, 107. 
Nach dem Parteitag verstärkte sich die Agitations- und Propagandaarbeit der KPD. Mit dem „Kommunistischen Landarbeiter" erschien ab Mai 1920 eine gesonderte Zeitung für das Landproletariat. Flugblätter und Flugschriften wurden herausgegeben. Bei den Bezirkssekretariaten und in den KPD-Ortsgruppen wurden Vertrauensleute bzw. Kommissionen mit den spezifischen Aufgaben der Landagitation betraut. Im Herbst 1920 konnte "Der Kommunistische Landarbeiter" berichten, daß im KPD-Bezirk Mitteldeutschland in 56 von 70 Ortsgruppen Landagitationskommissionen und in den fünf Unterbezirken Leipzig, Weißenfels, Zeitz, Merseburg und Bitterfeld Zentrale Landagitationskommissionen bestanden. ${ }^{10}$ Auf einer "Reichskonferenz der Landvertrauensleute" in Berlin trafen sich Anfang Novemer 1920 auch oppositionelle Gruppen des DLV und Delegierte des „Freien Landarbeiter-Verbandes" aus Ostpreußen, der Niederlausitz, aus Mitteldeutschland und Sachsen-Anhalt. ${ }^{11}$

Immer deutlicher wurde, $d a ß$ zwischen dem revolutionären Kampf für ökonomische und politische Veränderungen und der Gewinnung der Landarbeiter ein Zusammenhang bestand. Die Arbeiterpartei mußte Forderungen stellen und Ziele verfolgen, die den Landarbeitern eine Perspektive boten und ihren Traum von eigenem Grund und Boden ebenso berücksichtigten wie die sozialistische Umgestaltung des Dorfes.

Vom II. Weltkongreß der Kommunistischen Internationale gingen im Sommer 1920 weitere Impulse für das Ringen um eine noch breitere Einbeziehung der werktätigen Landbevölkerung in den revolutionären Kampf, um eine marxistisch-leninistische Lösung der Bodenfrage aus. Lenins „Ursprünglicher Entwurf der Thesen zur Agrarfrage “12 und das einleitende Referat, vorgetragen vom Mitglied der KPD, Ernst Meyer, analysierten differenziert die einzelnen Gruppen der Landbevölkerung und leiteten daraus entsprechende Schlußfolgerungen für die Politik der kommunistischen Parteien ab. ${ }^{13}$ Das an erster Stelle genannte Landproletariat wurde als aktiver Teil der Revolution gekennzeichnet, der für die Diktatur des Proletariats zu gewinnen sei. Die Kommunisten hatten die Aufgabe, „eine selbständige, von den anderen Gruppen der Landbevölkerung getrennte (politische wie militärische, gewerkschaftliche und genossenschaftliche wie kulturell aufklärende usw.) Organisation dieser Klasse zu schaffen, intensive Propaganda und Agitation in ihr zu betreiben "14 und sie schließlich für die Ziele der Partei zu gewinnen.

10 Vgl. W. Vogler, Probleme, a. a. O., S. 196 f.; H. Schäwel, a. a. O., S. $131 \mathrm{f}$.

$11 \mathrm{Vgl}$. Der Kommunistische Landarbeiter, Nr. 12, November 1920, S. $90 \mathrm{f}$.

$12 \mathrm{Vgl}$. W. I. Lenin, Werke, Bd. 31, Berlin 1959, S. $140 \mathrm{ff}$.

13 Vgl. F. Apel, Zur Kontinuität und Aktualität der Agrar- und Bündnispolitik der Kommunistischen Internationale, in: Bauern und Landarbeiter im Klassenkampf, a. a. O., S. 92 f.

14 W. I. Lenin, a. a. O., S. 141. 
Lenin sah neben den Landarbeitern in den Halbproletariern oder Parzellenbauern und in der Kleinbauernschaft jene Gruppen, die für den Sozialismus gewonnen werden konnten. Sie seien „wirtschaftlich, sozial und kulturell am Sieg des Sozialismus interessiert"15 und durch einen tiefen Abgrund von den Gutsbesitzern und Agrarkapitalisten getrennt. Damit wandte sich Lenin gegen die Auffassung von der „Einheit" der Landbevölkerung, die die herrschende Klasse mit Unterstützung der Agrarrevisionisten verbreitete. Die Thesen gingen auch sehr differenziert an das Verhältnis der Kommunisten zu den Mittel- und Großbauern heran und wurden zur Grundlage kommunistischer Bündnispolitik über den Sieg der sozialistischen Revolution hinaus.

Nach wie vor blieb die Frage der weiteren Verwendung des entschädigungslos enteigneten Bodens der Großgrundbesitzer in der Diskussion. Lenin sprach sich für die vorwiegende Beibehaltung der Großbetriebe in den entwickelten kapitalistischen Ländern aus, bezeichnete es jedoch als den größten Fehler, wollte man diese Regel zur Schablone erheben. Gegen jene gewandt, die eine Aufteilung des Bodens für Opportunismus und Verrat an der Revolution hielten, erklärte er, daß alle diese Fragen, auch eine vorübergehende Ertragsminderung, der Sicherung der Revolution unterzuordnen seien. Außerdem setze die Großproduktion einen „aufgeklärten, revolutionär bewußten Landproletarier voraus, der eine solide Schule der gewerkschaftlichen und politischen Organisation durchgemacht hat."16

Die Politik der kommunistischen Parteien aber hatte zu diesem Zeitpunkt noch nicht jene Reife erreicht, die eine schöpferische Anwendung der Leninschen Lösung der Agrarfrage ermöglichte. Auch in der Programmatik und Praxis der KPD gab es erst Ansatzpunkte für die Bewältigung des dialektischen Verhältnisse von Boden-, Bündnis- und Machtfrage. Ihr Agrarprogramm, angenommen im Dezember 1920, formulierte die Frage der Bodenaufteilung noch sehr vorsichtig. Es blieb bei der Forderung, nur in kleinbäuerliche Betriebe eingesprengte Güter aufzuteilen, die anderen genossenschaftlich zu bewirtschaften. E. Hoernle sprach später von nur ökonomischen, nicht politischen Gesichtspunkten, die das Programm bestimmten. Die demokratischen Postulate seien nicht ausreichend gewesen. ${ }^{17}$

Für viele Mitglieder der VKPD war die Agrarfrage Neuland. Noch gelang es der Partei nicht in genügendem $\mathrm{Maße}$, an die Stimmungen und elementaren Forderungen der Landarbeiter anzuknüpfen und dort wirk-

15 Vgl. ebenda, S. 143.

16 Ebenda, S. 148.

17 Vgl. E. Hoernle, Die Große Sozialistische Oktoberrevolution und das deutsche Dorf, a. a. O., S. 231 (Dok. Nr. 15). 


\section{LVIII}

sam zu werden, wo die opportunistische Gewerkschaftsführung versagte. Sie sammelte erste Erfahrungen beim Durchsetzen sozialer Belange der Landarbeiter. So verlangte die KPD für 1921 einen Rahmentarifvertrag für das ganze Reich, der folgendes berücksichtigen sollte: Achtstundentag, wesentliche Erhöhung des Barlohns, ausreichende Deputate, Gleichstellung der Frauenlöhne mit den Männerlöhnen, Verbot der Kinderarbeit, Wohnungsaufbesserungen und Neubauten auf Kosten der Gutsbesitzer. ${ }^{18}$ Auch für 1922 wurde ein Mustertarifvertrag entworfen ${ }^{19}$, der den unterschiedlichen Reifegrad des Klassenbewußtseins der Landarbeiter berücksichtigte und die nächstliegenden sozialen Forderungen enthielt.

Die Partei versuchte das System der Landagitation auch organisatorisch zu festigen. Zur Herstellung eines engeren Kontaktes der Bezirksleitungen der großen Agrarbezirke mit der Abteilung Land bei der Zentrale der KPD wurden zwei Agrarkommissionen gebildet: eine für die Parteibezirke Brandenburg, Pommern, Mecklenburg, Wasserkante und Ostpreußen und eine zweite für die Bezirke Halle-Merseburg, Sachsen, Thüringen und Magdeburg, in denen alle Bezirkslandsekretäre und Redakteure der Bezirkszeitungen zur Mitarbeit verpflichtet waren..$^{20}$ Trotz finanzieller Schwierigkeiten wurden Flugblätter in einer Auflagenhöhe von 50000 bis 100000 Stück herausgegeben.

Im Jahre 1922 zeigte sich die Partei den erhöhten Anforderungen, die die revolutionäre Nachkriegskrise an ihre Massen-, Gewerkschafts- und Bündnispolitik stellte, nicht voll gewachsen. Der Parteieinfluß war Ende 1922 in den ostelbischen Agrargebieten (Schlesien, Pommern, Ostpreußen) relativ gering und hauptsächlich auf die Städte beschränkt. Selbst im Bezirk Halle-Merseburg stand die organisatorische Basis der Partei in keinem günstigen Verhältnis zu ihrem politisch-ideologischen Einfluß auf dem Lande. Im Sommer 1922 war die KPD nur in 193 von insgesamt 1574 Landgemeinden des Regierungsbezirkes Halle-Merseburg mit Ortsgruppen vertreten. ${ }^{21}$

Die Unterschätzung der Landagitation fußte vor allem auf der opportunistischen Politik der Führungsgruppe der Partei um Brandler und Thalheimer. Wichtige Positionen auf dem Land wurden im Laufe des Jahres 1922 preisgegeben. „Der Kommunistische Landarbeiter“ stellte zu Beginn des Jahres, die unter den Kleinbauern verbreitete Zeitung „Der Pflug“ am 1. Oktober das Erscheinen ein. Ende 1922 wurde die zentrale Abteilung Land der Gewerkschaftsabteilung angegliedert. Das bedeutete die

18 Vgl. Dok. Nr. 22; Der Kommunistische Landarbeiter, 1921, Nr. 12, S. 91.

$19 \mathrm{Vgl}$. IML/ZPA, 3/10/94, Bl. 17 f.; Aufruf der Zentrale der KPD vom Februar 1922 an die Landarbeiter zur Vorbereitung des Lohnkampfes, in: Dokumente und Materialien, Bd. VII/2, S. $36 \mathrm{ff}$. (Dok. Nr. 26).

20 Vgl. W. Vogler, Probleme, a. a. O., S. 298.

$21 \mathrm{Vgl}$. IML/ZPA, 21/1/167, Bl. 101. 
Reduzierung der Agrarfrage auf die gewerkschaftliche Organisation der Landarbeiter.

Im Jahre 1923 oblag der jungen Kommunistischen Partei die schwierige Aufgabe, die Leninsche Revolutionstheorie sofort praktisch umzusetzen. Die im wesentlichen richtige Orientierung des Leipziger Parteitages vom Januar 1923 im Hinblick auf die Einheitsfront, die Bildung einer Arbeiterregierung und die Lösung der nationalen Frage mußte immer wieder gegen rechte und linke Abwéichungen verteidigt werden. ${ }^{22}$ Im Herbst 1923 erreichte die KPD noch nicht jenes Verhältnis von revolutionärer Klarheit, Prinzipienfestigkeit und Elastizität, um gegen die raffinierte Politik des Klassengegners und die verräterische Haltung der rechten SPD-Führer ihre revolutionären Forderungen durchzusetzen. Es hemmten sie dabei auch Versäumnisse in der Massenpolitik. So blieben die Dörfer im entscheidenden Monat Oktober überwiegend ruhig. ${ }^{23}$

In dem Maße, wie sich der Leninsche Kern der Partei festigte, das Thälmannsche $\mathrm{ZK}$ herausbildete und die Politik der Partei bestimmte, gelang es den Kommunisten immer besser, was die unmittelbare Arbeit ständig bewies, daß die KPD als einzige Partei die Interessen der werktätigen Landbevölkerung ehrlich, konsequent und kontinuierlich vertrat. Die KPD verband dabei außerparlamentarische und parlamentarische Kampfmethoden, wandte vielfältige Formen der politischen Agitation an und engagierte sich für Gegenwarts- und Zukunftsaufgaben des Landarbeiters.

Die Jahre 1925/26 waren agrarpolitisch von vielfältigen Initiativen gekennzeichnet. Die KPD-Bezirksorganisation Halle-Merseburg veranstaltete Pfingsten 1925 „rote Müntzer-Tage“ in Eisleben, um die dort noch lebendigen revolutionären Traditionen des deutschen Bauernkrieges zur Herstellung der Kampfgemeinschaft von Industrie- und Landarbeitern und des Bündnisses von Arbeiterklasse und Bauernschaft zu nutzen. Mit der Fürstenenteignungskampagne mobilisierte die KPD neben den Städten auch das flache Land. ${ }^{24} \mathrm{Ihr}$ Aufruf „Das Gesicht dem Dorfe zu!“, veröffentlicht in der „Roten Fahne“ vom 14. Februar 1926, kündete vom Beginn einer neuen Etappe in der marxistisch-leninistischen Agrarpolitik der Partei.

Auch in den nächsten Jahren standen in Aufrufen, Rundschreiben und programmatischen Forderungen das uneingeschränkte Koalitionsrecht für die Landarbeiter und ihre volle Gleichstellung mit den Industriearbeitern in allen Lohn- und Arbeitsrechtsfragen im Mittelpunkt der Tätig-

22 Vgl. M. I. Orlova, Agrarnaja politika KPG v 1923 g., in: Problemy novoj i novejšej istorii, Moskva 1972, S. $189 \mathrm{ff}$.

23 Vgl. V. Klemm, a. a. O., S. 89.

$24 \mathrm{Vgl}$. allg. H. Karl, Die deutsche Arbeiterklasse im Kampf um die Enteignung der Fürsten, Berlin 1957. 
keit der Partei. ${ }^{25}$ Es begann die Bildung von Parteiorganisationen auf dem Land und die verstärkte Arbeit der Landabteilungen bei den Bezirks- und Unterbezirksleitungen der Partei. Zu deren Aufgaben gehörten die Anleitung und Instruktion der Landvertrauensleute, der Vertrieb von Zeitungen und Flugblättern und die Organisierung roter Landsonntage. Auf dem 11. Parteitag 1927 in Essen wurden alle betrieblichen Parteiorganisationen verpflichtet, Patenschaften für ein bestimmtes Dorf zu übernehmen. ${ }^{26}$ Auch die Agitation unter den polnischen Saisonarbeitern wurde intensiviert. Erste Erfolge in der Tätigkeit der Landobleute zeigten sich am Ende der 20er Jahre.

Die KPD nutzte alle Ansatzpunkte zur Gewinnung der Landarbeiter aus. Sie forderte nach wie vor zunächst die gewerkschaftliche Organisation, die Wiederherstellung der Einheit des DLV mit den Splitterorganisationen ${ }^{27}$ und eine proletarische Klassenpolitik im DLV. Bei der durchgängig antikommunistischen Haltung rechter SPD- und Gewerkschaftsführer und der anwachsenden Härte des Klassenkampfes am Ende der 20er Jahre war die Gewerkschaftspolitik der Partei verstärkt sektiererischen Angriffen ausgesetzt.

Unter der Leitung Ernst Thälmanns wurde auch die parlamentarische Arbeit der KPD für den Ausbau des Masseneinflusses der KPD genutzt. "Die kommunistischen Abgeordneten verstanden es immer besser, aktuelle Tagesforderungen aufzugreifen und in Gesetzesvorschlägen für die sofortige Lösung dringender wirtschaftlicher und sozialer Probleme zusammenzufassen." Sie erarbeiteten Alternativen zur imperialistischen Agrarpolitik und schlossen darin sowohl die allseitige Verbesserung der materiellen und kulturellen Lebensbedingungen der werktätigen Landbevölkerung als auch ihre Befreiung von Ausbeutung und Unterdrückung ein. ${ }^{28}$

Im Preußischen Landtag, wo die landwirtschaftlichen Probleme eine besondere Rolle spielten, entwickelte die kommunistische Fraktion unter dem Vorsitz von Wilhelm Pieck eine initiativreiche Tätigkeit. Ihre Mit-

25 Vgl. Das Gesicht dem Dorfe zu! Aufruf des ZK, der Reichstags-Fraktion und der Landtags-Fraktionen der KPD v. 14.2.1926, in: Dokumente und Materialien, Bd. VIII, S. 316 ff.; Arbeiter und Arbeiterinnen in der Land-, Weinbau- und Forstwirtschaft! Wahlaufruf v. 1928, in: IML/ZPA, SUF/16.

$26 \mathrm{Vgl}$. Rundschreiben der Zentrale der KPD vom 23. Januar 1925 an die Bezirksobleute und Landvertrauensleute, in: IML/ZPA, St. 12/47, Bd. 1, Bl. 220; Beschluß des Essener Parteitages der KPD vom März 1927 zur Arbeit auf dem Lande, in: Dokumente und Materialien, S. 505 ff. (Dok. Nr. 39).

27 Vgl. z. B. Rundschreiben der Zentrale der KPD vom 23. Januar 1925, a. a. $O$.

$28 \mathrm{Vgl}$. Kommunisten im Reichstag. Einleitung von K.-H. Leidigkeit, K. Haferkorn, Berlin 1980, S. 17 f., 23. 
glieder wie H. Rau, F. Möricke, P. Schwenk und R. Neddermeyer hatten durch ihre zeitweilige Tätigkeit in den ostelbischen Provinzen Preußens zum Teil große Erfahrungen in der Landarbeit gesammelt. Sie kannten die Arbeits-, Lohn- und Wohnverhältnisse der Landarbeiter aus eigener Anschauung.

In den Anträgen und Anfragen der kommunistischen Fraktion wurden in den drei Wahlperioden des Preußischen Landtags bis 1932 solche Fragen in den Mittelpunkt gerückt, die sich aus der Rückständigkeit der ostdeutschen Landwirtschaft und den Angriffen der Großgrundbesitzer gegen die sozialen Rechte der Landarbeiter ergaben. Die kommunistischen Parlamentarier wandten sich unter anderem gegen die Beschränkung des Koalitionsrechts der Landarbeiter, das Einschränken ihrer persönlichen Freiheit durch schwarze Listen, den Zwang zur Frauen- und Kinderarbeit, gegen die willkürliche Kündigung von Tarifen und die Entlassung von Landarbeitern in den Wintermonaten, das Nichteinbeziehen von Landarbeitern und Landarbeiterinnen in den Versicherungsschutz, gegen Versammlungs- und Demonstrationsverbote und die körperlichen Mißhandlungen durch Junker und Gutsinspektoren. ${ }^{29}$

Im Unterschied zur Fraktion der SPD, die sich den reaktionären Vorstößen des Junkertums und dem schreienden Unrecht, das an Landarbeitern, ihren Frauen und Kindern begangen wurde, ebenfalls nicht entziehen konnte ${ }^{30}$, schlugen die Kommunisten grundsätzliche Lösungen vor. Immer verbanden sie damit weitergehende Vorstellungen vom Ausbau der sozialen Rechte der Landarbeiter. Die entschädigungslose Enteignung des Großgrundbesitzes und der Fürsten, die Aufhebung aller noch bestehenden gutsherrlichen Rechte und somit die grundlegende Veränderung der Besitzverhältnissegingen weit über das hinaus, was die sozialdemokratische Fraktion z. B. im Februar 1928 zum Beschluß vorlegte. Dort heißt es: „... dafür Sorge zu tragen, da $\beta$ die landwirtschaftlichen Großbesitzungen, die eine nach den örtlichen Verhältnissen zu bemessende Optimale, d. h. die volkswirtschaftlich angemessene Betriebsgröße, überschreiten - für den deutschen Osten etwa 750 ha -, den überschießenden Teil an die öffent-

29 Vgl. z. B. Preußischer Landtag, 2. Wahlperiode, 1. Tagung 1925, Urantrag Nr. 1645 v. 17. November 1925, in: ZStA Merseburg, Rep. 169 D, XIe F 2, Bd. 1, Bl. 30; Entschließungsantrag Nr. 7843 v. 28. Januar 1928, in: Ebenda, Rep. $169 \mathrm{D}$, XIe F 1, Bd. 2, Bl. 11; Preußischer Landtag, 3. Wahlperiode, 1. Tagung $1928 / 29$, Urantrag Nr. 3361 v. 13. Dezember 1929, in: Ebenda, Rep. 169 D, XIe F 4, Bd. 2, Bl. 124, (Dok. Nr. 35, 36, 46, 51).

30 Vgl. z. B. Preußischer Landtag, 2. Wahlperiode, 1. Tagung 1925, Nr. 1367, Große Anfrage Nr. 78 vom 22. Oktober 1925, in: ZStA Merseburg, Rep. 169 D, XIe, F 2, Bd. 1, Bl. 22; Preußischer Landtag, 3. Wahlperiode, 1. Tagung 1928, Große Anfrage Nr. 28 vom 27. Oktober 1928, in: Ebenda, Rep. 87 B, Nr. 334, Bl. 295, (Dok. Nr. 52). 
liche Hand gegen eine Entschädigung abzutreten haben ...".31 Die SPD wiederholte damit Forderungen ihres Bodenreformvorschlages vom 17. Mai $1923^{32}$, mit dem sie auf dem Höhepunkt der revolutionären Nachkriegskrise die Massen zu täuschen versucht hatte, und die auch in das Kieler Agrarprogramm von 1927 eingegangen waren. Sie hielt über den gesamten Zeitraum der Weimarer Republik hinweg an ihrer reformistischen Siedlungskonzeption fest. Außer der preußischen Landtagsfraktion trat auch die Reichstagsfraktion der KPD in den Jahren der relativen Stabilisierung des Kapitalismus gegen die Rationalisierung mit ihren Auswirkungen auf die Lage der Massen und die volksfeindliche Politik der Bürgerblockregierungen auf. ${ }^{33}$ Sie beschäftigte sich vor allem mit solchen sozialpolitischen Fragen wie dem Arbeitsschutz, der Arbeitszeit, dem Wohnungsbau, der rechtlichen und sozialen Gleichstellung der Frauen, dem Gesundheitswesen und der Sozialversicherung. So begründete Martha Arendsee 1927 die Notwendigkeit, auch die Landarbeiterinnen in den Mütterschutz und die Schwangerenfürsorge einzubeziehen. ${ }^{34}$

Ausgehend von der Lösung der Bodenfrage, erstrebten alle Anträge und Gesetzentwürfe der kommunistischen Reichstags- und preußischen Landtagsfraktion eine allseitige Verbesserung der materiellen und kulturellen Lebensbedingungen der werktätigen Landbevölkerung, besonders der Landarbeiter.

Während der Agrarkrise, die sich für die Landarbeiter in Lohn- und Sozialabbau und hoher Arbeitslosigkeit äußerte, mußte die KPD ihre Arbeit auf dem Land weiter verstärken. Der 12. Parteitag im Juni 1929 warnte angesichts der faschistischen Gefahr vor einer Vernachlässigung der Propaganda auf dem Dorf. Ernst Thälmann bezeichnete in seinem Referat die Landarbeiter als „Blut vom Blut und Fleisch vom Fleisch der Arbeiterklasse" und wandte sich gegen jegliche Trennung von Industrieund Landproletariat. ${ }^{35}$

Vor allem kam es darauf an, die unorganisierten Landarbeiter $\mathrm{zu}$ erreichen, den weiteren Rückgang der gewerkschaftlich Organisierten aufzuhalten und kommende Lohnkämpfe gut vorzubereiten und durchzuführen. ${ }^{36}$ Die Partei entwickelte im Programm zur nationalen und sozialen

31 Preußischer Landtag, 2. Wahlperiode, 1. Tagung 1925/28, Entschließungsanträge, Nr. 7864 vom 2. Februar 1928, in: Ebenda, Rep. 169 D, XIe, F. 2, Bd. 1, Bl. 58.

$32 \mathrm{Vgl}$. B. Wagner, Die Bodenreformpolitik der SPD, Berlin 1959, S. $52 \mathrm{ff}$., $121 \mathrm{ff}$.

$33 \mathrm{Vgl}$. Kommunisten im Reichstag, S. $21 \mathrm{ff}$.

34 Vgl. ebenda, S. $195 \mathrm{ff}$.

$35 \mathrm{Vgl}$. E. Thälmann, Reden und Aufsätze zur Geschichte der deutschen Arbeiterbewegung, Bd. 2, Berlin 1956, S. 124.

$36 \mathrm{Vgl}$. Die praktische Anwendung der Beschlüsse des VI. Weltkongresses der 
Befreiung, in ihrem Bauernhilfsprogramm und dem Arbeitsbeschaffungsplan Krisenalternativprogramme, die die Abwehr des Faschismus mit der Vorbereitung einer grundlegenden Umwälzung der Machtverhältnisse zu verbinden suchten..$^{37}$

Für die Agrar- und Bündnisfrage war die Verkündung des Bauernhilfsprogramms durch Ernst Thälmann am 16. Mai 1931 besonders bedeutungsvoll. Die KPD rief darin zur entschädigungslosen Enteignung des Großgrundbesitzes und unentgeltlichen Bereitstellung von Land für landarme Bauern und Bauernsöhne auf und schlug vor, die staatlichen Mittel zur Uberwindung der Agrarkrise und zur Unterstützung der Landarbeiter und werktätigen Bauern zu nutzen. Das Bauernhilfsprogramm verstärkte den Einfluß der KPD auf die Antikrisenbewegung der werktätigen Landbevölkerung. Seit Sommer 1930 mobilisierte die Partei die Landarbeiter und arme Bauernschaft gegen Faschismus und Krieg und für die Verteidigung der Sowjetunion. ${ }^{38}$ Besonders das bedrohliche Anschwellen des nazistischen Einflusses in den protestantischen Agrargebieten Ostelbiens, wie es sich bei den Septemberwahlen 1930 zeigte, veranlaßte führende Funktionäre der KPD, auf die "schweren Mängel unserer Arbeit auf dem Lande, unter dem ländlichen Proletariat und den verelendeten Bauern" hinzuweisen..$^{39}$

Die Partei hatte dort Erfolge erreicht, wo sie von den Bezirkslandabteilungen bis zu den Dorfzellen durchorganisiert war. Mitte 1930 gab es nur bei den Bezirksleitungen Berlin-Brandenburg, Ostpreußen, Danzig und Nordwest gut arbeitende Landabteilungen. Viele Ortsgruppen hatten keine Landkommission eingesetzt und nur ein Bruchteil der Parteizellen verfügte über einen Landobmann..$^{10}$ Die Gewinnung geeigneter Funktionäre und ihre Schulung wurden seit 1931 verstärkt in Angriff genommen. Im September 1932 konnte Heinrich Rau feststellen, daß in fast allen Parteibezirken Landabteilungen aus zwei bis neun Genossen bestanden. ${ }^{41}$

KI und des 12. Reichsparteitages auf die Arbeit der Partei unter den Landarbeitern und Bauern, hrsg. v. ZK der KPD, als Ms. gedr. September 1929, S. 3 ff.

37 Vgl. E. Thälmann. Eine Biographie, S. 499.

$38 \mathrm{Vgl}$. Die Wendung der Partei zur bolschewistischen Agrarpolitik und Massenarbeit im Dorfe (= Kampf um die Massen, Nr. 8), o. O., Juli 1930, S. 9 ff.; Rundschreiben Nr. 8 vom 3.7.1930, Anweisungen der ZK-Landabteilung, in: IML/ZPA, St. 10/66, Bd. 1a, Bl. 200 ff. (Dok. Nr. 62, 65).

$39 \mathrm{Vgl}$. Ph. Dengel, Das Ergebnis der Wahlen vom 14. September, in: Die Internationale, $1930, \mathrm{H} .19 / 20$, S. $590 ; \mathrm{H}$. Wagner, Wendung der KPD zur Dorfarbeit, in: Die Kommunistische Internationale, 1930, H. 37, S. $2000 \mathrm{f}$.

$40 \mathrm{Vgl}$. J. Reinhold, Die bündnispolitische Offensive der KPD auf der Basis der Forderungen des Bauernhilfsprogramms von 1931, in: Wissenschaftliche Mitteilungen der Historiker-Gesellschaft der DDR, 1982, II, S. 15.

$41 \mathrm{Vgl}$. ebenda. 


\section{LXIV}

Die verschärften Klassenkämpfe erforderten wirksamere Formen und Methoden der Landarbeit. Die Partei im Dorf organisatorisch zu verankern, hieß auch, verstärkt schriftliche und mündliche Propaganda zu betreiben. Besondere Erfolge wurden in Ostpreußen erreicht, wo die Bezirkslandabteilung unter maßgeblicher Leitung von Robert Neddermeyer eine Dorfzeitung herausgab, die reißenden Absatz fand. ${ }^{42}$ Darüber hinaus wurde die Patenschaftsarbeit der Betriebs- und Straßenzellen verstärkt.

Im Laufe der Jahre 1931 und 1932 gelang es der Kommunistischen Partei, große Teile der Landarbeiter zu gewinnen. Sie trat vor allem gegen Lohnraub auf, setzte sich für revolutionäre Gutsräte, für dieOrganisierung des antifaschistischen Massenselbstschutzes auf dem Dorf, für die Einbeziehung der polnischen Saisonarbeiter in die Streiks $^{43}$ und für die Gleichberechtigung der Landarbeiterinnen ${ }^{44}$ verstärkt ein. Es wurden „Landarbeiter-Stoßgebiete“ benannt. Dazu gehörten die Bezirke Brandenburg, Ostpreußen, Pommern, Schlesien, Mecklenburg, Magdeburg und Halle-Merseburg. Es war jeweils ein Plan für die Arbeit auf den wichtigsten Gütern auszuarbeiten. ${ }^{45}$

Das Reichsinnenministerium machte im Herbst 1932 die Nachrichtenstellen der Länder auf die qualitativ neue Stufe der Landarbeit der KPD aufmerksam. Es wies besonders darauf hin, „wie systematisch die Kommunisten ihre Kräfte zur Mobilisierung der Landarbeiter, Zwerg- und Kleinbauern einsetzen und welcher Mittel und Methoden sie sich bedienen, um Aktionen (Landarbeiterstreiks, Demonstrationen, bäuerliche Aktionen gegen Pachtzins, Zwangsversteigerungen usw.) vorzubereiten und auszulösen“. Als allgemeine Richtlinie gelte, „neben der KPD und RGO möglichst alle kommunistischen Massenorganisationen in den Dienst auf dem Lande zu stellen". 46

Infolge der systematischen Arbeit der Partei schwoll die Streikbewegung seit Frühjahr 1931 vor allem in den preußischen Provinzen Sachsen ${ }^{47}$, Brandenburg, Ostpreußen und Oberschlesien an. ${ }^{48}$ Dabei bedienten sich die Landarbeiter so ziemlich aller Kampfformen, angefangen von Betriebsversammlungen, Streikandrohungen, Demonstrationen vor den Herren-

$42 \mathrm{Vgl}$. H. Wagner, a. a. O., S. 2001; R. Neddermeyer, Es begann in Hamburg ..., S. $151 \mathrm{f}$.

$43 \mathrm{Vgl}$. IML/ZPA, St. 10/83, Bl. 123; ebenda, PSt. 3/222, Bl. 79 ff., $119 \mathrm{ff}$., 135 ff. (Dok. Nr. 47, 55, 58, 59, 61, 66, 67, 70).

$44 \mathrm{Vgl}$. Not und Kampf der Landarbeiterinnen (= Kampf um die Massen, Nr. 13), o. O. o. J. (1931).

$45 \mathrm{Vgl}$. IML/ZPA, St. 10/83, Bl. 125.

46 Ebenda, St. 10/105, Bd. 7, Bl. 188.

$47 \mathrm{Vgl}$. H. Zeise, a. a. O., S. $139 \mathrm{ff}$.

48 Vgl. WAPw Opolŭ, Oberpräsidium Oppeln, Nr. 968, Bl. 1; Nr. 971, Bl. 1. 
häusern, passiver Resistenz bis zu Streiks. ${ }^{49}$ Immer orientierte die Partei auf die sorgfältige Vorbereitung der Streiks unter Einbeziehung der DLVMitglieder, die Isolierung der opportunistischen Verbandsführer, die engste Zusammenarbeit der Streikenden mit den Erwerbslosenausschüssen der nächsten Stadt und den Kleinbauern. Sie forderte die Solidarität mit streikenden Saisonarbeitern.

Gemeinsam mit der Bauernkomitee-Bewegung, die nach der Veröffentlichung des Bauernhilfsprogramms Ausdruck des sich formierenden Bündnisses von Arbeiterklasse und Bauernschaft war $^{50}$, zeugten die zahlreichen Streiks der Landarbeiter vom zunehmenden Einfluß der Kommunistischen Partei in den ostelbischen Agrargebieten. Die Landabteilung des ZK der KPD schätzte in einem Rundschreiben vom Oktober 1932 ein: „Die Ergebnisse der Reichstagswahlen zeigen in fast allen Gebieten bei Landarbeitern, Zwerg- und Kleinbauern einen wachsenden Einfluß der Partei. ... Die Erfoge sind nachweisbar dort am stärksten, wo die Aktionen (Landarbeiterstreiks, Demonstrationen ... etc.) kühn und mit Energie durchgeführt worden sind. “51

Trotzdem war die Landarbeit der Partei nicht überall erfolgreich, und es gab besonders dort Fehlschläge, wo die KPD keine ausreichenden Stützpunkte besaß und junkerliche Organisationen langfristig den Boden für die faschistische Ideologie bereitet hatten. Das galt besonders für Pommern, wo die Bildung faschistischer Landzellen 1932 schon weit fortgeschritten war. ${ }^{52}$ Die opportunistischen Führer des DLV widersetzten sich den Streikforderungen der Mitglieder ihres Verbandes und betrieben eine einheitsfrontfeindliche und antikommunistische Politik.

Trotz Teilerfolgen nach Veröffentlichung des Bauernhilfsprogramms gelang es der KPD bis zur Jahreswende 1932/33 erst in Ansätzen, die werktätige Landbevölkerung in die Formierung der antifaschistischen Kampffront einzubeziehen.

$49 \mathrm{Vgl}$. R. Neddermeyer, Wie die deutschen Landarbeiter streikten, in: Internationale Gewerkschafts-Pressekorrespondenz, Jg. 2, Nr. 98 (13.12.1932), S. 1285 (Dok. Nr. 73).

$50 \mathrm{Vgl}$. J. Reinhold, a. a. O., S. 16 ff.; ders., Die Bündnispolitik der KPD auf dem Lande (1930-1932), in: BzG, 2/1982, S. $267 \mathrm{f}$.

51 IML/ZPA, St. 10/128, Bd. 5a, Bl. 143.

52 Vgl. Dok. Nr. 68, 72. 


\section{Lage und Kämpfe der Landarbeiter unter der faschistischen Diktatur}

Der Hauptstoß der in der Hitler-Hugenberg-Regierung vereinigten und am 30. Januar 1933 zur Macht gebrachten faschistisch-deutschnationalen Konterrevolution richtete sich sofort gegen die Arbeiterklasse, ihre Parteien und gewerkschaftlichen Organisationen. Kommunisten und Antifaschisten wurden bereits in den ersten Wochen der Nazidiktatur zu Tausenden verfolgt, ermordet und in die Konzentrationslager geworfen. Der offene Schlag gegen die Gewerkschaften erfolgte am 2. Mai 1933, nachdem der Bundesvorstand des ADGB seit dem 30. Januar eine Stillhaltepolitik betrieben, am 21. März gegenüber Hitler eine Loyalitätserklärung abgegeben $^{1}$ und auf den faschistischen Mißbrauch des 1 . Mai als „Feiertag der Arbeit" nicht reagiert hatte.

Mit der Zerschlagung der Gewerkschaften war die Voraussetzung geschaffen, gegenüber Industrie- und Landarbeitern einen harten $\mathrm{Kurs}^{2}$ einzuschlagen, den Schwerindustrie und Junkertum seit langem gefordert hatten und der Lohnstopp, Raub des Koalitions- und Streikrechts, der Freizügigkeit und verschärfte Ausbeutung vorsah. Durch Terror und gesetzliche Absicherungen wurde bis zum Vorabend des zweiten Weltkrieges in Deutschland das „Militärzuchthaus für die Arbeiter“ voll ausgebaut..

Die Faschisten begannen sofort nach dem 30. Januar durch staatsmonopolistische Regulierungsmaßnahmen mit einer Konzentration der agrarischen Produktivkräfte, um die gesamte Landwirtschaft auf den künftigen Aggressionskrieg auszurichten. Sie versicherten sich zuerst und vor allem der Landarbeiter und Bauern, unter denen sie sich bereits vor 1933 besonders in den ostelbischen Gebieten eine Massenbasis zu schaffen versucht hatten. Als erstes zerschlugen sie den unter dem Einfluß der KPD stehenden Reichsbauernbund und den EVLF, die revolutionäre Klassenorganisation der Landarbeiter. In den DLV, den ZdL und den Reichslandarbeiterbund schickten sie Kommissare, um diese Organisationen von innen her

$1 \mathrm{Vgl}$. H. Bednarek, Gewerkschafter im Kampf gegen die Todfeinde der Arbeiterklasse und des deutschen Volkes, Berlin 1966, S. 12.

2 Vgl. N. Steinberger, Die Agrarpolitik des Nationalsozialismus, MoskauLeningrad 1935, S. 53.

$3 \mathrm{Vgl}$. L. Zumpe, Wirtschaft und Staat in Deutschland 1933-1945, Berlin 1980 , S. $88 \mathrm{ff}$. 
auszuhöhlen und im Sommer 1933 in einer einheitlichen faschistischen Scheinlandarbeitergewerkschaft zusammenzufassen. Sie gliederten sie als Reichsbetriebsgemeinschaft 14 - Landwirtschaft - der Deutschen Arbeitsfront (DAF) an. Noch vor der Bildung des Reichsnährstandes (RNS) als staatsmonopolistischer Zwangsorganisation der Landwirtschaft hatte die herrschende Klasse die Landarbeiter weitgehend in der Hand.

Nach Bildung des Reichsnährstandes im September 1933 wurden die Landarbeiter - laut Verordnung vom 8. Dezember 1933 als zum RNS gehörig - diesem im März 1934 eingegliedert. Der RNS trat der DAF als Korporativmitglied bei. ${ }^{4} 1935$ wurden die Landarbeiter ganz dem RNS unterstellt, um die harmonische „Landvolkgemeinschaft" von Großgrundbesitzern, Bauern und Landarbeitern zu demonstrieren. Als sich 1938 trotz drakonischer Maßnahmen zur Regulierung des Arbeitsmarktes und lautstarker faschistischer Propaganda die Arbeits- und Lebensbedingungen der Landarbeiter nicht verbessert hatten und ihre Landflucht anhielt, wurde erneut die Zwangsmitgliedschaft jedes Landarbeiters in der DAF gefordert. ${ }^{5}$

Hinter diesen organisationspolitischen Kompetenzstreitigkeiten standen handfeste Rivalitäten zwischen DAF und RNS. Sie waren Ausdruck der Widersprüche, die sich aus der Notwendigkeit des Ausbaus bzw. der Festigung und Erhaltung des Regimes auf dem Land auf der einen und 'der Einbeziehung der Landwirtschaft in Aufrüstung und Krieg auf der anderen Seite ergaben. Soziale Zugeständnisse an die Landarbeiter bewegten sich nur im engen Rahmen aggressiver Klassenpolitik und wurden in den Kriegsjahren zunehmend durch die Parteiinstanzen allein bestimmt.

Zunächst wurden auf dem Rücken der werktätigen Landbevölkerung auch die Auseinandersetzungen zwischen Nazis und Deutschnationalen um die politische Führung und Struktur der Agrarwirtschaft ausgetragen. Der Leiter des agrarpolitischen Apparates der NSDAP und Anwärter auf den Posten des preußischen und Reichsministers für Ernährung und Landwirtschaft, Richard Walther Darré, verstand es, gegen den Junkerfreund und ersten Wirtschafts- und Ernährungsminister des neuen Kabinetts, Alfred Hugenberg, Front zu machen. Die Landarbeiter lockte er weiter mit den Versprechungen der Jahre vor 1933, wie sozial gerechte Arbeitsverträge, Verbesserung der Wohnverhältnisse, Erhöhung der Löhne, Ausschal-

4 Vgl. ZStA Potsdam, Deutsche Reichsbank, Volkswirtschaftliche Abteilung, Nr. 2064, Bl. 208; allg. R. Jäckel, Die faschistische Politik gegenüber der werktätigen Landbevölkerung in Deutschland (1933-1935), Diss. A, Berlin 1979, S. 46 ff., 77; H. Gies, Die Rolle des Reichsnährstandes im nationalsozialistischen Herrschaftssystem, in: Der „Führerstaat“: Mythos und Realität, Stuttgart 1981, S. 282 f.

5 Vgl. T. W. Mason, Sozialpolitik im Dritten Reich, Opladen 1977, S. 258 f. 


\section{LXVIII}

tung der Konkurrenz ausländischer Saisonarbeiter und Schaffung von Siedlerstellen für „tüchtige“ Landarbeiter. ${ }^{6}$

Die Faschisten hatten mit dieser Propaganda bei den Wahlen zwischen 1930 und 1932 in den protestantischen Agrargebieten des Ostens besonders große Erfolge gehabt. ${ }^{7}$ Ihr agrarpolitischer Apparat traf dort auf einen durch den konservativen Nationalismus gut vorbereiteten Boden und konnte in vielem ideologisch profitieren, demagogisch anknüpfen und organisatorisch fortführen. ${ }^{8}$ Das bedeutete aber nicht, daß sich die ostelbischen Junker geschlossen und widerspruchslos zu den Nazis bekannten und diese sich mit den ständisch-korporativen Organisationsprinzipien der Landbünde und des Reichslandarbeiterbundes einverstanden erklärten.

Darré sagte den pommerschen Junkern schon 1931 nach, die Peitsche führen zu wollen ${ }^{9}$, und kritisierte zusammen mit anderen faschistischen Agrarexperten am Tag der Gründung der Harzburger Front im Oktober 1931, „daß die Arbeitnehmer im Pommerschen Landbund nicht frei und unabhängig vom Wohlwollen der Arbeitgeber" seien. ${ }^{10}$ Der RLAB seinerseits begrüßte sofort den 30 . Januar ${ }^{11}$ und erklärte im Mai 1933 die rückhaltlose und freudige Unterstellung unter die Führung Hitlers.

Alfred Hugenberg und sein Staatssekretär Hans Joachim v. Rohr mißtrauten mit vielen ihrer Klassengenossen dem kleinbürgerlichen Massenanhang der Faschisten und besonders der auf Bauernfang ausgehenden Agrarpropaganda Darrés. Sie erkannten in ihm einen Vertreter jenes Flügels des deutschen Monopolkapitals, dessen agrarpolitische Vorstellungen auf eine verstärkte staatliche Agrarregulierung hinausliefen, und der bereit war, Teile des junkerlichen Besitzes zu opfern. Darré konnte nämlich zu Beginn der Nazidiktatur Massenmobilisierung der Landarbei-

6 Vgl. Dok. Nr. 72; F. Hildebrandt, Nationalsozialismus und Landarbeiterschaft, München 1930, S. $3 \mathrm{ff}$; Die Nazis auf dem Lande. Material über die zwiespältige Tätigkeit der Nationalsozialisten auf dem Lande (= Schriften des DLV, Nr. 33), Berlin 1932, S. 80; allg. J. Reinhold, Die Bestrebungen der NSDAP zur Gewinnung einer Massenbasis innerhalb der Bauernschaft während der Weltwirtschaftskrise, in: Jenaer Beiträge zur Parteiengeschichte, Nr. 45, Jena 1981, S. 109 ff.

7 Vgl. L. Fahlbusch, Zu Problemen der wachsenden nationalsozialistischen Massenbeeinflussung auf dem Lande in den Jahren 1928-1932, in: Ebenda, Nr. 43, Jena 1978, S. 29.

$8 \mathrm{Vgl}$. R. Berndt, Agrarkonservatismus und Faschismus, in: WZ der Universität Halle-Wittenberg, 3/1982, S. 97.

9 Vgl. Pommerscher Landbund v. 28. 11.1931, zit. nach: ZStA Potsdam, Reichslandbund, Pressearchiv, Nr. 2941, Bl. 7.

$10 \mathrm{Vgl}$. Deutsche Bauernzeitung, Nr. 41, v. 11.10.1931, zit. nach: H. Hildebrandt, Die Rolle, a. a. O., S. 163 (Anm.); allg. J. Petzold, Die Demagogie des Hitlerfaschismus, Berlin 1982, S. $337 \mathrm{ff}$.

11 Vgl. ZStA Merseburg, Rep. 87 B, Nr. 203, Bl. 88 f. (Dok. Nr. 74). 
ter und Kleinbauernschaft nur mit antijunkerlichen Siedlungsversprechen betreiben.

Hitler hatte bereits 1928 im Interesse der Ausbreitung der NSDAP nach Nord- und Ostdeutschland den Punkt 17 des 25-Punkte-Programms seiner Partei dementiert, in dem ein Gesetz zur unentgeltlichen Enteignung von Boden gefordert wurde. ${ }^{12}$ Im Januar 1931 legte er vor einem auserwählten Gremium märkischer Junker seine grundsätzliche Position zur Erhaltung des Eigentums dar. ${ }^{13}$ Trotzdem mußten sich Junker und Nazis immer wieder erneut engagieren.

Nach seiner Ernennung zum Reichsminister für Ernährung Ende Juni 1933 zielte Darrés Agrarpolitik ausschließlich auf die Einordnung der Landwirtschaft in die Kriegsvorbereitung. Er begann, teilweise Hindernisse zu beseitigen, die einer modernen kapitalistischen Landwirtschaft im Osten Deutschlands und der angestrebten ernährungswirtschaftlichen Autarkie entgegenstanden. Konsolidierung der faschistischen Diktatur auf dem Dorf und Umstellung der Landwirtschaft auf kriegswirtschaftliche Belange - das bestimmte trotz innerer Widersprüchlichkeit und Rivalität zu Schacht und Göring sein Agrarkonzept.

Besonders unter der zeitweiligen Schwächung der Massenbasis des Faschismus in der ersten Hälfte des Jahres 1934 forcierte Darré demagogisch Siedlungsagitation und Siedlungspolitik, so daß das erste Halbjahr 1934 als der siedlungspolitische Höhepunkt der Zeit des Hitlerfaschismus gelten kann. ${ }^{14}$ Mit der Siedlungsagitation sollte der Forderung der Landarbeiter nach Enteignung entgegengewirkt werden. Ausgehend vom „Gesetz über die Neubildung deutschen Bauerntums" vom Juli 1933, haben die Nazis die Siedlungspolitik ihrem Gesamtinteresse eingepaßt. Sie verfügten eine „Auslese" der Siedler und berücksichtigten dabei vor allem treue Hitleranhänger. ${ }^{15}$ Die Erwartungen der großen Masse der Landarbeiter und Kleinbauern wurden getäuscht und in eine sozialimperialistische Richtung gelenkt. An Deutschlands Ostgrenze sollte ein „lebendiger Deich aus deutschen Menschen " geschaffen werden. ${ }^{16}$

12 Vgl. R. Kühnl, Der deutsche Faschismus in Quellen und Dokumenten, Köln 1975 , S. 106 f.

13 Vgl. Gossweiler/Schlicht, Junker und NSDAP 1931/32, Dokumentation, in: ZfG, 4/1967, S. $644 \mathrm{ff}$.

14 Vgl. R. Jäckel, a. a. O., S. 123; A. v. Saldern, Mittelstand im „Dritten Reich“, Frankfurt/New York 1979, S. $78 \mathrm{ff}$.

$15 \mathrm{Vgl}$. Richtlinien über die Neubildung deutschen Bauerntums vom 1. Juni 1935, in: ZStA Potsdam, Film-Nr. 8602, Bl. 264 ff., auch Dok. Nr. 83.

16 Vgl. H. v. Schlange-Schöningen, Bauer und Boden, Hamburg 1933, S. 76. H. v. Schlange-Schöningen (1886-1960) vertrat zusammen mit Schleicher und Darré jenen Flügel des deutschen Monopolkapitals, dessen Vorstellungen auf eine verstärkte staatliche Agrarregulierung hinausliefen und der 


\section{LXX}

Die Zahl der Neusiedlerstellen, die seit 1933 unter die des Jahres 1932 sank und bis 1939 weiter abnahm ${ }^{17}$, wies prozentual bei den bäuerlichen Betrieben zwischen 10 und 20 Hektar den höchsten Anteil auf. Von ihnen waren die wenigsten mit ehemaligen Landarbeitern besetzt. Schon vor 1933 bildete die großbäuerliche Schicht die soziale Hauptstütze der Nazis auf dem Land.

Prozentuale Verteilung der Neusiedlerstellen zwischen 1932 und $1936^{18}$ :

\begin{tabular}{lrrrrr}
\hline Größe der Stellen & 1932 & 1933 & 1934 & 1935 & 1936 \\
\hline unter 2 ha & 5,8 & 5,3 & 4,8 & 5,7 & 5,1 \\
$2-5$ ha & 10,1 & 7,0 & 7,7 & 5,9 & 6,4 \\
$5-10 \mathrm{ha}$ & 28,1 & 27,2 & 17,2 & 10,3 & 8,6 \\
$10-20 \mathrm{ha}$ & 51,3 & 53,3 & 53,0 & 53,5 & 50,3 \\
$20-50 \mathrm{ha}$ & 4,3 & 6,4 & 15,6 & 21,8 & 26,8 \\
50 und mehr ha & 0,4 & 0,8 & 1,7 & 2,8 & 2,8
\end{tabular}

Die Bevorzugung der Großbauern entsprach der staatsmonopolistisch ausgerichteten Agrarkonzeption der Faschisten und schloß bis zum 30. Juni 1934 auch antijunkerliche Attacken Darrés nicht aus. Er beabsichtigte aber weder, noch vermochte er es, die ökonomischen und politischen Einflüsse des Junkertums zu eliminieren. Auch hat die Reichsnährstandspolitik mit ihren Hauptbestandteilen, Marktordnung und Erbhofgesetz, der „Sicherung und Wahrung aktueller und alter Kapital- und Junkerinteressen" gedient. ${ }^{19}$

Vor allem garantierte der Faschismus den Agrarkapitalisten und Junkern günstige Bedingungen für die Ausbeutung der Landarbeiter. Eine moderne, kapitalistisch wirtschaftende und durchrationalisierte Landwirtschaft, die die Kriegsernährung sicherzustellen hatte, brauchte einen Landarbeiter, der sich willig unterordnete, "Soldat der Arbeit" war.

Mit der Landarbeiterproblematik eng verbunden waren für die faschi-

bereit war, Teile des junkerlichen Besitzes zu opfern. Das ließ den ehemaligen Deutschnationalen Schlange in Opposition zu den extrem reaktionären und faschistischen Kreisen von Industrie- und Agrarkapital geraten. 1945 war er Mitbegründer der CDU in den Westzonen, 1946 Leiter des Zentralamts für Ernährung und Landwirtschaft der britischen Besatzungszone und von 1947 bis 1949 mit gleichen Funktionen Direktor im Verwaltungsrat der Trizone.

17 Vgl. Statistisches Jahrbuch für das Deutsche Reich, Jg. 1938, S. 90 f.; Jg. 1939/40, S. 93.

18 Vgl. ebenda, Jg. 1938, S. 91; Jg. 1939/40, S. 93.

19 Vgl. L. Zumpe, a. a. O., S. 110. 
stische Wirtschafts- und Sozialpolitik solche Fragen wie die Beseitigung der Arbeitslosigkeit bzw. ab 1935/36 des Facharbeitermangels, die Regulierung des Arbeitsmarktes und die Ausgestaltung der Lohn- und Arbeitsbedingungen. Sechs Millionen Arbeitslose 1933 standen der Stabilisierung dieses Regimes und der Aufrüstung zunächst entgegen. Deshalb wurde die Arbeitsbeschaffung $\mathrm{zu}$ einer politisch zwingenden Notwendigkeit und einem Hauptschlager faschistischer Propaganda.

Uber den „Freiwilligen Arbeitsdienst“, die „Landhilfe“ und über Notstands- und Fürsorgearbeiten erreichte die Hitlerregierung im ersten Jahr ihres Bestehens einen Rückgang der Arbeitslosenzahl um die Hälfte. Sie knüpfte dabei an die Arbeitsbeschaffungsprogramme der Präsidialkabinette an und beschäftigte die Arbeitslosen zunächst vorwiegend in der Landwirtschaft. Verbunden mit dem Ziel, die arbeitslosen Industriearbeiter, vor allem die Arbeiterjugend, in Lagern zusammenzufassen, erreichte das Regime, daß ein Heer billiger landwirtschaftlicher Arbeitskräfte bereitstand, das lohndrückend wirkte. 1935 kennzeichnete das Arbeitsdienstpflichtgesetz nicht nur ,den Ubergang zur Militarisierung des Arbeitsmarktes" ${ }^{\prime 20}$, sondern schuf mit zunehmender Massenflucht aus der Landwirtschaft das einzige Arbeitskräftereservoir. Noch vor Ausbruch des zweiten Weltkrieges zeigten sich die Grenzen und Widersprüche der Arbeitsmarktregulierung in der Landwirtschaft, die seit 1934 gegenüber den Landarbeitern mit Brachialgewalt durchgesetzt worden war.

Mit der Zerschlagung der Landarbeitergewerkschaften beraubte der Staat die lohnabhängige Landarbeiterschaft ihres tariflichen Interessenvertreters. Die Lohntarife wurden gekündigt, und die Regelung der Lohnfrage oblag dem „Betriebsführer“. Im September 1933 wurde die Arbeitslosenversicherung für die Landarbeiter aufgehoben. Zur selben Zeit verlangten Arbeitgeberverbände der Provinz Sachsen bei Kontraktbrüchen von Landarbeitern, „wenn nicht Wiedereinführung der Gesindeordnung möglich ist", Freiheits- oder Arbeitsstrafen. ${ }^{21}$ Sie brachten damit jene alten Forderungen zum Ausdruck, die auf den Herr-im-Hause-Standpunkt zielten und seit der Novemberrevolution Programm der reaktionären Kräfte waren.

Schon im Frühjahr 1934 wurde eine Reihe von Gesetzen erlassen, die regulierend in die Freizügigkeit landwirtschaftlicher Arbeiter eingriffen und weitere Zwangsmaßnahmen vorsahen.

An erster Stelle stand das "Gesetz zur Ordnung der nationalen Arbeit" vom 20. Januar 1934, das den Landarbeitern jedes Koalitions- und Streikrecht nahm und sie der Ordnung des Betriebes, die der "Betriebsführer" bestimmte, unterwarf. Es deklarierte das „Führer-Gefolgschafts-Prinzip“

20 Vgl. ebenda, S. 98.

$21 \mathrm{Vgl}$. ZStA Merseburg, a. a. O., Nr. 270, Bl. 5 ff. 


\section{LXXII}

und begünstigte ein persönliches Abhängigkeits- und Untertanenverhältnis, wodurch die politische und soziale Entrechtung der Landarbeiter vollendet wurde. Der „Vertrauensmann“ oder der „Vertrauensrat", der an die Stelle des beseitigten Betriebsrates trat, arbeitete mit dem „Betriebsführer" zusammen und hatte für den "Arbeitsfrieden" zu sorgen. ${ }^{22}$

Die Landarbeiter wurden auch als erste bereits 1934 in ihrer Freizügigkeit eingeschränkt. Trotzdem stieg der Arbeitskräftebedarf durch die „Erzeugungsschlachten“ seit 1934 ständig an. Das „Gesetz zur Regelung des Arbeitseinsatzes“ vom 15 . Mai $1934^{23}$ wurde durch die „Anordnung über die Beschränkung des Einsatzes landwirtschaftlicher Arbeitskräfte in nichtlandwirtschaftlichen Betrieben und Berufen" vom 17. Mai $1934^{2 / 4}$ weiter vervollkommnet. Die Einstellung von Landarbeitern im Bergbau, in der Metallindustrie, beim Autobahnbau und bei der Reichsbahn wurde untersagt. Da die Wirkung offenbar nicht ausreichte, wurde bereits im Februar 1935 ein weiteres Gesetz erlassen, das die zwangsweise Rückführung von Arbeitskräften in die Landwirtschaft ermöglichte. ${ }^{25}$

Verstärkt wurden auch Jugendliche auf das Land gelenkt. Das geschah über die "Landhilfe“ und den Arbeitsdienst und durch die Verordnung über die Verteilung von Arbeitskräften vom August $1934 .{ }^{26}$ Mit der Einführung des Arbeitsbuches und der endgültigen „Zentralisierung" des Arbeitseinsatzes war 1935 die Arbeitskräftelenkung komplett.

In der Landwirtschaft sollten diese Maßnahmen mit Zwang und Demagogie verwirklicht werden. Trotzdem hielt die Landflucht an. Die Polizei versuchte, kontraktbrüchigeLandarbeiter in Konzentrationslagern und Gefängnissen gefügig zu machen. ${ }^{27}$ Die Organe des Reichsnährstandes eröffneten zudem ein sozialdemagogisches Trommelfeuer.

Am 1. September 1934 ernannte der Reichsbauernführer den ehemaligen Landarbeiter Helmuth Reinke zum Reichskommissar für Landarbeiterfragen und berief ihn im März 1935 zum Sonderbeauftragten. ${ }^{28}$ Reinke sah das Landarbeiterproblem in erster Linie nicht als „Leib- und Magenfrage“, sondern als eine Frage der „inneren Werte des bäuerlichen Menschen“. Er forderte dazu auf, die bäuerliche Familien-, Hof- und Betriebsgemeinschaft zu schaffen, die Stellung des Landarbeiters zu heben und ihn über das

22 Vgl. Reichsgesetzblatt, 1934, T. I, S. 45 ff.; L. Zumpe, a. a. O., S. 94.

23 Vgl. Reichsgesetzblatt, a. a. O., S. 381 ff. (Dok. Nr. 78).

24 Vgl. ebenda.

25 Vgl. ebenda, 1935, T. I, S. $130 ;$ L. Zumpe, a. a. O., S. 95; R. Giersch, Zum Platz der sozialen Demagogie in der Nachkriegsplanung des faschistischen deutschen Imperialismus, in: Jenaer Beiträge zur Parteiengeschichte, Nr. 45, S. $82 \mathrm{f}$.

26 Vgl. L. Zumpe, a. a. O., S. 96.

27 Vgl. ebenda.

28 Vgl. Dok. Nr. 79; ZStA Potsdam, Deutsche Reichsbank, Nr. 2098, Bl. 200. 
Heuerlingswesen, das ihm drei bis vier Morgen Land gewährte, zu einem "bodenverwurzelten“ Menschen zu machen..$^{29}$ Die Reden Reinkes aus den Jahren 1934/35, stark der Blut-und-Boden-Mystik verpflichtet, konnten nicht darüber hinweggehen, „artgemäße" Lohnformen für die Landarbeiter, die Beseitigung des Hofgängerwesens und den Schutz der Landarbeiterin als Mutter zu fordern..$^{30}$ Die Eindrücke Reinkes und der anderen Reichsnährstandsorganisatoren während ihrer Reisen durch das Land offenbarten der faschistischen Führung die Ursachen der Landflucht, die in unzulänglichen Arbeits- und Lebensbedingungen der Landarbeiter offen zutage traten. 1935 mußte das Büro für Sozialpolitik der DAF zugeben, daß der Fortschritt der weiterhin auf der vorläufigen Landarbeitsordnung vom Januar 1919 basierenden vielgestaltigen Tarifforderungen für Landarbeiter gegenüber der Zeit vor 1933 allein darin bestehen dürfte, „als ihre Innehaltung in ganz anderer Weise erzwungen werden kann"31.

Faschistische Zeitungen prangerten wiederholt die miserablen Wohnverhältnisse der Landarbeiter auf ostelbischen Gütern an und machten Stimmung gegen die Besitzer, die vor "Ehrengerichten" zu Geld- oder Haftstrafen verurteilt wurden ${ }^{32}$, deren Eigentum man aber nicht antastete. Außer mit Siedlungsversprechen, die im Fall des Heuerlingswesens die Landarbeiter in ein neues Abhängigkeitsverhältnis gebracht hätten, hielten die Funktionäre des Reichsnährstandes die Landarbeiter mit jährlichen pompösen Erntedankfesten auf dem Bückeberg ${ }^{33}$, „Landarbeitertagen“ in den ostelbischen Provinzen Preußens und in Mecklenburg, der Pflege ländlicher Sitten und Bräuche und einer ,echt national-sozialistischen Behandlung" an Stelle von höheren Barlöhnen hin.

Die Einbeziehung der werktätigen Landbevölkerung in die soziale und kulturelle Betreuung übernahm die DAF. Dazu wurde im Oktober 1935 ein Abkommen zwischen dem Reichsbauernführer Darré und dem Reichsleiter der DAF, Robert Ley, abgeschlossen („Bückeberger Abkommen“), das die Aufgabengebiete beider Organisationen festlegte und Kompetenzstreitigkeiten vermeiden sollte. ${ }^{34}$ Es bedeutete einen Sieg des Reichsnährstandes, da seine Mitglieder, die in den Genuß der Leistungen der DAF („Kraft durch Freude“, Unterstützungseinrichtungen) kommen wollten, ein besonderes Entgelt an die DAF zahlen mußten. Ähnliche Vereinbarungen

29 Vgl. ebenda, Bl. 253; H. Reinke, Der deutsche Landarbeiter, Berlin 1935 (2. Aufl.), S. 8, 53.

30 Vgl. ebenda, S. $32 \mathrm{ff}$.

31 Vgl. Tarifforderungen für Landarbeiter, in: Soziale Praxis, Jg. 44, H. 36 (5. 9. 1935), Sp. 1052.

$32 \mathrm{Vgl}$. Die Landarbeiterfrage, hrsg. v. Arbeitswissenschaftlichen Institut der DAF, Berlin Ende Mai 1938, S. 80 (Dok. Nr. 97).

33 Vgl. ZStA Potsdam, Deutsche Reichsbank, Nr. 2099, Bl. 41.

34 Vgl. ebenda, DAF, AWI, Zeitungen, Nr. 6140, Bl. 28. 


\section{LXXIV}

Darrés hatte es im Februar 1935 mit dem Reichsarbeitsführer Hierl über die Ableistung des Arbeitsdienstes für jeden Bauern- und Landarbeitersohn und mit der NS-Frauenschaft über die koordinierte Einflußnahme auf die Landfrauen gegeben. Unter der Führung von Großagrarierinnen oder Großbäuerinnen war die Frauenschaft für die „weltanschaulich-politische Schulung“ und der RNS für „die Förderung der bäuerlich-kulturellen und ständischen Aufgaben" zuständig. ${ }^{35}$

Trotz Einschränkung der Freizügigkeit, trotz Terrors und sozialdemagogischer Phrasen hielt die Abwanderung der Landarbeiter an. 1939 ergab sich - bei vorsichtiger Interpretation der Ergebnisse der verschiedenen Betriebszählungen - folgender Rückgang der in der Landwirtschaft beschäftigten Lohnarbeiter im Vergleich zu 1925 und $1933^{36}$ :

\begin{tabular}{llcl}
\hline Jahr & \multicolumn{3}{c}{ Anzahl der Lohnarbeiter in 1000} \\
& ständige & Saisonkräfte & insgesamt \\
\hline 1925 & 2305,9 & 987,0 & 3292,9 \\
1933 & 2074,0 & 825,7 & 2899,7 \\
1939 & 1936,0 & 858,4 & 2794,4
\end{tabular}

Die Abnahme ständig beschäftigter Arbeitskräfte bezog sich - nach der amtlichen Statistik - weniger auf Betriebe über 50 Hektar und mehr, wo 75 Prozent der Lohnarbeiter beschäftigt waren, als vorwiegend auf das Gesinde, das in den bäuerlichen Betrieben von 5 bis 50 Hektar überwog. So betrug die Abnahme männlicher Arbeitskräfte in den Betriebsgrößenklassen

\begin{tabular}{|c|c|c|c|}
\hline \multicolumn{2}{|c|}{ 5-10 Hektar } & \multicolumn{2}{|c|}{44 Prozent, } \\
\hline $10-20$ & $"$ & 31 & " \\
\hline $20-50$ & $"$ & 23 & " \\
\hline über 50 & , & 2 & ” \\
\hline
\end{tabular}

Hauptursache der Abwanderung waren die rüstungswirtschaftlich bedingten höheren Löhne (sog. Locklöhne) in einigen Industriezweigen, so daß die "Sicherstellung des Arbeitskräftebedarfs für staats- und wirtschaftspolitisch bedeutsame Aufgaben" jedes Freizügigkeitsverbot immer wie-

$35 \mathrm{Vgl}$. R. Jäckel, a. a. O., S. 168.

36 Vgl. G. G. Kotow, Agrarverhältnisse und Bodenreform in Deutschland, Bd. 1, Berlin 1959, S. 100; L. Zumpe, a. a. O., S. 283.

$37 \mathrm{Vgl}$. Wirtschaft und Statistik, hrsg. vom Statistischen Reichsamt, Jg. 21, Berlin 1941, S. $216 \mathrm{f}$. 
der durchlöcherte.$^{38}$ Die Rüstungskonzerne begannen, sich die Facharbeiter gegenseitig wegzuengagieren. Hinzu kam, daß sich bis 1939 nichts an den Arbeits- und Lebensbedingungen der Landarbeiter änderte. Spezielle Untersuchungen des Arbeitswissenschaftlichen Instituts der DAF zur Landarbeiterfrage wiesen für 1938/39 aus, daß in Pommern, Schlesien und Ostpreußen der Naturallohnanteil nach wie vor 85,2 bzw. 73,8 bzw. 79,0 Prozent betrug ${ }^{39}$; der Gesamtlohn des Landarbeiters glich dem eines ungelernten Metallarbeiters. ${ }^{40}$

Das Hofgängerwesen verbot dem Deputanten zudem einen Wohnungswechsel und verhinderte die berufliche Entwicklung der Jugend. Infolge fehlenden Versicherungsschutzes, besonders für Frauen und Kinder, waren die Landarbeiter die Bevölkerungsgruppe, „an der der wirtschaftliche Aufschwung fast spurlos vorüberging" . ${ }^{41}$ Das Lohngefälle Stadt-Land weitete sich zu einem West-Ost-Gefälle aus. Einen Ausweg sahen die Faschisten nur in verschärftem Arbeitszwang.

In der Vierjahrplanperiode waren folgende Mittel und Wege vorgesehen, um in der Landwirtschaft den Arbeitskräftemangel zu beheben: 1. verstärkter Einsatz von Maschinen, 2. Forcierung des Landarbeiterwohnungsbaus und 3. Beschäftigung von mehr ausländischen Arbeitskräften. ${ }^{42} \mathrm{Da}-$ mit versuchte Göring den Realitäten Rechnung zu tragen. Der Zwang zu stärkerem Maschineneinsatz führte bereits bis $1939 \mathrm{zu}$ Fortschritten in der Technisierung. ${ }^{3}$

Für viele Landarbeiter war fehlender bzw. völlig unzureichender Wohnraum Anlaß zur Landflucht. Selbst faschistische Publikationen kritisierten die mangelnde Bereitschaft der Gutsbesitzer zu Veränderungen. Die Verordnung von 1937 über die „beschleunigte Förderung des Baues von Heuerlings- und Werkwohnungen sowie von Eigenheimen für ländliche Arbeiter und Handwerker" sah zwar langfristige Darlehen vor, wurde aber zu einem Zeitpunkt verabschiedet, als Baugewerbe und Bauindustrie durch die Rüstungswirtschaft stark überlastet waren. ${ }^{44}$ Zeitgenössische Darstellungen sprachen von 50000 Landarbeitern, die bis 1939 neue, aus öffentlichen Mitteln finanzierte Wohnungen erhielten. ${ }^{45}$ Das bedeutete im Ver-

$38 \mathrm{Vgl}$. L. Zumpe, a. a. O., S. 272 f., 277.

$39 \mathrm{Vgl}$. Die Landarbeiterfrage, a. a. O., S. 71.

$40 \mathrm{Vgl}$. ebenda, S. 19; Die Landarbeiterfrage. Soziologische und lohnpolitische Untersuchung, Sonderdruck aus dem Jahrbuch 1939 des Arbeitswissenschaftlichen Instituts der DAF, Berlin, S. $410 \mathrm{ff}$.

41 Vgl. T. W. Mason, a. a. O., S. 169 (Dok. Nr. 88, 89, 92, 100).

42 Vgl. L. Zumpe, a. a. O., S. 282.

43 Vgl. Dok. Nr. 90; V. Klemm, a. a. O., S. 137.

44 Vgl. Dok. Nr. 87; L. Zumpe, a. a. O., S. 283.

45 Vgl. P. Petersen, Der Bauer und die sozialen Fragen der Zeit, Berlin 1940, S. 75. 


\section{LXXVI}

gleich zu den durch das Arbeitswissenschaftliche Institut 1938 errechneten fehlenden betriebseigenen Wohnungen auf dem Land von $350000^{46}$ einen Tropfen auf den heißen Stein.

Viel Aufhebens wurde um sogenannte Landarbeitermusterdörfer gemacht, während die Pläne zur Entwicklung eines „neuen Dorftyps des Ostens", wie sie auf einer Tagung zur Förderung landwirtschaftlichen Bauens im November 1941 am Beispiel des Adolf-Hitler-Koogs in Cloppenburg diskutiert wurden ${ }^{47}$, Bauwissenschaft und Architektur in den Dienst faschistischer Eroberungspolitik stellten. Der deutsche Landarbeiter wurde auf die Zeit nach dem Krieg vertröstet.

Seit 1936 verhandelten die staatlichen Behörden mit einigen ausländischen Regierungen über die Entsendung von Arbeitern nach Deutschland, so mit denen Österreichs, der Tschechoslowakei, Jugoslawiens, Hollands und Polens. Insgesamt waren 1937/38 121368 und im Mai 1939155314 ausländische Arbeiter in der Landwirtschaft tätig. ${ }^{48}$ Die Steigerungsrate betrug seit 1936/37 140 Prozent. Wie vor 1932 hatten die ausländischen Arbeiter eine lange Arbeitszeit und einen geringen Lohn. Hinzu kamen rassische Diskriminierungen. Nach Ausbruch des Krieges wurden Hunderttausende von Ausländern zur Arbeit in Deutschland zwangsverpflichtet.

Bis 1939 wurde deutlich, daß die „Landarbeiterfrage“ nicht zu lösen war. Die Forcierung der Aufrüstung konnte einerseits nicht ohne Korrumpierung von Teilen der Arbeiter durchgesetzt werden, während andererseits die aggressiven Ziele gravierende Verbesserungen der lohn- und sozialpolitischen Verhältnisse ausschlossen. Im landwirtschaftlichen Bereich lösten weder gesetzliche Zwangsregelungen noch demagogische Phrasen von der „Herbeiführung ausgeglichener sozialer Zustände“49 ${ }^{\text {zwischen }}$ Stadt und Land, zwischen Großgrundbesitzern, Bauern und Landarbeitern die gesellschaftlichen Grundprobleme.

1938 häuften sich Maßnahmen, die das soziale Ansehen der Landarbeiterschaft steigern und ihre Abwanderung eindämmen sollten. Dahinter stand der massive Druck der DAF und ihres Arbeitswissenschaftlichen Instituts auf die Führungsorgane des RNS. ${ }^{50}$ Die faschistische Sozialpolitik wurde auch im agrarischen Bereich zur umfassenden Kriegsvorbereitung und Absicherung der ersten Aggressionshandlungen benutzt.

Darré schuf ein staatliches Ausbildungssystem, das die landwirtschaftlichen männlichen Arbeitskräfte über eine zweijährige Landarbeits- und

46 Vgl. Die Landarbeiterfrage, Ende Mai 1938, S. 62 f.

47 Vgl. ZStA Potsdam, Arbeitsgemeinschaft zur Förderung des landwirtschaftlichen Bauwesens, Nr. 1, Bl. 1 ff.

48 Vgl. L. Zumpe, a. a. O., S. 285; die Zahlen differieren etwas bei K. Dohse, a. a. O., S. 113, Tabelle 9.

$49 \mathrm{Vgl}$. Die Landarbeiterfrage, S. 62 (Dok. Nr. 93, 94).

$50 \mathrm{Vgl.} \mathrm{H.} \mathrm{Gies,} \mathrm{a.} \mathrm{a.} \mathrm{O.,} \mathrm{S.} 287$. 
Sonderberufslehre zu Facharbeitern machen sollte. Die „Förderungsgemeinschaft für die Landjugend", ins Leben gerufen am 1. Mai 1938, war dafür die entsprechende Institution.

Trotzdem blieb die Gewinnung von Lehrlingen für landwirtschaftliche Fachberufe bis in die Kriegsjahre hinein problematisch. ${ }^{51}$ Auch die Zahlung von Kinderbeihilfen seit 1 . April 1938 sollte besonders den kinderreichen Landarbeiterfamilien zugute kommen. Im selben Jahr erschien eine Verordnung zur Förderung der Landbevölkerung, die die Stundung von Ehestands- sowie die Vergabe von Einrichtungsdarlehen vorsah. ${ }^{52}$

Diese sozialen Maßnahmen, verbunden mit kultureller Betreuung, Urlaubsgestaltung, „Mütterdienst“ und öffentlichen Ehrungen auserwählter Landarbeiter in „Musterbetrieben“ und „Musterdörfern“, waren dazu bestimmt, die landwirtschaftlichen Arbeitskräfte bei der Stange zu halten. Aber auch das „Pflichtjahr für Mädchen“ ab 15. Februar 1938, das dem Frauenarbeitsdienst entsprach und in der Land- und Hauswirtschaft abgeleistet werden mußte, löste das Arbeitskräfteproblem in der Landwirtschaft nicht. Es blieben nur Verlängerung des Arbeitstages, intensivste Ausbeutung und gesteigerter Arbeitsaufwand für Bäuerinnen und Landarbeiterinnen. Damit gestaltete sich in der Landwirtschaft das Verhältnis der Faschisten zur Frauenberufsarbeit besonders widersprüchlich. Während des Krieges sprach der totale Einsatz der Arbeitskraft von Landarbeiterinnen und werktätigen Bäuerinnen jedem variierten faschistischen Frauenleitbild Hohn. ${ }^{53}$

Bis 1939 gelang der Masse der Landarbeiter weder der soziale „Aufstieg“ zum Heuerling oder Neubauern, noch hielt ihr Lohn einem Vergleich mit Industriearbeiterlöhnen stand. Was blieb, war der Aufruf zu „Opfern für die Volksgemeinschaft".$^{54}$

Der Ausbruch des zweiten Weltkrieges verschärfte die sozialpolitischen Probleme für die Landarbeiter, und mit der Mobilmachung der Männer spitzte sich die Arbeitskräftelage weiter zu. Seit Ausbruch des Krieges verstärkten sich die terroristischen Züge des Naziregimes. Aus Furcht vor dem Verlust seiner Massenbasis, vor Mißstimmungen breiter Bevölkerungskreise, vor Sabotageakten und Widerstandsaktionen konnten geplante

51 Vgl. ZStA Potsdam, Reichsministerium für Ernährung und Landwirtschaft, Nr. 2063, Bl. 8 ff. (Dok. Nr. 95, 101).

$52 \mathrm{Vgl}$. Reichsgesetzblatt, 1938, T. I, S. 835 (Dok. Nr. 98).

53 Vgl. Dok. Nr. 111; L. Zumpe, a. a. O., S. 346, 361; allg. S. Jacobeit, Arbeitsund Lebensbedingungen der Bäuerin in Klein- und Mittelbetrieben. Ein Beitrag zur Lebensweise der Frau auf dem Lande in der Zeit der faschistischen Diktatur des deutschen Imperialismus 1933-1939, agr. Diss. A, Berlin 1979.

54 Vgl. Die Landarbeiterfrage, soziologische und lohnpolitische Untersuchung, S. 414. 


\section{LXXVIII}

und im Herbst 1939 auch zeitweilig praktizierte verschärfte arbeitszeitliche, lohn- und gehaltspolitische Maßnahmen nicht voll durchgesetzt werden..$^{55}$ Auch während des Krieges untersuchte das Arbeitswissenschaftliche Institut der DAF die ,auftauchenden Schwierigkeiten und Spannungen der Gegenwart" und befaßte sich darüber hinaus mit "grundlegenden Arbeiten für den sozialen Neubau“ und die "kommende soziale Ordnung in Deutschland". 56

Ausländische Zwangsarbeiter und Kriegsgefangene sollten nach dem Willen des Staates das sich verschärfende Arbeitskräfteproblem lösen. Die Verschleppung von Arbeitskräften nach Deutschland war langfristig und zynisch eingeplant. Durch die Ernennung eines „Generalbevollmächtigten für den Arbeitseinsatz" im März 1942 wurde die Deportation von Millionen Zwangsarbeitern systematisch betrieben.

Aus kriegswirtschaftlichen und politischen Gründen war von Kriegsbeginn an ihr Einsatz in umfangreichem $\mathrm{Ma}$ für die Landwirtschaft vorgesehen. „In den ersten Wochen des Krieges waren es vorwiegend polnische Kriegsgefangene, die mit äußerster Beschleunigung der Landwirtschaft, besonders den großen Gütern, zur Arbeit in der Hackfruchternte überwiesen wurden. Ihre Arbeitskraft war, wie es ausdrücklich und offiziell angeordnet wurde, , auf das schärfste anzuspannen'. 300000 Gefangene (70 bis 80 Prozent aller nach Deutschland gebrachten polnischen Kriegsgefangenen) wurden auf diese Weise in Arbeitskommandos innerhalb nur weniger Tage nach ihrer Einlieferung eingesetzt. Wie sich die faschistischen Behörden brüsteten, war es ihnen gelungen, trotz der bis zum Eintreffen der meisten Kriegsgefangenen zum Teil schon sehr vorgerückten Jahreszeit den weitaus größten Teil der polnischen Kriegsgefangenen noch rechtzeitig bei der Hackfruchternte, vor allem in den östlichen und mitteldeutschen Gebieten, einzusetzen. “57

In den folgenden Kriegsjahren stieg die Zahl ausländischer Zwangsarbeiter in der Landwirtschaft ständig und betrug bis 1941 etwa die Hälfte und seit 1942 im Durchschnitt mehr als ein Drittel aller in der Kriegswirtschaft eingesetzten Kräfte.

In den Jahren des "totalen Krieges" $1943 / 44$ waren in landwirtschaftlichen Großbetrieben über zwei Millionen ausländische Arbeiter und Kriegsgefangene zwangsverpflichtet. Bei Verringerung der Zahl deutscher Arbeitskräfte hieß das, daß 1942 ein Drittel und 1944 zwei Drittel aller in der Landwirtschaft Tätigen ausländische Zwangsarbeiter waren. ${ }^{58}$ Diese

$55 \mathrm{Vgl}$ L. Zumpe, a. a. O., S. $347 \mathrm{ff}$.

56 Vgl. Das Arbeitswissenschaftliche Institut der DAF 1935-1942, hrsg. v. AWI der DAF, Berlin, Februar 1943, S. 3, 15 ff.

57 D. Eichholtz, Geschichte der deutschen Kriegswirtschaft, Bd. 1: 1939-1941, Berlin 1969, S. 94; vgl. auch Dok. Nr. 103, 105.

58 Vgl. J. Lehmann, Zum Verhältnis des Einsatzes von Kriegsgefangenen und 
Arbeitskräfte verrichteten nach dem Urteil des Nürnberger Gerichtshofes Sklavenarbeit, und zwar vorrangig auf den großen Gütern Ost-, Nordund Mitteldeutschlands. Ihre Arbeitsbedingungen waren grundsätzlich schlechter als die deutscher Arbeiter ${ }^{59}$, was der Generalbevollmächtigte für den Arbeitseinsatz, Sauckel, rassentheoretisch begründete.

Die ostelbischen Großgrundbesitzer, in der Ausbeutung ausländischer Saisonarbeiter jahrzehntelang erfahren, konnten - gestützt auf staatliche Lohnbestimmungen und Behandlungsvorschriften - ihre Wünsche nach billigen, unbeschränkt auszubeutenden Arbeitern verwirklichen. Hinzu kam ein ganzes System von Terrormaßnahmen, das die osteuropäischen Zwangsarbeiter - vor allem polnische und sowjetische - diskriminierte, sie in Lagern gefangenhielt, ihnen die elementarsten Menschenrechte verweigerte und sie verhungern ließ oder zu Tode folterte. Flucht, Sabotage und Widerstand, aber auch die Notwendigkeit, die Arbeitsleistung der ausländischen Arbeiter einigermaßen zu erhalten, zwangen das Regime immer wieder zu einer „artgemäßen Betreuung“ unter Aufsicht der Gestapo. So wies die Gestapoleitstelle Magdeburg im Sommer 1942 die Landräte an, „,in den Unterkünften aus eigener Kraft eine artgemäße Freizeit zu gestalten", Nachrichtensendungen in russischer und ukrainischer Sprache zuzulassen und eine „straffe, aber gerechte Behandlung" zu gewährleisten." ${ }^{60}$ Diskriminierung, Terror und Mord blieben die festen Bestandteile des Zwangsarbeitsregimes. Von 10 Millionen nach Deutschland verschleppten Zwangsarbeitern erlebten nur 7,5 bis 7,9 Millionen ${ }^{61}$ die Befreiung.

Das Naziregime vervollkommnete während des Krieges die terroristischen Machtmittel und Manipulationsmethoden gegenüber der werktätigen Landbevölkerung. Der Machtzuwachs der Gauleiter, die in Preußen vielfach in Personalunion das Amt des Oberpräsidenten bekleideten, setzte sich nach unten im örtlichen Rahmen fort und schränkte die sozialpolitischen Aufgabenbereiche von RNS und DAF vollständig ein. Anfang 1943 wurden sogenannte Dorf- oder Ortsdreiecke, bestehend aus dem NSDAPOrtsgruppenleiter, dem Bürgermeister und dem Ortsbauernführer, propagiert. Sie sollten der „Gemeinde die Leistungsgemeinschaft, aber auch jene

ausländischen Zwangsarbeitern in der Gesamtwirtschaft und Landwirtschaft des faschistischen Deutschland während des II. Weltkrieges (unter besonderer Berücksichtigung polnischer Kriegsgefangener), in: Deutscher Imperialismus und polnische Arbeiter, a. a. O., S. 104 ff., 114; K. Dohse, a. a. O., S. $129 \mathrm{f}$., Tabelle 11, 12 .

$59 \mathrm{Vgl.} \mathrm{E}$. Seeber, Zwangsarbeiter in der faschistischen Kriegswirtschaft, Berlin 1964, S. $161 \mathrm{ff}$; D. Eichholtz, a. a. O., S. 96 f.; L. Zumpe, a. a. O., S. $355 \mathrm{f}$.

$60 \mathrm{Vgl}$. IML/ZPA, St. 3/899 I, Bl. $112 \mathrm{ff}$.

61 Vgl. E. Seeber, a. a. O., S. $89 \mathrm{ff}$. 


\section{$\operatorname{LXXX}$}

seelische und charakterliche Haltung vorexerzieren", die von jedem Gemeindemitglied verlangt werden müsse. ${ }^{62}$

Das Schlagwort von der "sozialen Leistungsgemeinschaft" füllte seit 1943 die Spalten der Zeitungen. Nach wie vor galt es, wie die Führung des RNS zugab, „die „Landflucht zu bekämpfen, die Arbeits- und Lebensverhältnisse auf dem Lande zu verbessern, das Berufsethos der Landarbeit zu heben und so Bauern und Landarbeiter fester mit dem Boden und der Arbeits- und Pflichtengemeinschaft der bäuerlichen Betriebe zu verbinden “ ${ }^{\circledR}$ Sogar Garten und Stall des Landarbeiters wurden in die Erzeugungsschlacht einbezogen.

Die Verschärfung des Zwangsablieferungssystems, die Ausweitung der staatlichen Machtbefugnisse und die Bespitzelung der Dorfbevölkerung durch Ortsgruppenleiter und Ortsbauernführer sollten trotz der sich abzeichnenden militärischen Niederlage Hitlerdeutschlands die Stabilität des Hinterlandes erhalten. Die imperialistischen Nachkriegsplanungen bezogen mit der Sozialpolitik auch die Landarbeiterfrage ein und versuchten auf diese Weise, sozialen und politischen Erschütterungen entgegenzuwirken. ${ }^{64}$

Terror und Propaganda erreichten, da $\beta$ bis in die letzten Monate des Krieges die Massenbasis des Faschismus auf dem Dorf erhalten blieb. Die Befreiung Deutschlands vom Hitlerfaschismus gab den demokratischen Kräften unter Führung der KPD die Chance, unter den Landarbeitern und Kleinbauern einen Umdenkungsprozeß einzuleiten, der zur Entmachtung der ostelbischen Großgrundbesitzer und zur Aufteilung des enteigneten Bodens führte.

62 Vgl. Deutschland im zweiten Weltkrieg, Bd. 3, Berlin 1979, S. 179.

63 Vgl. ZStA Potsdam, DAF, AWI, Zeitungen, Nr. 4511, Bl. 3 (Dok. Nr. 113, 114).

64 Vgl. R. Giersch, a. a. O., S. 92. 


\section{Die Organisierung des antifaschistischen Widerstandes auf dem Lande durch die KPD und ihre agrarpolitische Konzeption 1933-1945}

Úber zwölf Jahre bekämpften in Deutschland und im Ausland Angehörige aus allen Klassen und Schichten des deutschen Volkes das Nazisystem. Kern und soziale Hauptkraft dieses antifaschistischen Widerstandes war die Arbeiterklasse, wobei die Organisationen der KPD den entschiedensten und wirksamsten Teil bildeten. Seinem Wesen nach war antifaschistischer Kampf Klassenkampf zwischen den Kräften der Reaktion und des Imperialismus auf der einen und denen der Demokratie und des Sozialismus auf der anderen Seite.

Die Kommunistische Partei Deutschlands war nach der Errichtung der Nazidiktatur die einzige organisierte Kraft mit einer einheitlichen Führung und mit klarer Zielsetzung. Durch die faschistische Terrorwelle wurde in den ersten Wochen und Monaten die Arbeit der Landabteilungen des Zentralkomitees stark eingeschränkt. Viele Verbindungen rissen ab und mußten unter äußersten Schwierigkeiten wieder geknüpft werden. Schon im April 1933 intensivierten die neu eingesetzten Landinstrukteure ihre Arbeit, um die Verhältnisse unter den Landarbeitern, den erwerbslosen Frauen und Jugendlichen und den Kleinbauern möglichst genau zu analysieren und die Mittel und Methoden aufzudecken, mit denen es dem Gegner gelungen war, in diese Teile der Bevölkerung einzudringen. ${ }^{1}$ Eine solche ständige Entlarvung der nationalen und sozialen Demagogie der Nazis war Voraussetzung und zentraler Bestandteil des antifaschistischen Kampfes.

Aus dieser Tätigkeit, die von der Kommunistischen Internationale unterstützt wurde, gewann die KPD jedoch die Erkenntnis, daß es dem Faschismus deshalb gelingt, „die Massen zu gewinnen“, wie G. Dimitroff auf dem VII. Weltkongreß der Komintern ausführte, „weil er in demagogischer Weise an ihre brennendsten Nöte und Bedürfnisse appelliert. Der Faschismus entfacht nicht nur die in den Massen tief verwurzelten Vorurteile, sondern er spekuliert auch auf die besten Gefühle der Massen, auf ihr Gerechtigkeitsgefühl und mitunter sogar auf ihre revolutionären Traditionen. Warum spielen sich die deutschen Faschisten ... vor den Massen als Sozialisten auf und geben ihren Machtantritt als ,Revolution' aus? Weil sie bestrebt sind, den Glauben an die Revolution, den Drang zum Sozialismus,

1 Vgl. ZStA Mersebung, Rep. 87 B, Nr. 19467, Bl. 38 (Dok. Nr. 77).

6 Ostelb. Landarbeiter III 


\section{LXXXII}

der in den Herzen der breiten werktätigen Massen Deutschlands lebt, auszunutzen." 2

Wie ernst die Kommunistische Partei Deutschlands eine solche analytische Tätigkeit nahm, welche Bedeutung sie dabei dem tieferen Eindringen in die faschistische Agrarpolitik beimaß, beweist nicht zuletzt die gründliche Vorbereitung der demokratischen Bodenreform, die konzeptionell auf der Brüsseler Konferenz $z^{3}$ begann und im „Agrarprogramm des Blocks der kämpferischen Demokratie" vom Herbst 1944 Gestalt annahm.

Zunächst erfolgte die Anwendung des Leninismus auf die neuen Bedingungen des Klassenkampfes schrittweise. Angesichts des brutalen Terrors des Hitlerregimes gegenüber den Kommunisten, der Passivität rechter SPD- und Gewerkschaftsführer, aber auch des weiteren Eindringens faschistischer Ideologie in Teile der Landarbeiter- und Bauernschaft mußten die entsprechenden strategischen und taktischen Schlußfolgerungen erst gezogen werden. ${ }^{4}$ Ernst Thälmann wies auf der illegalen Tagung des ZK der KPD am 7. Februar 1933 darauf hin, die Losung von der Volksrevolution neu zu durchdenken. Er forderte die Arbeiterklasse zum Massenkampf gegen die Hitlerregierung auf, ohne sofort die Diktatur des Proletariats auf die Tagesordnung zu setzen.

Mit dem Ubergang in die Illegalität setzte sich das ZK der KPD für die Einheitsfront und für Einheitsgewerkschaften ${ }^{5}$ ein und rief die Kommunisten auf, nicht nur für Lohnerhöhungen und bessere Arbeitsbedingungen zu kämpfen, sondern zugleich für das Streik- und Koalitionsrecht, die Versammlungs- und Pressefreiheit.

Für die Agitation hieß das, die Landarbeiter bei der Beseitigung der Arbeitslosigkeit und der Abwehr jedes Pfennigs Lohnabbau zu unterstützen, sie für den Zusammenschluß mit den Kleinbauern und für die Solidarität mit den eingekerkerten Antifaschisten zu gewinnen. ${ }^{6}$ Immer wieder erinnerte die KPD die verschiedenen Klassen und Schichten daran, die Versprechen der Faschisten aufzugreifen und deren Erfüllung zu verlangen. So erhielten schon im August 1933, während des Höhepunktes von Darrés Siedlungsagitation, Landarbeiter und Kleinbauern Flugblätter, Klebe- und Streuzettel, in denen sie angehalten wurden, Siedlungsaus-

2 VII. Weltkongre $\beta$ der Kommunistischen Internationale, Berlin 1975, S. 95.

$3 \mathrm{Vgl}$. Die Brüsseler Konferenz der KPD, Berlin 1975, S. $145 \mathrm{ff}$.; E. Hoernle, Methoden und Organisationsformen der nationalsozialistischen Massenbeeinflussung auf dem Lande, in: Ders., Zum Bündnis, a. a. O., S. $201 \mathrm{ff}$.

4 Vgl. K. Mammach, Die deutsche antifaschistische Widerstandsbewegung 1933-1945, Berlin 1974, S. $57 \mathrm{f}$.

$5 \mathrm{Vgl}$. IML/ZPA, St. 3/29, Bl. 6; Geschichte des FDGB, S. $140 \mathrm{f}$.

6 Vgl. ZStA Merseburg, a. a. O., Bl. 40 f. (Dok. Nr. 82). 
schüsse zu bilden, Aufteilungsvorschläge zu machen und mit den Arbeitern gemeinsam für die Verteidigung ihrer Rechte zu kämpfen. ${ }^{7}$

Die KPD konzentrierte ihre Widerstandsarbeit auf dem Lande dort, wo die Nazis größere Massen zusammengezogen hatten. 1933/34 waren dies die Arbeitsdienstlager, von denen die städtischen Arbeitslosen als Landhelfer oder Notstandsarbeiter eingesetzt wurden. Die arbeitsrechtlich und sozial ungeklärte Lage der Arbeitsdienstler auf der einen, ihre unwillkommene Funktion als Lohndrücker in der Landwirtschaft auf der anderen Seite waren Quellen von Unzufriedenheit und politischer Unruhe, so daß es sogar zu vereinzelten Arbeitsverweigerungen in den landwirtschaftlichen Gebieten Ostdeutschlands kam. ${ }^{8}$

Solche Streikaktionen nahmen zu, nachdem, bedingt durch den Mangel an Arbeitskräften, in der Landwirtschaft mehr Wanderarbeiter vermittelt wurden. Seit 1935, besonders im Jahr 1936, streikten auf mitteldeutschen Gütern schlesische und oberschlesische Landarbeiter. Die Berichte der Gestapo wiesen solche Arbeitsniederlegungen für den Gau MagdeburgAnhalt, wo Anfang Juli 1936 schlagartig Streiks in verschiedenen landwirtschaftlichen Betrieben ausbrachen ${ }^{9}$, aber auch für Güter im Raum Halle, in Pommern und in Schlesien aus. ${ }^{10}$ An der Spitze der oft nur Stunden dauernden Streiks für höhere Löhne und bessere Arbeitsbedingungen standen in vielen Fällen Kommunisten. Sie machten sich zu Sprechern für die gewerkschaftlichen Forderungen der Landarbeiter und entlarvten zugleich die faschistische Agrarpolitik und -propaganda. Viele kommunistische Landarbeiter wurden verhaftet und in die Konzentrationslager verschleppt.

In dem Maße, wie die KPD in Vorbereitung und Auswertung des VII. Weltkongresses der KI ihre antifaschistische Strategie und Taktik vervollkommnete, arbeitete sie auch ihre bündnis- und agrarpolitische Konzeption weiter aus. ${ }^{11}$ Nach ihren Tagungen vom Sommer 1934 und Januar 1935 verstärkte sie den Kampf um die Aktionseinheit der Arbeiterklasse, um den Wiederaufbau freier Gewerkschaften und damit des Deutschen Landarbeiterverbandes. Trotz der destruktiven Haltung des Prager Parteivorstandes der SPD und einiger Gewerkschaftsführer kam es 1934/35 $\mathrm{zu}$ ersten erfolgreichen antifaschistischen Aktionen in verschiedenen In-

7 Vgl. IML/ZPA, a. a. O., Bl. 25, 128 f.; H. Kühnrich, Die KPD im Kampf gegen die faschistische Diktatur 1933-1945, Berlin 1983, S. $111 \mathrm{f}$.

$8 \mathrm{Vgl}$. IML/ZPA, St. 3/713, B. 5 ff.; ebenda, St. 3/463, Bl. 9, 27.

9 Vgl. ebenda, Bl. 200.

10 Vgl. ebenda, Bl. 112, 188, 213, 233 f., 243 ff., 292.

$11 \mathrm{Vgl}$. J. Piskol, Zur Entwicklung der agrarischen Konzeption der KPD 1935 bis 1945, in: Wissenschaftliche Mitteilungen der Historiker-Gesellschaft der DDR, 1982/II, S. 55 ff. 


\section{LXXXIV}

dustriegebieten Deutschlands ${ }^{12}$, die es ebenso auf die besonderen Bedingungen landwirtschaftlicher Betriebe auszudehnen galt. Unter strenger Beachtung der Regeln der Illegalität suchten die Kommunisten alle Möglichkeiten auszunutzen, um die Landarbeiter auf den Gütern zusammenzufassen und zu organisieren, sie in Form von Broschüren und Flugblättern aufzuklären und ihnen ihre ureigensten Forderungen bewußt zu machen. ${ }^{13}$ Im Vordergrund standen als Tagesaufgaben Maßnahmen gegen das Wohnungselend, die Verlängerung der Arbeitszeit und die niedrigen Löhne der Landarbeiter.

Auch Edwin Hoernle, Agrarspezialist der KPD im Moskauer Exil, forderte in seinem Aufsatz „Das deutsche Dorf und die antifaschistische Volksfront“, den er in Heft 3 des Jahrgangs 1936 der Zeitschrift „Die Internationale" veröffentlichte ${ }^{14}$, den Kampf „mit den einfachsten kleinsten Schritten“ zu beginnen. "Sich keine Mehrarbeit gefallen lassen, keine Lohnherabsetzung hinnehmen, gute Qualität des Deputats und gutes Gewicht verlangen, auf strenge Einhaltung der Arbeitspausen achten, auf pünktliche(r) Auszahlung des Lohnes ohne Abzüge oder Einbehaltung eines Teils bestehen, anständige Wohnung verlangen und ähnliches mehr sind die ersten Schritte der Landarbeiter zur Brechung der faschistischen Gewalt auf dem Gutshof." 15

Die Einheits- und Volksfrontpolitik, wie sie die KPD auf der Brüsseler Konferenz präzisierte, schloß auch die Bündnispolitik mit den Bauern ein. Die breite antifaschistische Volksfront verlangte das Bündnis mit der gesamten Bauernschaft, ohne deren soziale Differenzierung außer acht zu lassen. Trotz vorrangiger Konzentration auf die Lösung der sozialen Fragen des Landproletariats und der armen Bauernschaft bezog die Partei in den Kampf um grundlegende politische Forderungen - wie Aufdeckung der Aufrüstungs- und Kriegspolitik der Nazis - die gesamte Bauernschaft ein. So verstärkte sie ab 1937/38 in den Dörfern sowohl West- wie Ostdeutschlands ihre Tätigkeit. In „Bauernbriefen“ wurden der Arbeitskräftemangel und der Rückgang der landwirtschaftlichen Produktion als Auswirkungen der Aufrüstungspolitik entlarvt, vor allem aber Stellung bezogen gegen einen neuen drohenden Krieg und seine verheerenden Folgen. ${ }^{16}$

Ebenso gewann auch die Bodenfrage immer größere Bedeutung. In dem

12 Vgl. K. Mammach, a. a. O., S. 82 ff.; Geschichte des FDGB.

13 Vgl. Die Landarbeiter im Dritten Reich, in: Internationale GewerkschaftsPressekorrespondenz, Nr. 9, Mitte Mai 1935; IML/ZPA, St. 3/1000, Bl. 63 (Dok. Nr. 85).

14 Vgl. ebenda, Bl. 67 ff.; E. Hoernle, Bauer und Bodenrecht im Dritten Reich, in: Ders., Zum Bündnis, a. a. O., S. 252 ff.

$15 \mathrm{IML} / \mathrm{ZPA}$, St. 3/100, Bl. 73.

16 Vgl. ebenda, St. 3/891, Bl. 379, 382; St. 3/1049, Bl. 54. 
Maße, wie die KPD um die schöpferische Anwendung der Leninschen Revolutionstheorie auf Deutschland rang, mußte sie sich mit der Frage der Enteignung und der Aufteilung des Großgrundbesitzerlandes eindeutiger und klarer auseinandersetzen. Ausgehend von der Brüsseler Konferenz 1935, entsprach nur die alternative Gesellschaftskonzeption der KPD und darin eingeschlossen die Demokratisierung des Dorfes - den objektiven Gegebenheiten.

1936 antwortete E. Hoernle auf die Frage: „Was werden die Kommunisten den Bauern geben?" „Die deutsche Arbeiter- und Bauernmacht wird sofort den gesamten Boden und das landwirtschaftliche Inventar der Fürsten, Junker und Kapitalisten beschlagnahmen und den Landarbeitern und werktätigen Bauern unentgeltlich übergeben. Damit zerschlägt sie die Kette der Lohnknechtschaft, der Pachtknechtschaft und der Zinsknechtschaft des werktätigen Landvolkes. Das revolutionäre Proletariat verspricht nicht nur dies den arbeitenden Dorfmassen. Es ruft sie auf, selber den Boden zu ergreifen, selber mit Hilfe der Arbeiter die Junker von ihren Beamtenstuben zu verjagen. Die Kommunisten folgen hierbei dem großen Beispiel der russischen Oktoberrevolution, als das siegreiche Proletariat unter Führung der Bolschewiki den russischen Bauern Boden und Inventar des Adels, der Kirche und des Zaren übergab."

Der faschistischen Verleumdung von dem versklavten Bauern in der Kollektivwirtschaft stellte er entgegen: „Heute heißt es, den Bauern aus Schulden, Steuernot und Pachtknechtschaft zu befreien. Erst wenn der Boden den Bauern gehört, kann die Frage der Bewirtschaftungsweise überhaupt aufgeworfen werden. Laßt uns erst einmal gemeinsam Junker und Kapitalisten zum Teufel jagen, damit der Weg frei wird für ein besseres Leben." 17

In der Resolution der Berner Konferenz vom Februar 1939 gehörte zu den Grundforderungen für eine neue demokratische Republik: „Schutz des bäuerlichen und mittelständischen Eigentums. Demokratische Bodenreform zugunsten der Bauern und Landarbeiter. "18 Neben der Liquidierung des Großgrundbesitzes war die Schaffung lebensfähiger Wirtschaften werktätiger Bauern als Hauptinhalt der antifaschistisch-demokratischen Bodenreform vorgezeichnet.

1942 behandelte das von E. Hoernle ausgearbeitete Dokument ${ }^{19}$ „Bauernhilfe im befreiten Deutschland“ wichtige agrarpolitische Aufgaben der antiimperialistisch-demokratischen Etappe der Revolution und perspektivische sozialistische Zielstellungen. Breiten Raum widmete es der Entwicklung von Formen bäuerlicher Gemeinschaftsarbeit, vermengte aber noch anti-

17 E. Hoernle, Das deutsche Dorf, a. a. O., Bl. 71.

18 Die Berner Konferenz der KPD, Berlin 1974, S. 138.

$19 \mathrm{Vgl}$. J. Piskol, a. a. O., S. 55 f. 


\section{LXXXVI}

imperialistisch-demokratische Aufgaben mit der sozialistischen Lösung der Agrarfrage. Es war eine Nationalisierung des enteigneten Bodens und die Schaffung von staatlichen und kommunalen Mustergütern in beträchtlichem Umfang vorgesehen. Diese Forderungen zeugten von einer gewissen Uberschätzung des Reifegrades des subjektiven Faktors und der Unterschätzung einiger historischer Besonderheiten wie des Landhungers und des ausgeprägten Eigentumssinns der deutschen Bauern, aber auch der Landarbeiter.

Trotz dieser zeitbedingten Einschränkungen entsprachen die agrarpolitischen Forderungen der KPD den Interessen der „werktätigen und ausgebeuteten Massen auf dem Lande, die das städtische Proletariat in den Kampf führen oder jedenfalls für sich gewinnen muß", wie Lenin in seinen Agrarthesen 1920 formuliert hatte. ${ }^{20}$

Darüber hinaus waren die agrarpolitischen Vorstellungen der KPD so gefaßt, daß die gesamte werktätige Bauernschaft gewonnen und an die sozialistische Revolution herangeführt werden konnte.

Das „Agrarprogramm des Blocks der kämpferischen Demokratie“, Bestandteil des von Anton Ackermann im Herbst 1944 entworfenen „Aktionsprogramms des Blocks der kämpferischen Demokratie“"21, präzisierte die Agrarkonzeption der KPD weiter. Die sich abzeichnende militärische Niederlage des deutschen Faschismus und die Befreiung des deutschen Volkes forderten von der KPD konkrete Maßnahmen für die demokratische Umgestaltung. Das Agrarprogramm, von E. Hoernle im Auftrag der Parteiführung ausgearbeitet, enthielt Angaben zur Größe der zu enteignenden Güter (150 Hektar), zum Eigentümerstatus des Neubauern und verdeutlichte jene Gedanken aus dem Dokument von 1942, die auf eine sofortige Verbesserung der Lage der Landarbeiter und Bauern und perspektivisch auf eine gemeinsame genossenschaftliche Bearbeitung des Bodens gerichtet waren. ${ }^{22}$

Die KPD hatte damit die bis dahin reifste Agrarkonzeption vorgelegt, die den Leninismus schöpferisch verarbeitete. Sie beachtete Lenins Hinweise von 1920, daß die Umwandlung der enteigneten landwirtschaftlichen Großbetriebe in staatliche oder genossenschaftliche einen „aufgeklärten“ Landarbeiter voraussetzt, der eine solide gewerkschaftliche Schule durchgemacht hat. Sie stellte die nationalen und historischen Besonderheiten in Rechnung und berücksichtigte, daß die Forderungen der Landarbeiter und landarmen Bauern nach Boden weder durch die Bourgeoisie noch durch die Sozialdemokratie erfüllt worden waren.

$20 \mathrm{Vgl}$. W. I. Lenin, Ursprünglicher Entwurf, S. 141.

21 Vgl. E. Hoernle, Zum Bündnis, a. a. O., S. 333 ff. (Dok. Nr. 115).

22 Vgl. ebenda; H. Laschitza, Kämpferische Demokratie gegen Faschismus, Berlin 1969, S. 201 f.; Geschichte der Sozialistischen Einheitspartei Deutschlands, Abriß, Berlin 1978, S. 100. 
Zum Zeitpunkt der Befreiung des deutschen Volkes vom Hitlerfaschismus verfügte die KPD über ein marxistisch-leninistisches Agrarprogramm, das den konkreten Bedingungen in Deutschland entsprach und Ziel, Inhalt und Methoden einer konsequent antiimperialistischen Umwälzung auf dem Land enthielt. ${ }^{23}$ Es fand Eingang in den Aufruf der KPD vom 11. Juni 1945 und in die Bodenreformdirektive des Zentralkomitees von Ende August $1945^{24}$, die die Bodenreformgesetzgebung unmittelbar vorbereitete. Kernstück aller Maßnahmen war die revolutionäre Lösung der Bodenfrage mit einer radikalen Boden- und Besitzreform zugunsten der Landarbeiter, landarmen Bauern und Umsiedler.

Die demokratische Bodenreform, die Anfang September 1945 in allen Ländern bzw. Provinzen der damaligen sowjetischen Besatzungszone begann, wurde unter Führung der Arbeiterklasse „zu einer bis dahin beispiellosen erfolgreichen revolutionären Massenaktion".25 Ihre Ergebnisse waren grundlegend für die gesamte weitere antiimperialistische Entwicklung. Mit der Vernichtung der klassenmäßigen Existenz des Junkertums in den traditionellen ostelbischen Gebieten erlitt auch das deutsche Monopolkapital eine entscheidende Niederlage. Mit Beseitigung des gutsherrlichen Großgrundbesitzes wurde zugleich seiner politischen und wirtschaftlichen Macht auf dem Lande ein Ende gesetzt und ebenso die Hauptquelle des Militarismus endgültig ausgetrocknet. Der Weg zur Entwicklung demokratischer dörflicher Verhältnisse war frei.

Bereits auf dem 15. Parteitag der KPD im April 1946 konnte mit vollem Recht eine optimistische Bilanz der in einem früheren ostelbischen Kernland erfolgten Gesellschaftsumwälzung gezogen werden: „... daß die Provinz Brandenburg nicht mehr die Provinz des militaristischen Potsdamer Geistes oder eine Provinz der Ostelbier ist, sondern daß ein neues demokratisches Brandenburg entstanden ist, dem die werktätigen Schichten heute das Gepräge geben." 26

„Mit der Beseitigung des Großgrundbesitzes, der ökonomischen Stärkung der Klein- und Mittelbauern und der Herausbildung gesellschaftlichen Eigentums auf dem Lande wurden feste Fundamente für das Bündnis

23 Vgl. Nehring/Piskol, Zur Dialektik von antifaschistisch-demokratischer Umwälzung und sozialistischer Revolution in der Agrarpolitik von KPD und SED 1945-1949, in: Wissenschaftliche Mitteilungen der Historiker-Gesellschaft der DDR, 1982/I, S. $11 \mathrm{ff}$; dies., Zur führenden Rolle der KPD in der demokratischen Bodenreform, in: ZfG, 4/1980, S. $324 \mathrm{ff}$.

$24 \mathrm{Vgl}$. KPD und demokratische Bodenreform. Dokumentation, in: BzG, 5/1975, S. $849 \mathrm{ff}$.

25 Vgl. Geschichte der SED, S. 101; allg. R. Stöckigt, Der Kampf der KPD um die demokratische Bodenreform, Berlin 1964.

26 Bericht über die Verhandlungen des 15. Parteitages der KPD, Berlin 1946, S. 162. 


\section{LXXXVIII}

zwischen der Arbeiterklasse und der gesamten werktätigen Bauernschaft gelegt und die Bauernbefreiung erfolgreich eingeleitet. Eine alte Forderung der Bauern und Landarbeiter, von der revolutionären Arbeiterbewegung aufgegriffen, wurde verwirklicht. Zugleich waren damit die Voraussetzungen geschaffen, um die jahrhundertewährende soziale und kulturelle Rückständigkeit des Dorfes und den Gegensatz zwischen Stadt und Land ... allmählich zu überwinden. “27

27 Geschichte der SED, S. 103. 